\title{
The Shape of Segregation: The Role of Urban Form in Immigrant Assimilation
}

\author{
by \\ Arianna Salazar Miranda \\ Master of Architecture, Veritas University (2010) \\ Submitted to the Department of Urban Studies and Planning \\ in partial fulfillment of the requirements for the degree of \\ Master in City Planning \\ at the \\ MASSACHUSETTS INSTITUTE OF TECHNOLOGY \\ June 2016 \\ (c) Arianna Salazar Miranda, MMXVI. All rights reserved. \\ The author hereby grants to MIT permission to reproduce and to distribute \\ publicly paper and electronic copies of this thesis document in whole or in \\ part in any medium now known or hereafter created.
}

Author

Department of Urban Studies and Planning May 18, 2016

Certified by

Albert Saiz

Associate Professor

Thesis Supervisor

Accepted by

P. Christopher Zegras

Associate Professor Chair, MCP Committee 


\title{
The Shape of Segregation: The Role of Urban Form in Immigrant Assimilation
}

\author{
by \\ Arianna Salazar Miranda \\ Submitted to the Department of Urban Studies and Planning \\ on May 18, 2016, in partial fulfillment of the \\ requirements for the degree of \\ Master in City Planning
}

\begin{abstract}
In this thesis I investigate the relationship between the built environment and the residential segregation of immigrants at the building level. I use micro-data that includes the exact address of all the foreign and native population in Barcelona, combined with geometric indicators for urban shape at the block level. Using these data, I construct measures of segregation over time to evaluate the degree to which individuals from different origins, share building space with other immigrants or with the native-born Spaniards. Differences in the built environment appear to have a sizable effect on how immigrants coexist with host communities. The arrival of immigrants to suburban areas is associated with less segregation than other areas. In particular, certain spatial qualities such as open space centrality, coverage and compactness are beneficial in mediating the effect of immigrants on segregation. My results reinforce the idea that a process of suburbanization might have decreased segregation between immigrants and natives, possibly due to native communities being less sensitive to coexisting with immigrant populations in less dense areas.
\end{abstract}

Thesis Supervisor: Albert Saiz

Title: Associate Professor 


\section{Acknowledgments}

My experience at MIT has been nothing short of amazing. This thesis is the result of many experiences I have encountered at MIT from dozens of remarkable individuals who I wish to acknowledge.

My sincere thanks to the members of my committee, whose own work I greatly admire: to Professor Albert Saiz, your support and life guidance have profoundly enriched this thesis and my time at MIT. You have instilled in me a desire to become a lifelong learner. To Professor Jinhua Zhao, thank you for offering me valuable comments toward improving my work and for being such an inspirational professor.

Thank you to Professor Brent Ryan, for your support in helping me craft the initial stages of my thesis.

Thank you to my family for always believing in me. This accomplishment would not have been possible without you.

Thank you to my DUSP family: Rida, Jenna, Isadora, Lindiwe, and Andrea for being constant sources of support and laughter. To Lyndsey, for being such a wonderful and patient reader.

To Pascual, whose creativity has been an unending source of inspiration. Thank you for your unfailing support and continuous encouragement.

This research was made possible in part throught the Mitchell ++ Fund. 


\section{Contents}

1 Introduction $\quad 9$

2 Literature Review $\quad 14$

2.1 Determinants of segregation . . . . . . . . . . . . . . . . . . 14

2.2 Urban form . . . . . . . . . . . . . . . . . . . . . . 16

2.2.1 Measuring urban form . . . . . . . . . . . . . . 16

2.2.2 Morphological measures of urban form . . . . . . . . . . . 17

2.2.3 Aggregate measures of urban form . . . . . . . . . 18

2.2 .4 Context . . . . . . . . . . . . . . . . . . . 19

3 Data sources and measurement $\quad 21$

3.0 .1 Urban footprints . . . . . . . . . . . . . . . 21

3.0.2 Population and census data . . . . . . . . . . . . . . 21

3.0.3 Ammenities . . . . . . . . . . . . . . . . . . 22

3.1 Measuring segregation . . . . . . . . . . . . . . . 23

3.2 Shape metrics . . . . . . . . . . . . . . . . . . . . . . . . . 29

4 Methodology 41

4.0 .1 Building typologies . . . . . . . . . . . . . . . . . . 41

5 Empirical results $\quad 55$

5.0.1 The impact of urban form on segregation . . . . . . . . 55

$\begin{array}{lll}6 & \text { Conclusions } & 73\end{array}$

$\begin{array}{ll}\text { References } & \mathbf{7 6}\end{array}$ 
Appendix A 


\section{Chapter 1}

\section{Introduction}

Over the last 20 years, migration from the global south to the global north has increased dramatically. Nowhere in the developed world has the entry of new immigrants occurred so rapidly and at such a large scale as in Spain. In 1990 the share of foreign-born individuals living in Spain was 2.1 percent; by 2010 it had reached 13.8 percent. Spain's immigrants arrived from a wide variety of geographic origins. While Romania is currently the main country of origin,the largest region of immigrants is South America. Receiving one third of Europe's migratory inflows, Spain is Europe's most important destination of international migration (Pellegrino, 2004), and it is the world's second largest behind the USA (OECD, 2007).

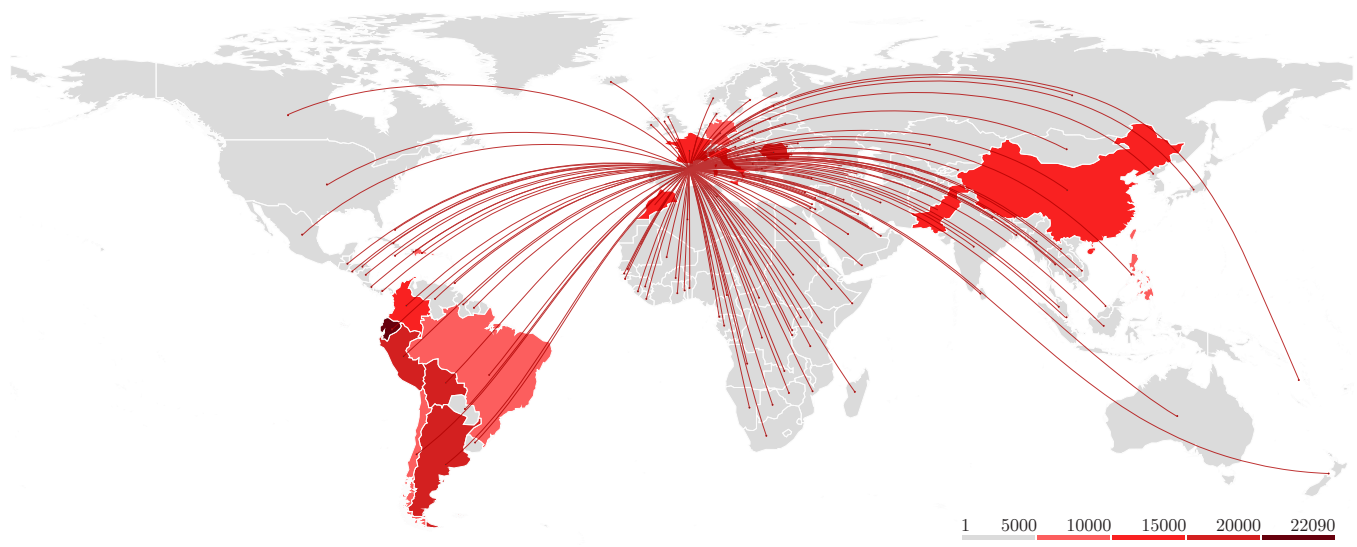

Figure 1-1: Immigrant arrivals by country of origin in 2008 
At immigration destinations the large inflow has been accompanied by the formation of immigrant enclaves. Some have expressed concerned that the spatial concentration of immigrants in particular neighborhoods will create new social rifts. While it is true that ethnic enclaves can provide important social and economic resources for newcomers, enclaves also have been associated with concentrated poverty, social exclusion and alienation. Planning is a potentially powerful means of mitigating the consequences of immigrant segregation. Zoning regulations and the design of the built environment can foster patterns of segregation; design reform can reverse segregation, although this is not widely appreciated. City planning idealism has long had embedded within it the idea that social mixing can be achieved through planning and design (Talen, E. 2012). If certain urban forms facilitate the formation of ethnically diverse populations (Hanson, 2000) ${ }^{1}$, then understanding this relationship more fully should help us to identify design and policy measures that can be adjusted to produce preferred immigration outcomes. ${ }^{2}$

In this thesis I investigate the relationship between the built environment and the residential segregation of immigrants. Focusing on the city of Barcelona, I study how the development and configuration of open urban areas has mediated both the residential segregation of immigrants and the response of natives to their arrival (e.g., native flight). Linking data on residents' demographic characteristics to their exact street addresses, I ask whether certain urban typologies exacerbate the segregation of immigrants while others facilitate their assimilation.

For three reasons Barcelona provides a promising setting to study how urban form affects the settlement of immigrant populations. First, between 1998 and 2008, Catalonia experienced an unusually large influx of immigrants, absorbing $22 \%$ of Spain's new entries, or nearly one million people. Second, this accelerated growth in immigration has been accompanied by a significant physical expansion of the urban footprint, leaving behind a consolidated set of distinct clustered urban areas. ${ }^{3}$ Each cluster exhibits geometric and relational characteristics that allow me to define dis-

\footnotetext{
${ }^{1}$ Hanson has shown that different urban design ideas are related to certain preconditions for sociability. Some urban layouts separate people from one another; in other words, certain spatial relations hinder physical contact between geographically close neighbors.

${ }^{2}$ In European countries and US traditional public housing strategies have resulted in large areas of poverty concentration. Many policy debates have focused on urban segregation issues.

${ }^{3}$ The term cluster describes a set of neighboring objects that are associated through some functional or geographical linkage (Portnov and Erell, 2001)
} 
tinctive urban types. Third, the implementation of the master plans - including the Urgency Plan of 1957 and Eixample $-{ }^{4}$ has produced three overarching urban models that have been applied to most of the city: the traditional compact model (historic city core), the dispersed model of new residential areas (suburban), and mixed land uses, which are exemplified by industrial and commercial activities (expansion).

I conduct my empirical analysis at the block and building level. By computing several geometric indicators for urban shape, I assemble a dataset of spatial measurements for more than 5000 blocks in Barcelona's urban area. These measurements include centrality and compactness, which target the properties of the overall shape of the open urban areas, as well as building intensity, height variance and coverage, which capture the intricacies of the built-up form. Since spatial characteristics by themselves only describe a particular aspect of the built configuration, I also construct urban typologies that further explore relationships between the built configuration. I define 8 typologies that can distinguish among the most general urban models (historic city core, suburban, expansion) and can capture detailed variations among them. ${ }^{5}$

Data analyzed include the exact street addresses of the resident population (foreign and native) and their socioeconomic and demographic characteristics before and after the 1998-2008 immigration shock. From these data I construct measures of segregation over time and across ethnic groups in order to evaluate the degree to which individuals, differentiated by nativity, share building space with other immigrants or with the native born (Cutler et al, 2008).

Following an inflow of immigrants, I find that typologies with lower building density and increased access to open space are the most conducive to lower levels of segregation between natives and immigrant groups in a given block. I also find that differences in the configuration of open space have a relevant mediating effect on the integration of native and immigrant populations. In particular, typologies that have high levels of open space compactness are less likely to promote segregation. Overall, the evidence suggests that suburban typologies, which have a greater share of open spaces and overall lower densities, are less conducive on average to segregation

\footnotetext{
${ }^{4}$ The Urgency Period (1950's-1960's) was characterized by rapid and unplanned growth.

${ }^{5}$ I also address the imbalance of clusters by assuring that attributes are tightly clustered around the mean and by balancing the number of observations among each cluster.
} 
and more conducive to the successful assimilation of immigrants. This finding is consistent with evidence that in recent years immigrants have preferred to locate in suburban areas rather than city cores (Li 1998a).

My research is grounded in two bodies of literature: urban segregation and studies of the built environment. The literature on built form has produced practical methods for measuring the built environment, but their connection to the urban segregation literature remains unexplored. The literature that focuses on segregation has produced valuable insights about how immigrant arrivals affect native displacement, particularly in the US. However, this literature pays little attention to the issue of how immigrant segregation is affected by built form. In this thesis I employ several methods to examine how spatial form affects the assimilation of immigrants and their relationship with natives.

This research makes several contributions to the existing literature on planning. First, I propose a new method to measure and characterize urban form. Currently there is little consensus about what methods best describe the spatial characteristics of parcels, buildings and blocks. My proposed measurements provide a suitable alternative means of identifying the social impacts of urban form. Furthermore, the methodology that I employ to measure spatial attributes is potentially applicable to other cities.

Second, I analyze the determinants of segregation at a very low-level of aggregation: the building level. This allows me to observe whether within a given block, natives and immigrants live in the same buildings or are segregated across buildings. Although past studies that have utilized census tracts as their units of analysis have provided information about the relationship between ethnic diversity and place, they can hide high levels of segregation at lower levels of analysis. To my knowledge this thesis is the first work to study segregation and urban form at such a granular scale. ${ }^{6}$

The remainder of the thesis is organized as follows. Section 2 reviews the literature and places my work in its historical and scholarly context. Section 3 outlines the spatial metrics and segregation outcomes proposed. Section 4 explains how the dataset was constructed, and it describes in detail how the urban typologies are

\footnotetext{
${ }^{6}$ Most researchers who investigate residential segregation use census tracts as their unit of analysis (e.g., Crowder, Pais, and South 2012; Glaeser and Vigdor 2012; Massey and Denton 1993).
} 
employed. Section 5 presents my empirical strategy and my main results; the latter pertain to the effects of urban form on the immigrant assimilation process. Section 6 concludes with a discussion of the limitations of this thesis and suggestions for future research. 


\section{Chapter 2}

\section{Literature Review}

\subsection{Determinants of segregation}

Residential segregation refers to the degree to which two or more groups live separately from one another in different parts of the same urban environment (Massey Denton, 1988). A concern frequently expressed in the planning literature is that segregation, when it is linked to poverty and deprivation, hinders the socioeconomic integration of minority groups. Galster (2008), for example, demonstrates that neighborhood segregation is associated with limited economic opportunities because it reduces access to jobs, and this, in turn, concentrates poverty, which exacerbates social alienation. See also the findings of (Zubrinsky (2003) and Massey and Denton $(1993))$

Of course, it is also true that not all ethnic enclaves suffer discrimination or disadvantage and that many provide information, support, and networking opportunities. Indeed, Sabatini (2006) asserts that the spatial concentration of a social group can help preserve its cultural identity and promote social and political empowerment. Other research on segregation (Cutler, Glaeser, and Vigdor 2008) finds that residing near, but not in, an enclave can be beneficial to professional immigrants who serve the community.

It is also important to recognize that segregation can produce a variety of outcomes, some of them positive, and that outcomes often are context-dependent (Sabatini 2006). Charalambous (n.d.) finds that locating enclaves close to economically active, well-integrated streets actually enables social integration in the urban envi- 
ronment. That certain spatial configurations can affect social outcomes is indicated by recent studies in New Urbanism. ${ }^{1}$, whose proponents claim that compact urban forms, pedestrian-friendly neighborhoods, and mixed land uses produce more social benefits than typical suburbs. Similarly, Song and Knapp (2004) show that New Urbanist neighborhoods in Portland, Oregon, have higher residential property values and high levels of social integration.

During the last two decades, the literature on residential segregation has proposed three main explanations for this phenomenon: place stratification, socioeconomic status differences, and ethnic group preferences. The first approach suggests that persistent segregation is due to discrimination against certain groups in the housing market (Bosch et al. 2010). Discriminatory practices include banks denying mortgage loan applications to particular ethnic groups, real estate agents steering prospective homebuyers to segregated neighborhoods (Munnell et al,. 1996; Galster, 1998), and private landlords resisting immigrant tenants (Aelbers et al. 1991). Borjas (2013) suggests that the most important impacts of immigration are to be found not in labor market but in other spaces that natives and immigrants share.

The second explanation, that the underlying cause of segregation is socioeconomic differences between ethnic groups, suggests that ethnic differences in income level and educational attainment leads to physical separation into homogeneous neighborhoods. The underlying logic of this argument suggests that as the socioeconomic circumstances of immigrants improve, they will opt to live in higher income neighborhoods, which typically are native majority neighborhoods. In other words, if ethnic segregation is primarily due to socioeconomic differences, then segregation should disappear as the socioeconomic status of ethnic groups improves. But in the Netherlands differences in the residential preferences of ethnic groups persist even when analysts control for individual level characteristics (Bolt and van Kempen, 2010).

The third explanation asserts that residential segregation occurs because people prefer to live near others whose social, economic, and cultural circumstances are similar. For example, in the United States, residential segregation occurred be-

\footnotetext{
${ }^{1}$ Urban design practices that were prominent until the rise of the automobile prior to World War II; it encompasses two main concepts: building a sense of community and the development of ecological practices
} 
cause natives preferred to move to all-native neighborhoods (Card et al. 2008; Saiz and Wachter, 2011). During this so-called "White Flight" phenomenon, whites fled the more integrated inner city for the less integrated suburbs. Here urban sprawl produced ethnically segregated areas (Banerjee and Verma, 2005).

Clearly, complementary mechanisms influence how social groups interact with one another and occupy urban spaces. Segregation, it should be emphasized, cannot be attributed to a single cause.

\subsection{Urban form}

Urban form refers to the physical form of urban areas at scales that vary from courtyards to conurbations. ${ }^{2}$ The built environment, it is argued, has determinative impact on residents' daily experience and it significantly influences resident's behaviors. From this conclusion a number of studies postulate that the built environment shapes social outcomes in the arenas of energy consumption, public health and social integration. Several studies find that urban form affects outcomes. For example, a higher concentration of residential and leisure land uses is associated with decreases in energy consumption (Newman and Kenworthy 1999), which is associated with an improvement in health indicators (Hoehner, Ramirez et al. 2005; Rundle, Roux et al. Forthcoming) and greater social cohesion (Jacobs 1961; Pendola).

Although analysts have grown increasingly interested in the role of the environment in segregation, they remain unsure how segregation is affected by the settlement pattern preferences of various social groups. ${ }^{3}$ The role that the physical environment plays in social processes is becoming increasingly important.

\subsubsection{Measuring urban form}

Configurational studies provide valuable insights into how urban form can be measured. Previous research has focused on the configuration of street and block patterns, parcel dimension, and land use. Qualitative methods include morphological descriptions (Conzen, 1969; Bergauser Pont and Haupt, 2009) while quantitative

\footnotetext{
${ }^{2} 2$ Urban form has been examined at geographical scales that range from the regional (Fina and Siedentop, 2008) to the neighborhood (Song and Knaap, 2004).

${ }^{3}$ Some have suggested social housing projects reduce the increasing fragmentation of cities. However, traditional public housing strategies frequently lead to poverty concentration.
} 
ones range from network component analysis, graph theory, and space syntax to fractal dimension (see for example, Kansky, 1963; Vaughan, 1987; Wright et al., 1995; Batty and Longley, 1995; Hillier, 1996). ${ }^{4}$ My work resembles that of Pont and Haupt (Bergauser Pont and Haupt, 2009), who propose morphological measures that describe spatial attributes. Table 2.1 illustrates some of the frequently used metrics in planning studies.

Table 2.1: Urban form measures

\begin{tabular}{lll}
\hline \hline & & Measures of urban form in recent planning studies \\
\cline { 2 - 3 } & Measurement & Indicator \\
\hline Galster, G., et al & Urban Sprawl Index & land use: density, centrality, concentration and clustering \\
Burton, E. & consumption patterns & urban form: street design, network, land use mix and access \\
Jabareen, Y.R & Density and social equity & density, mix of uses and intensification \\
Bertaud, A. & Urban form types and sustainability & density by measures its distribution and variation. \\
Tsai, Y. & City structure & spatial distribution of population given census data and commuting trips \\
Berghauser Pont \& Haupt & building density & size, density, Gini coefficient and Moran coefficient \\
Torrens and Alberti & neighborhood mix & land occupancy and building density \\
\hline $\begin{array}{l}\text { Notes: The table provides an overview of some of the most prominent metrics that are used to } \\
\text { quantify urban form. }\end{array}$
\end{tabular}

\subsubsection{Morphological measures of urban form}

Morphological analysis focuses on the attributes of individual characteristics of the built environment rather than on the relationships between them. For example, Anderson (1993) shows that the relative position of parcels within individual blocks produces important differences in accessibility and the exposure of spaces. Anne Vernez Moudon employed a methodologically similar analysis to examine a set of city blocks in San Francisco (Moudon 1986). Her analysis of block sizes and subdivisions suggests that parcel dimensions influence the types of buildings that will later occupy them. Mangin and Panerai (1999) show that the dimensioning of parcels and city blocks can invite certain kinds of building types, which, in turn, can lead to predictable patterns of densification and infill. Similarly, Jacobs (1993) argues that urban layouts play an important role in the generation of urban life, heterogeneity, and urban qualities.

\footnotetext{
${ }^{4}$ The goal of most recent attempts to analyze and quantify urban form has been to quantify the sprawl phenomena rather than to examine urban form per se.
} 
Other studies combine quantitative and qualitative methods to classify and describe urban environments. Urhahn (1994), for example, catalogues urban neighborhoods on the basis of form, density, land use, and mobility infrastructure. To define street patterns Marshall combines quantitative attributes that are related to configuration, composition, and complexity.

\subsubsection{Aggregate measures of urban form}

The core difference between aggregate and morphological measures lies in the resolution at which they operate. Morphological measures tend to operate at a fine resolution, and thus describe individual elements of the built environment ${ }^{5}$, while aggregate measures typically estimate densities of built elements per unit area of land. Aggregate measures provide useful summary statistics for areal units. These include average perimeter of city blocks and distribution measures such as dissimilarity and evenness. Along these lines, Torrens and Alberti (2000) look at density levels of places to determine their levels of sprawl.

Although the concept of urban density offer many analytical advantages, critics in urban planning have argued that density by itself is a coarse measure that cannot describe all important qualities of the built environment. Those who employ a wide range of density measures no doubt will produce more nuanced comparisons of urban form. For example, side-by-side comparisons of residential density, unit density, floor area ratios (FAR), and building coverage can reveal important typological differences in urban form (Pont and Haupt, 2010). Studies by Galster et al. (2001) suggest that other measures, such as continuity, concentration, clustering, centrality and proximity, can be used to compare the compactness of urban forms at a granular level of analysis. In response to the limitations inherent in examinations of density alone, I propose a choice of spatial indicators that together encompass density but also produce additional information about other spatial properties.

\footnotetext{
${ }^{5}$ Aggregate measures of the built environment are useful when outcome variables are measured at an aggregated scale.
} 


\subsubsection{Context}

In this section I briefly review the evolution of urban form in the city of Barcelona. The capital of Catalonia has been a recurrent paradigm in the fields of international urban development and architecture since the early days of Cerdà's expansion plan through the period of urban renewal that was prompted by the 1992 Olympic Games.

The city underwent intense development from the end of the nineteenth century through the first half of the twentieth century. Broadly speaking, the city consists of four main areas: the medieval old city, or city center (Ciutat Vella); the Eixample expansion plan that was designed by Idelfons Cerdà; the Old Villages, which were largely developed during the 1960s and 1970s through the Urgency Plan of 1957; and the neighborhoods redeveloped for major events such as the 1992 Olympics and the 2004 Forum de les Cultures, which started during the mid - 1980s and continues to the present.

Distribution of municipal boundaries in Barcelona

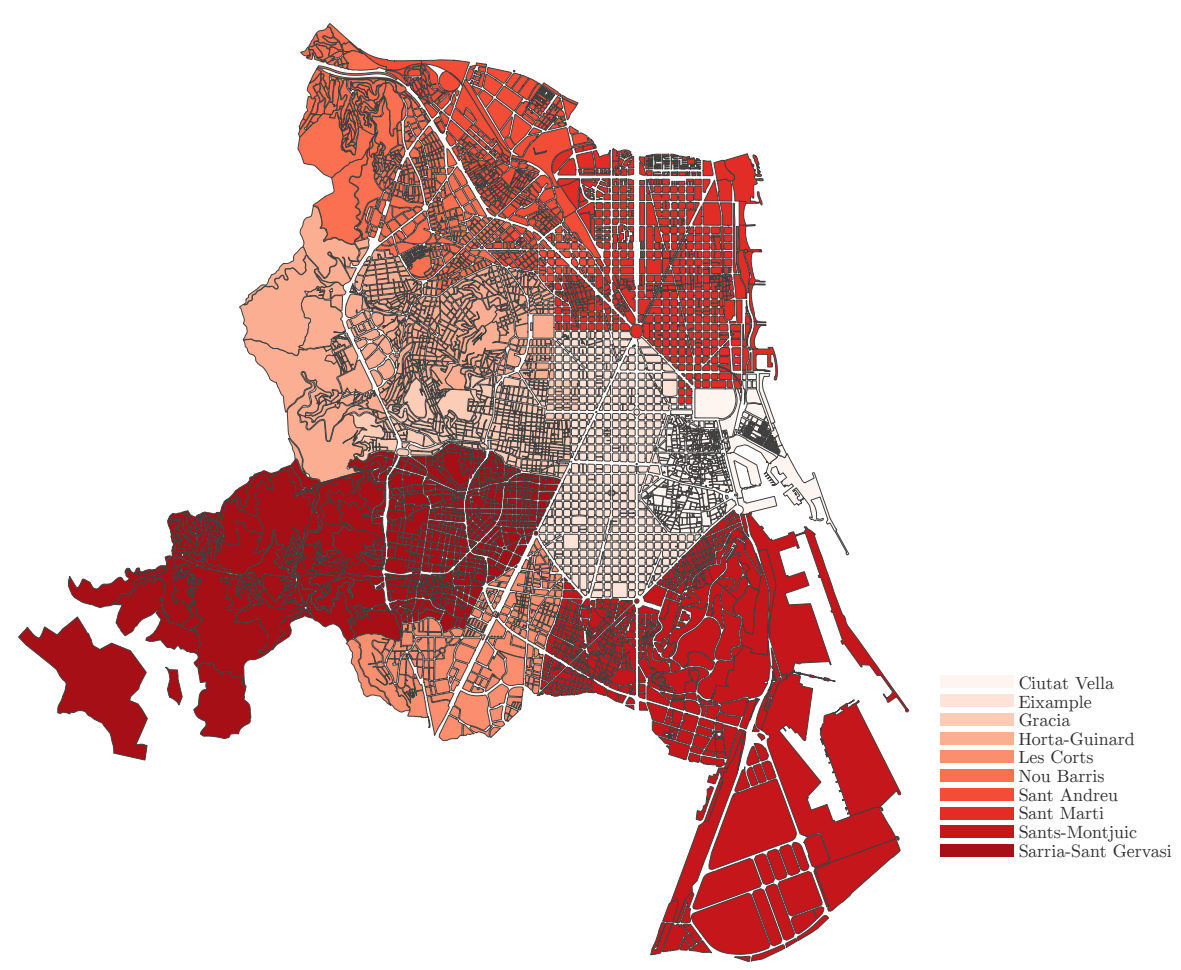

Figure 2-1: The 10 muncipality boundaries reproduced to a large extent the perimeters of old municipalities that had been annexed during the late 19th century. The units grouped together areas of approximately 200,000 inhabitants 


\section{City center}

The city center provides an excellent example of historic continuity and the current landscape of an urban core. Today's urban core today consists of 192 hectares of narrow streets, alleyways and small squares.

\section{Old villages}

The 'Urgency Plan of 1957 involved 900 hectares of land and 127,000 dwellings in the same area that was affected by Cerdà's original Eixample plan. This impulsive development left many areas with limited programmatic diversity, inadequate commercial space, and relatively disconnected from the city center. Scattered over the territory, low density developments have continued to extend towards the city's outskirts.

\section{Cerdà Eixample plan}

The plan proposed by Cerdà implemented a 1,969 hectare grid of streets located between the city center and the Old villages. The development rapidly spread, thereby connecting Barcelona to outlying towns, which at the turn of the century were incorporated into the city. The grid, 1,000 blocks in size, had streets 20 to 30 meters wide. Two parallel buildings were placed on each block, and yards and green spaces between blocks linked pedestrian paths to middle and inner open spaces and the street network. 


\section{Chapter 3}

\section{Data sources and measurement}

\subsubsection{Urban footprints}

Data on urban blocks that I use to construct the shape metrics were obtained from the Barcelona City Hall open data service. These data include information on land use, building height, and open space (distinguished by type) for all of the city's urban area, which is about five thousand blocks. The region of analysis, defined by administrative divisions provided by the Barcelona City Hall, consists of 10 municipalities (see Figure 2-1). 1 The open data source provides information for 2011. Ideally it would be best to examine data on the urban layout that dates to the period prior to the large immigration flow (1998). However, it is plausible that there was little variation in urban form over the 10 year period of my study, and therefore my measures constructed in 2011 could provide a good approximation of the preexisting urban form. ${ }^{2}$

\subsubsection{Population and census data}

To complement the spatial measures I examine a high-quality dataset that was gathered by the Padron (official population registry) and covers the period from 1998 to 2008. The data offer a full picture of the official location of every individual living in Spain, including his or her exact street address, sex, date of birth, place of birth

\footnotetext{
${ }^{1}$ The ten municipalities included in the analysis are: Ciutat Vella, Eixample, Sants-Montjuic, Les Corts, Sarria-Sant Gervasi, Gracia, Horta-Guinardo, Nou Barris, Sant Andreu and Sant Mart A. Given that detailed information is only available for these urban municipalities, I examine this area rather than the larger metropolitan region.

${ }^{2}$ The physical form can certainly change, but this change occurs in long time spans.
} 
(categorized by country for immigrants and by municipality for natives), nationality, and education level (up to high school). ${ }^{3}$

The Municipal dataset is collected every January 1 and for several reasons it offers a good measure of residential choice. First, public funds from the national government are assigned on the basis of the population that is reported at the time of the annual dataset collection. Consequently, every municipality is incentivized to report appropriately. Second, individuals have incentives to register because by doing so they gain access to municipal services, such as education and health. Immigrants, too, are similarly motivated because registration proves residency. According to the law 4/2000, all registered immigrants, even if undocumented, are granted access to all public services.

Using the geographic coordinates associated with each person's address, I match the building address to its corresponding block using ArcGIS. ${ }^{4}$ Additionally, because the 2001 Census (INE, 2005) data provides socioeconomic characteristics only at the censal section ${ }^{5}$, I assign each block to the average characteristics of its censal section as of $2001 .^{6}$

\subsubsection{Ammenities}

I use the location of amenities gathered from all the points of interest (POI) through ESRI StreetMap Premium Europe NAVTEQ 2009 Release 2 (ESRI, 2009), and I use them as controls in my empirical analysis. Since I do not want to capture the effect of amenities when analyzing urban form, I control for differences in access to POI's between neighborhoods. To do this I include two measures of distance to amenities: (1) distance to the closest feature and (2) a gravity measure that provides the sum of every amenity weighted by the inverse of the distance between the amenity and

\footnotetext{
${ }^{3}$ Under Spanish law, everyone in the country must register and changes in address must be reported.

${ }^{4}$ The matching process, which is not always perfect, can introduce additional measurement error. For example, addresses can be assigned to longitudes and latitudes that are far from their actual locations. However, the geolocated data that I use (Moraga \& Ferrer-Carbonell, 2015) includes latitude, longitude and street address of every person. I first use the latitude and longitude and then corroborate the precision of the matching by comparing it to the results of the street addresses. The two matching approaches produce relatively similar results

${ }^{5}$ Censal sections, which are administrative divisions devised for electoral purposes, are supposed to have between 500 and 2,500 inhabitants.

${ }^{6}$ The term block or urban block term I use in a conventional sense to refer to the city's smallest area that is surrounded by streets.
} 
the address. The impedance function is constructed by elevating the distance to the factor of 2 in the weighted sum, which gives lower weight to amenities that are further away (see appendix for details). These amenities include distance to closest transportation hubs (metro stops and bus stops), highway and road exits, services, recreation, and education facilities. Figure 3-10 provides a detailed categorization of all variables used.

\subsection{Measuring segregation}

Residential segregation within a population can be measured in several ways. In contrast to previous studies, which have measured segregation at aggregate levels such as census tracts, through analyses of micro-data I construct alternative dissimilarity and exposure indexes that consider the spatial allocation of immigrants across buildings. ${ }^{7}$ Following Cutler et al. (Cutler, Glaeser, \& Vigdor, 2008), I compute two measures of residential segregation that compare the distribution of members of a group with that of individuals who are not members of that group. The index is calculated by dividing the city into blocks and using the following equation:

$$
\text { Micro - dissimilarity Index } \mathrm{b}_{\mathrm{b}}=\sum_{i} \frac{1}{2}\left|\frac{\text { native }_{i}}{\text { native }_{\text {total }}}-\frac{\text { immigrant }_{i}}{\text { immigrant }_{\text {total }}}\right|
$$

Here native $_{i}$ denotes the number of Spanish-born individuals living in building $i$, native total $_{\text {the number of individuals living in the entire block, and immigrants }}$ and immigrantstotal those residents who do not belong to the group in question. The micro-dissimilarity index takes a value of zero when immigrant and native populations are evenly distributed across buildings within a given block, and a value of one when native members live in different buildings from immigrant members. Intermediate values can be interpreted as the share of native individuals who, to achieve an even distribution within the block, would have to move to other buildings.

Figure 3-1 illustrates how the micro-dissimilarity index distinguishes between two scenarios: a situation in which $50 \%$ of the people who live in a block are segregated

\footnotetext{
${ }^{7}$ The methods proposed are sensitive not just to the relative mix of people in an area, but also to their spatial arrangement. See ??
} 
immigrants who all live in the same building; and one in which the same share of immigrants on a block are equally spaced across buildings.

Spatial allocation of immigrants in a block

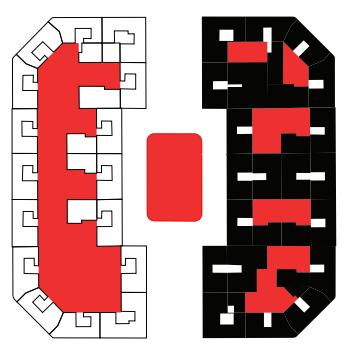

$50 \%$ segregated

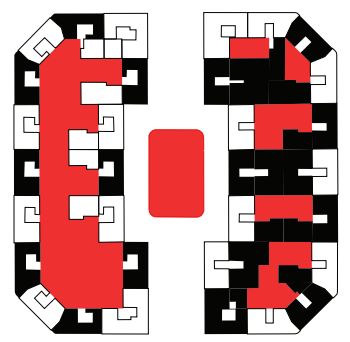

$50 \%$ distributed

Figure 3-1: Segregation measured with the Micro-dissimilarity index.

The second segregation measure used is the exposure index (Bell, 1954), which expresses the probability that within a given building one member of the immigrants group interacts with a member of the native group. I calculate the index using the following formula:

$$
\text { Micro - exposure Index } \mathrm{b}=\sum_{i} \frac{\text { native }_{i}}{\text { population }_{\text {total }}} * \frac{\text { immigrant }_{i}}{\text { population }_{\text {total }}}
$$

Here native $_{i}$ denotes the number of Spanish-born who live in building $i$, immigrants im $_{i}$ the number of immigrant individuals in the building, and population total $_{\text {the overall }}$ population of a given block. The denominator scales the index so that it has a theoretical range of between zero and one. An index value of one implies that the immigrant group has high interaction and is spread across buildings. A value of zero occurs when native members are concentrated in buildings where all residents belong to the same group.

Figure 3-2 shows the summary statistics on immigrant segregation for the tenyear period of analysis. The figure shows weighted average segregation levels wherein weights are equal to the size of the total population per block each year. The indices of micro-dissimilarity and micro-exposure tend to move in opposite directions over time. Micro-dissimilarity began at a relatively elevated level, and since 1999 it has 
been decreasing constantly for the entire immigrant population. In contrast, microexposure levels have followed the opposite tendency, thus mirroring trends in the overall size of the immigrant population, which reached its relative maximum in 2008.

Micro-dissimilarity and micro-exposure, 1998-2008

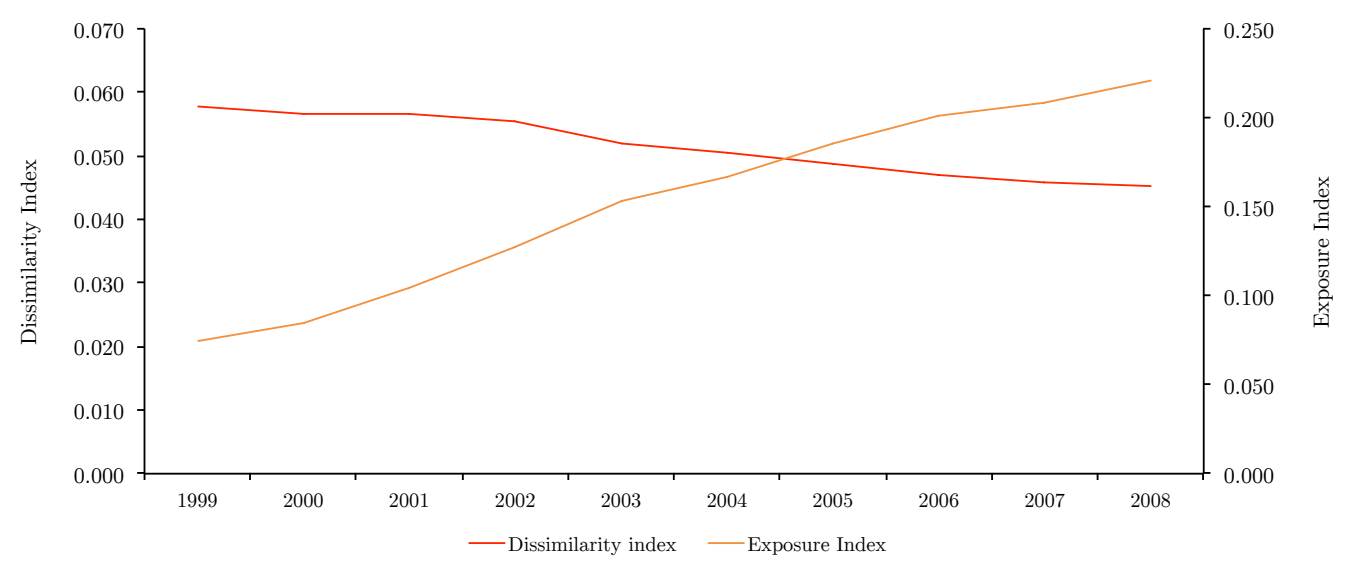

Figure 3-2: Indices are weighted averages for immigrant communities wherein weights are equal to the number of immigrants in the community.

The gap between groups appears to have closed after 2005. Although the microexposure index improves mechanically with the influx of immigrants, whether the micro-dissimilarity index increases or decreases is determined by whether immigrant populations settle in the same buildings as native ones. The fact that it has been constantly decreasing suggests that newcomers are mixing with native populations rather than settling in established immigrant buildings. 8

Table 3.1 and Figure 3-3 present summary statistics of the indices that I have generated for a selection of major immigrant groups, each of which I define by region of origin. In 1999, the largest immigrant groups consisted of peoples from Latin America, Africa, and Europe. Immigrant groups from Latin America experienced lower micro-dissimilarity levels (0.07) relative to immigrants from Africa and Asia, who experienced average micro-dissimilarity levels on the order of 0.08. Perhaps this transpired because Latin Americans share close cultural affinities with native

\footnotetext{
${ }^{8}$ I define an immigrant community as a group of individuals who were born in the same country and now reside in the same block. The values shown can be interpreted as the segregation experienced by the average immigrant during a given year.
} 
Spaniards, which might have led to a relatively easy assimilation process. For example, immigrants might cluster when they share cultural characteristics such as a common language. Starting in 2002, all immigrant groups experienced a drop in segregation, perhaps because of the implementation of law 4/2000 (regularized in 2001), which aimed to ensure the integration of legal immigrants and limit unauthorized immigration. Ten years later, in 2008, a new cohort of immigrants experienced segregation levels that were similar in trend but lower in magnitude.

Micro-dissimilarity by origin, 1998-2008

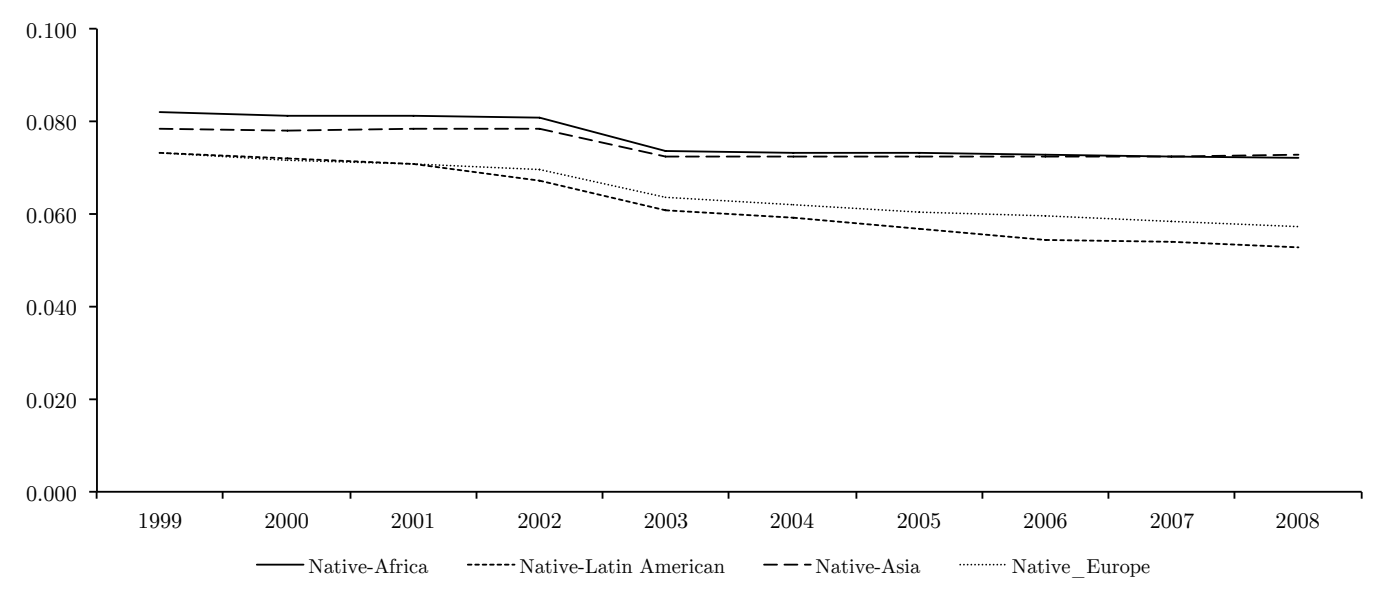

Figure 3-3: Indices are weighted averages for immigrant communities wherein weights are equal to the number of immigrants in the community.

Micro-exposure by origin, 1998-2008

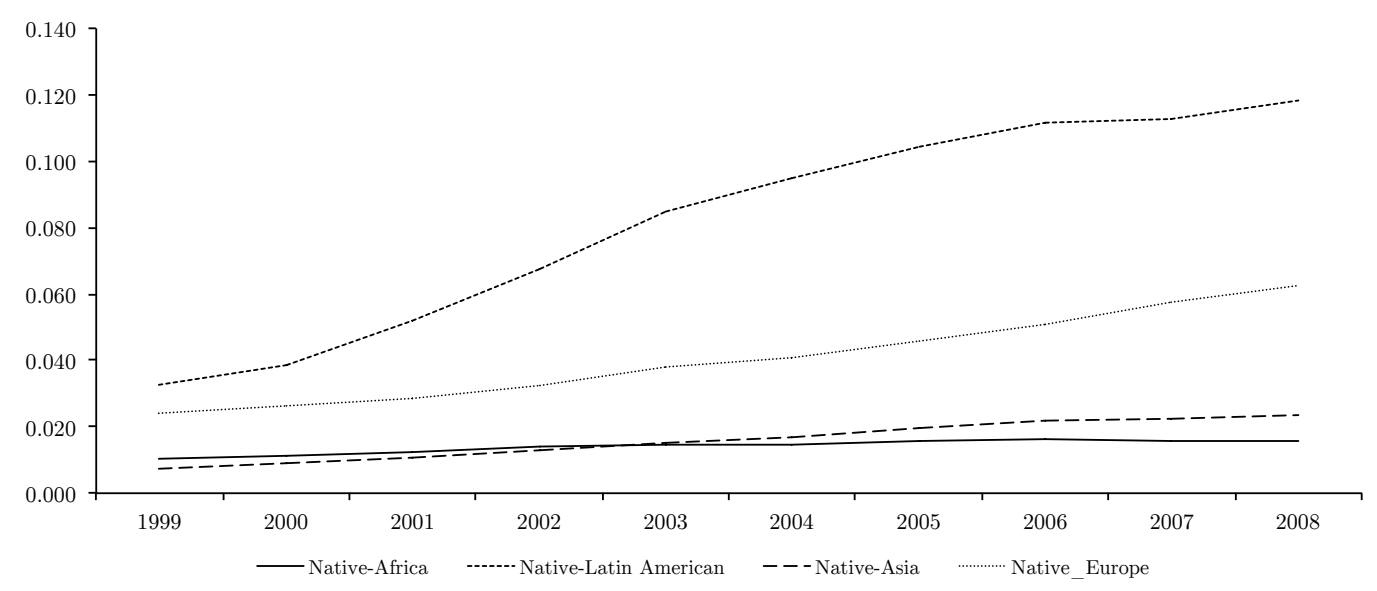

Figure 3-4: Indices are weighted averages for immigrant communities wherein weights are equal to the number of immigrants in the community. 
In 2008, the largest immigrant groups continued to be from Europe (mostly Bulgaria and Romania) and Africa, with a growing percentage from Asia. Asian and African groups experienced the highest segregation: their micro-dissimilarity levels reached 0.07, which was comparable to those experienced in 1999. Latin Americans experienced the biggest drop in segregation: their micro-dissimilarity level, 0.05 fell, well below the indices for European immigrants. At the same time, the micro-exposure level of Latin Americans - on the order of 0.11-was remarkably high, and it contrasts greatly with the micro-exposure level (0.03) experienced by Latin Americans in 1999 (see Figure 3-4). This substantial change might suggest that native populations are becoming more tolerant of and willing to coexist with Latino immigrants. However, the micro-exposure index increases mechanically with arrivals, and so I pose this conclusion tentatively.

Overall, the micro-exposure and micro-dissimilarity indices convey different dimensions of the segregation trend. By incorporating both metrics I provide a superior characterization of broad trends in segregation. 


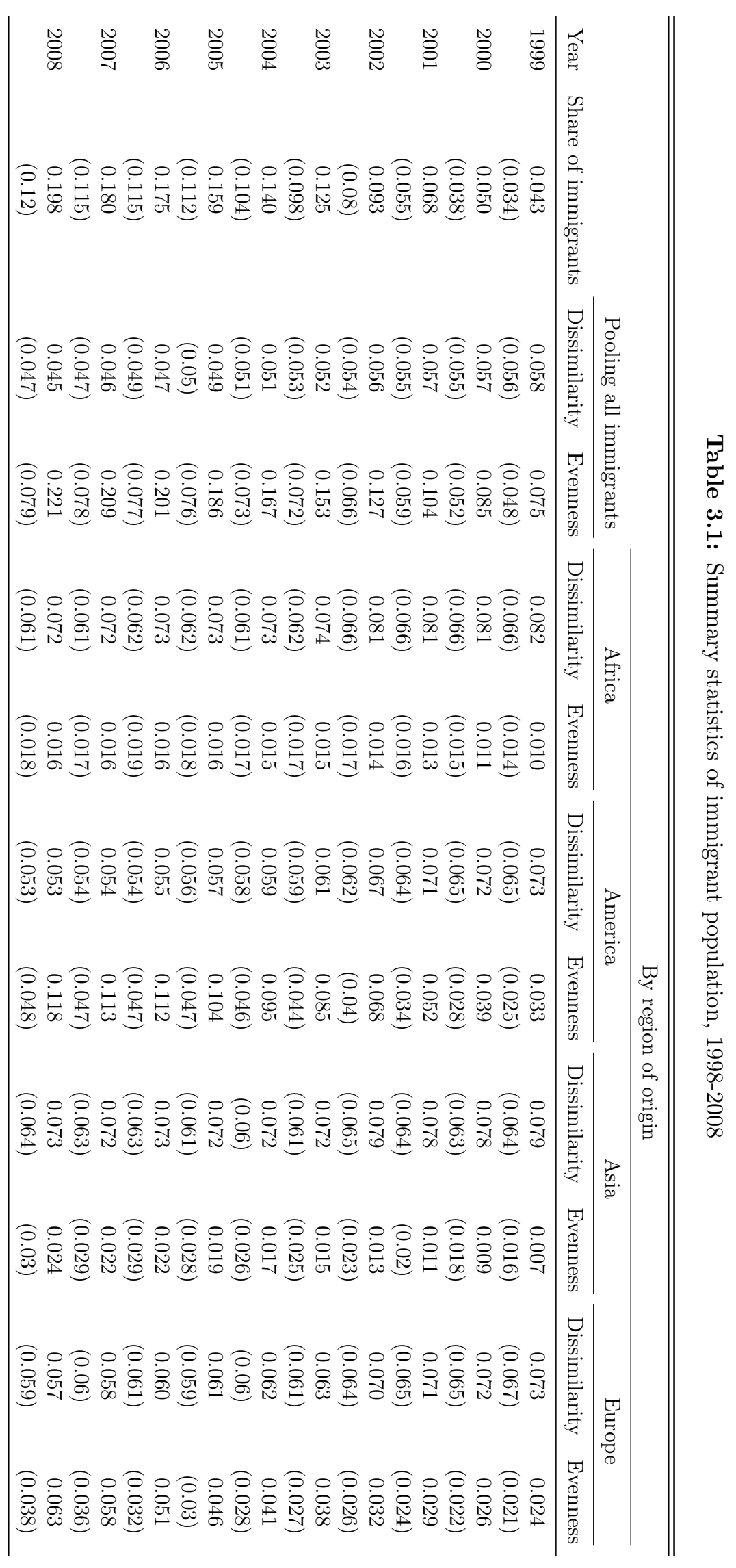




\subsection{Shape metrics}

In the literature on the metrics of the built environment, the most common scale of analysis is the neighborhood or the city (see Alan Betaud and Malpezzi 2003). In contrast, my study examines urban form at a much smaller scale: the block. To this end, I draw upon previous research that examines morphological concepts of form, as I explain below.

\section{Density measures}

To analyze built form in its three dimensions I examine the density of the built environment. Building density is the most commonly used metric, but it is widely understood that it does not necessarily reflect change in the layout of the urban fabric (Space matrix, 85). An illustrative example is the typical block in the Cerdà expansion plan. Individual blocks that have similar built densities can differ greatly in how their built mass and open spaces are distributed. I employ an alternative approach that combines a wider range of density measures, and this produces a more nuanced comparison of urban form. ${ }^{9}$

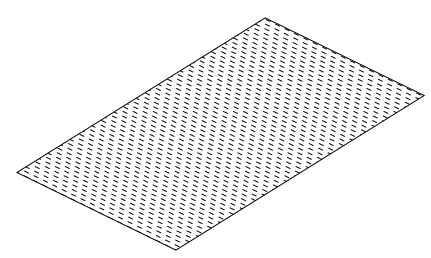

(i) Area of the block

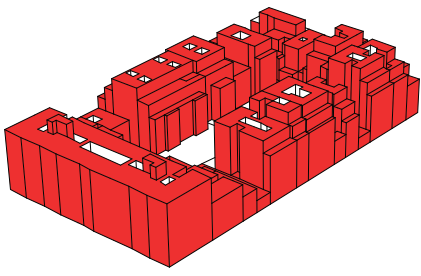

(ii) Built-up mass area

Figure 3-5: Building density

1. Building density expresses the relation between the building gross floor area and the total area of the block. Figure 3-5 provides a visual example of the areas used in the calculation. I estimate building density by multiplying the footprint of every building by its height and then dividing its sum by the total area of the block. ${ }^{10}$

\footnotetext{
${ }^{9}$ Bergauser Pont and Haupt (2009) suggests that mixing various density measures produce a better characterization of urban form.

${ }^{10} \mathrm{I}$ approximate the height of each building by multiplying the number of floors by the standard floor height.
} 
The more closely spaced together or the taller the buildings the higher the density of the block.

Studies suggest that dense environments are characterized by walkable, pedestrianbased access to needed services and neighborhood-based facilities. They also contribute to a vibrant and diverse quality of life (Jacobs, 1961; Kunstler, 1994; Newman and Kenworthy, 2006). Churchman (1999) suggests that density is the most intuitive characteristic of urban form, and often it is regarded as indicative of sprawl (Galster et al., 2001). This is significant because studies link sprawled development to a lower efficiency of land consumption and the lessening of a sense of community.

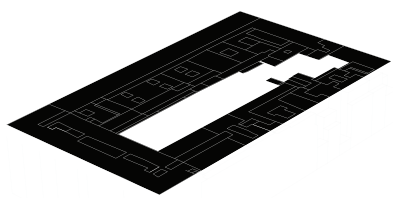

(i)

ground area

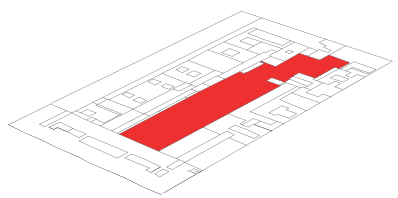

(ii)

Open space

Figure 3-6: Coverage

2. Coverage expresses the relation between the built ground area and the open space in a given block (see Figure 3-6). I estimate building coverage by dividing the footprint area of each building by the total area of the block. The higher the building coverage, the less dense the buildings are developed and the higher the share of open space.

Studies suggest that where there is higher lot coverage (between 60 and 80 percent (Jacobs) ) more people are attracted to the public realm. In the city of Barcelona there are stark differences in coverage. For example, in the original Cerdà Expansion plan, coverage was limited to a total of 50 percent in order to guarantee hygienic conditions (Busquets, J. Barcelona, The Urban Evolution of a Compact City), but in many areas coverage has now reached almost 90 percent.

3. Height Variance measures changes in building height in a given block (see 3-7). I 


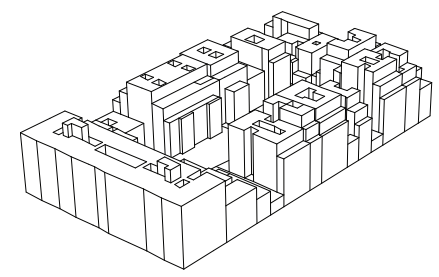

(i)

Built-up mass

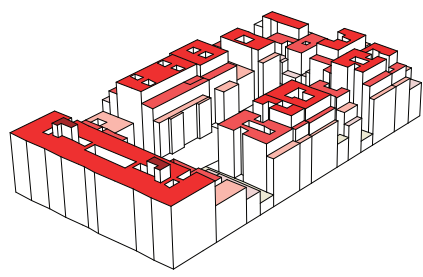

(ii)

Variations in building height

Figure 3-7: Height Variance

estimate height variance by ordering the buildings in a block according to their distance from the block centroid. I then compute the absolute change in height among consecutive buildings within this ordering. The height variance index is defined as the average of these changes. The more variation in building height, the more heterogeneous the built-up environment is. A block whose buildings differ greatly from one another in terms of height is associated with increased levels of height variance. The measurement takes a lower value where the build-up is more homogeneous.

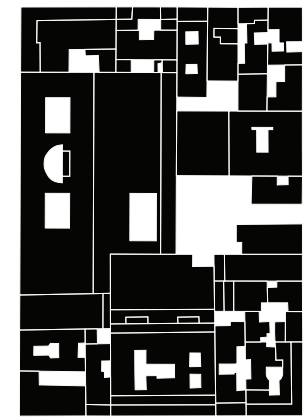

(i) Figure-ground

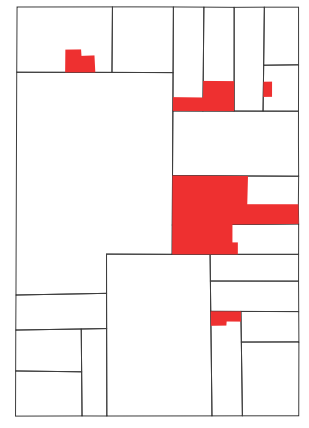

(ii)

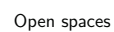

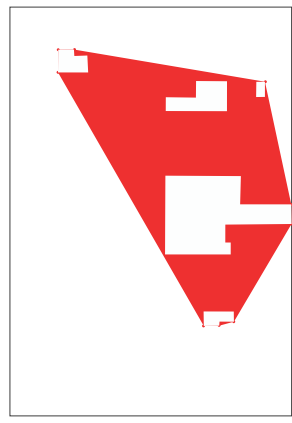

(iii)

Figure 3-8: Compactness

4. Compactness measures the degree to which the resources of a city, people, buildings, or open spaces are spatially spread out. I quantify the degree of concentration between open spaces in a given block by calculating the area of open spaces, and I then divide the sum by its convex hull (see Figure 3-8). The convex hull is defined as the smallest convex polygon that can accommodate all the open spaces in a block area. The closer open spaces are to one another, the more compact they are. Com- 
pactness takes a value of one where open spaces in a given block are clustered closer to each other and a value of zero where open spaces are scattered or absent.

Compact neighborhoods bring with them environmental, social, and economic benefits; for example, social connections are strengthened where people live close together (see Owen, 2009). Most of the studies have measured compactness in terms of resources per unit area of land. Using the openness index, for example, Burchfield, Overman, et al. (2006) measure dispersion as the average percentage of open space in the square kilometer that surrounds each residential development. However, using this approach the analyst cannot distinguish homogenous and heterogeneous distributions within a block.

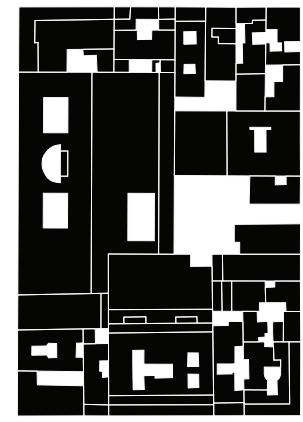

(i)

Figure-ground

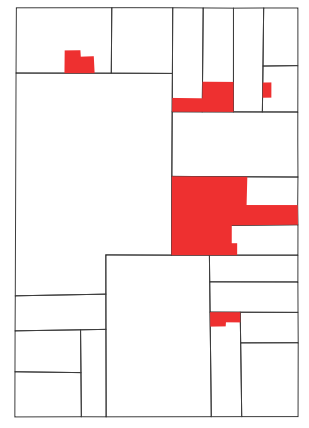

(ii)

Open spaces boundaries

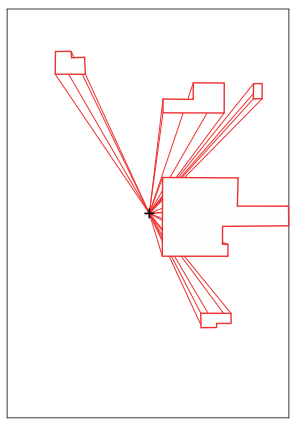

(iii)

distance to block centroid

Figure 3-9: Centrality

5. Centrality measures the degree to which the open spaces are concentrated towards the center of a given block (see Figure 3-9). I describe the spatial distribution of open spaces by measuring their deviation from the block centroid. I do this by computing for every block the distances from the centroid to the border of the block's open spaces, and I then average the distances. To have a measure that is comparable across differently sized blocks, I normalize the centrality measure by dividing it by the perimeter of the block. The value of centrality lies in the ease of access from all surrounding locations. Centrality takes a value of one where open spaces are peripheral and a value of zero where open spaces are located centrally in a given block. 
Wilson (2000) finds that central spaces are important for integration. Similarly, Hillier and Hanson conclude that pedestrian flows and human way-finding capacity affect the level of integration of urban spaces.

Figure 3-11 to 3-15 show the spatial allocation of the metrics in Barcelona's urban area. I describe the historic center as the city core, the Cerdà expansion plan as the middle ring of development, and the newly developed areas in the outskirts as the periphery or suburbs. Figure 3-11 shows that building density is high in the city core, and on the basis of building density alone the core and periphery can be distinguished. However, building density tells us little about the configuration of open spaces within these areas or about build-up. A clearer picture emerges when I overlay the height variance metric. As Figure 3-12 shows, the highest values are concentrated in the middle ring of development, in contrast to the city core and garden-style suburban areas, which have the lowest values and are the most homogeneous. Evidently buildings in the historical center and the newly developed areas are relatively homogenous in terms of height. Are open spaces configured differently in the core, middle ring, and periphery? Figure 3-13 shows that most centrally located open spaces are found in the middle ring and the city core. In other words, in these areas, open spaces are limited and mostly cluster near the center of the block. As shown in Figure 3-14, compactness reaches maximum levels (level 1) in the middle ring of development - a fact that I attribute to the original extension plan, which indicated that open spaces of the courtyard type should be placed at the center of each block. These findings find further support in the centrality metric: as indicated in Figure 3-14, the highest centrality metric values occur in the middle ring and the core. The lowest centrality values occur in the periphery, suggesting that many open spaces are located adjacent to streets or backyards.

Figures 6-2 and 6-5 in the appendix further illustrate the spatial variation that is captured by the measures that I employ. To ensure that my measurements capture complementary characteristics of the built form in Table 3.2 I present the correlation values for all the metrics.

In this chapter I have described the results of each of my spatial metric analyses of general patterns in the city. But each individual metric can characterize only particular aspects of the built form. In the following chapter I construct typologies 
Table 3.2: Shape metric correlations

\begin{tabular}{|c|c|c|c|c|c|}
\hline & \multicolumn{5}{|c|}{ Spatial measurements } \\
\hline & Coverage & Compactness & Building density & Centrality & Height variance \\
\hline Coverage & 1 & & & & \\
\hline Compactness & 0.491 & 1 & & & \\
\hline Building density & -0.2806 & 0.0208 & 1 & & \\
\hline Centrality & 0.5705 & 0.0768 & -0.157 & 1 & \\
\hline Height variance & -0.3573 & -0.2541 & 0.1806 & -0.2419 & 1 \\
\hline
\end{tabular}

using measures that I have previously described in order to define clusters of blocks that share similar and distinctive spatial characteristics. 


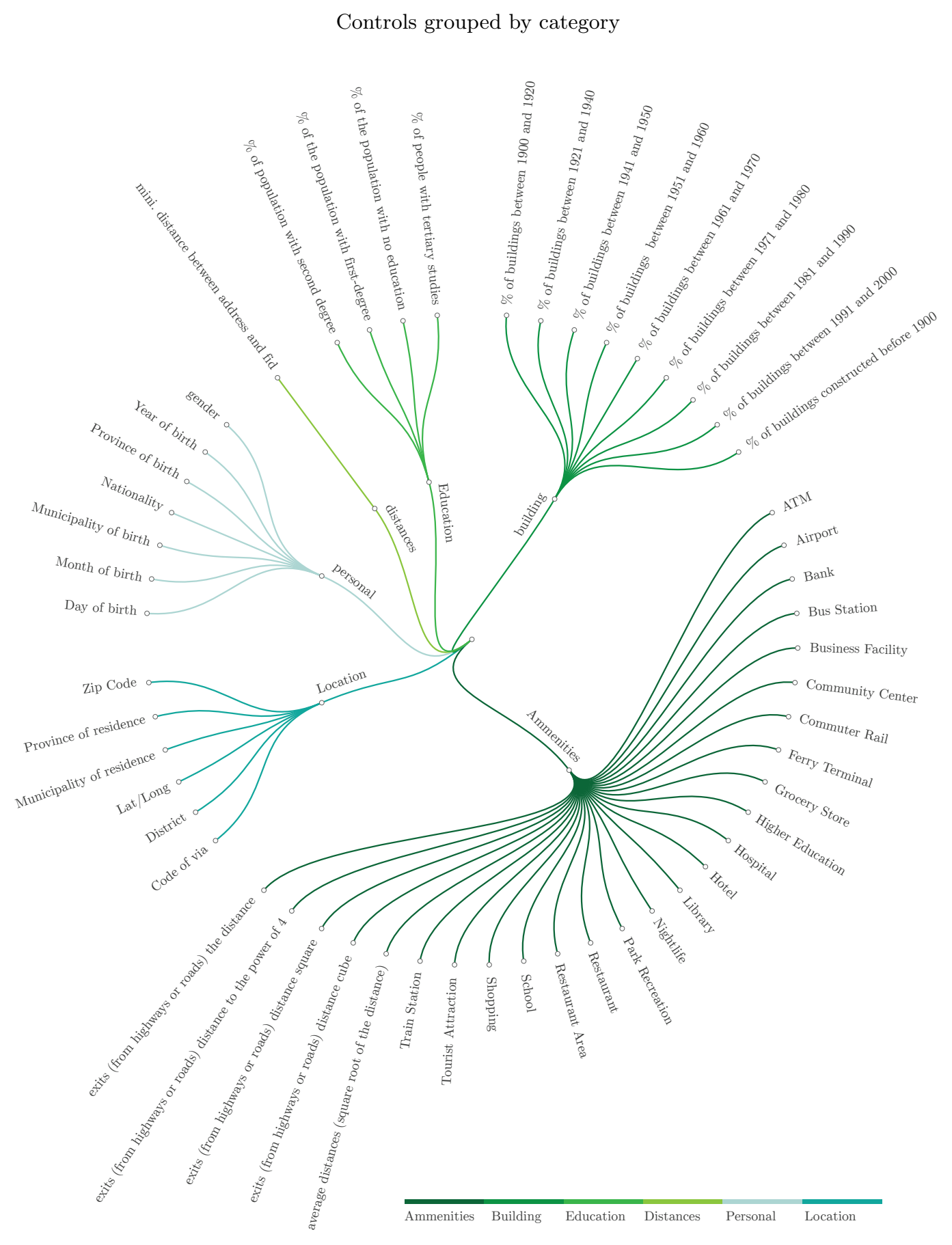

Figure 3-10: The figure provides the list of controls used in the regression models grouped by category. They are constructed based on data from INE (2009), INE (2005) and ESRI (2009). 
Shape metric | Building Density
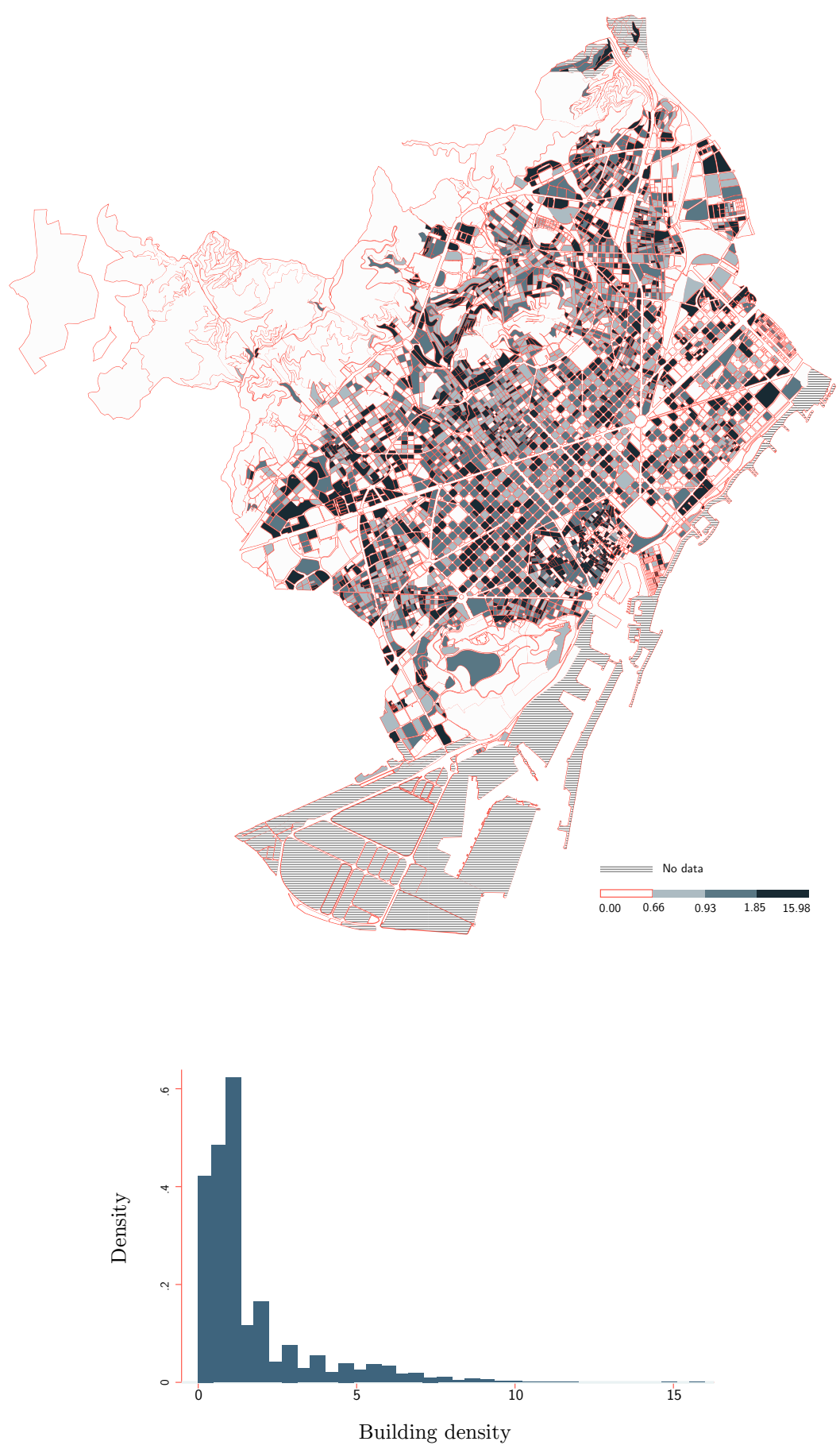

Figure 3-11: The Figure maps the spatial allocation of building density for each block in the urban area. High densities are featured closer to the historic center - where the plots of land are the smallest. Intermediate values cluster in a scattered pattern throughout all the territory. 
Shape metric | Building height variance
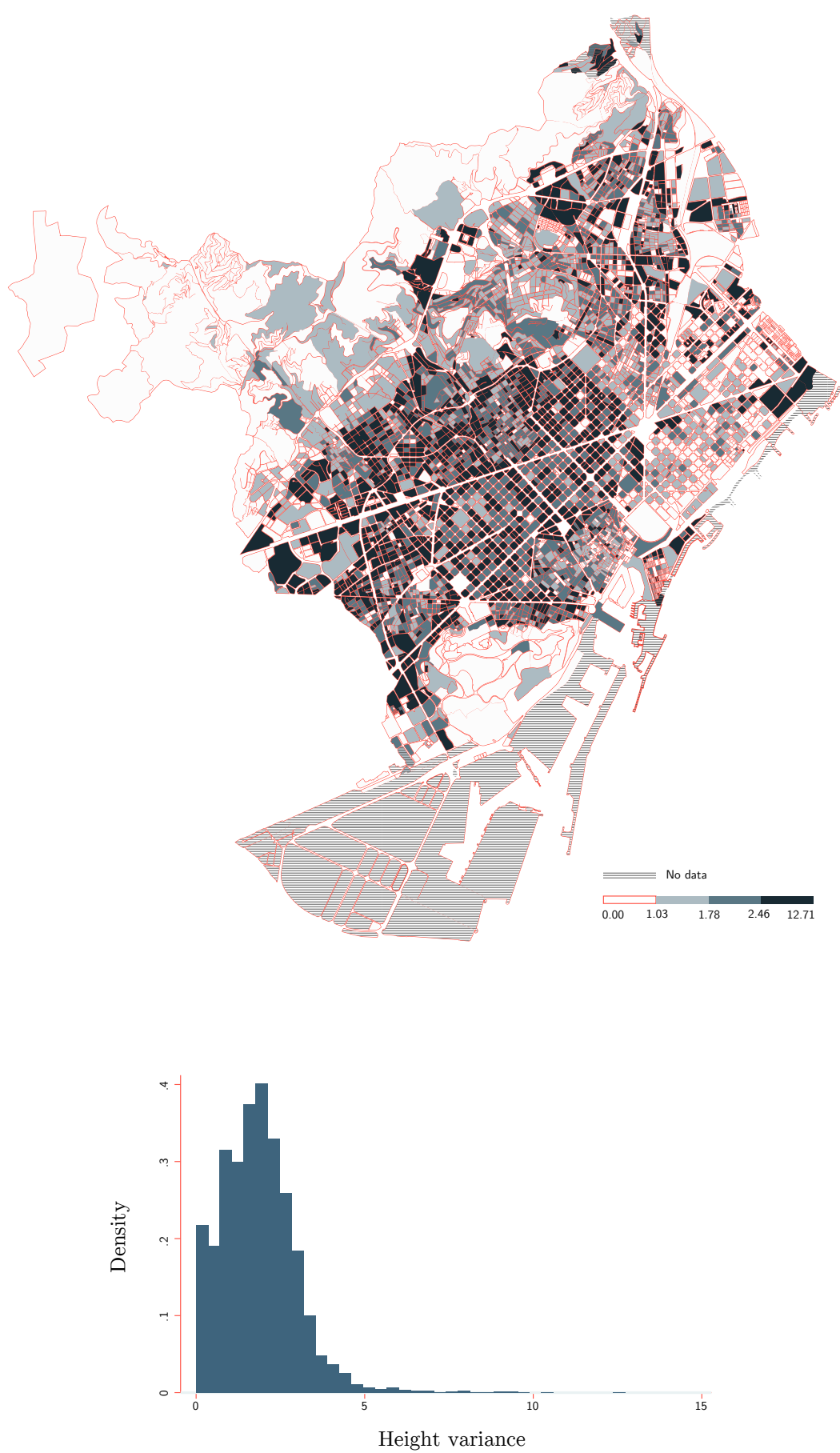

Figure 3-12: The Figure maps the spatial distribution of height variance for each block in the urban area. The lowest height variance is located towards the peripheral areas of the city, while the highest values cluster towards the middle ring of development. 


\section{Shape metric | Centrality}
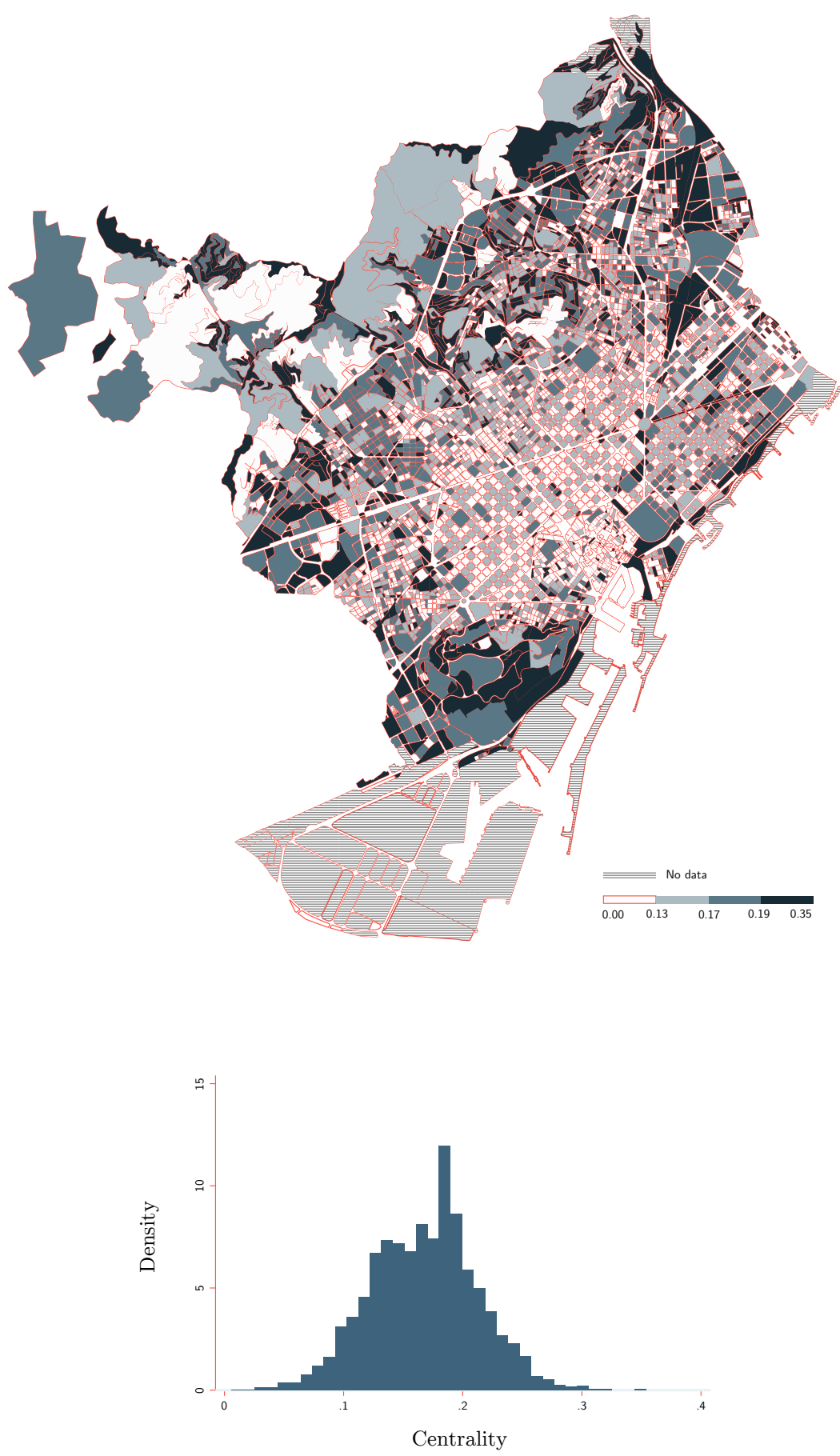

Figure 3-13: The Figure maps the spatial distribution of centrality for each block in the urban area. The lower values of centrality — which indicate higher centrality levels - are mostly found close to the historic center and its surrounding areas. The lower centrality levels found in the peripheral areas suggest that despite having a greater overall share of open space, these are mostly configured adjacent to the street. 
Shape metric | Compactness
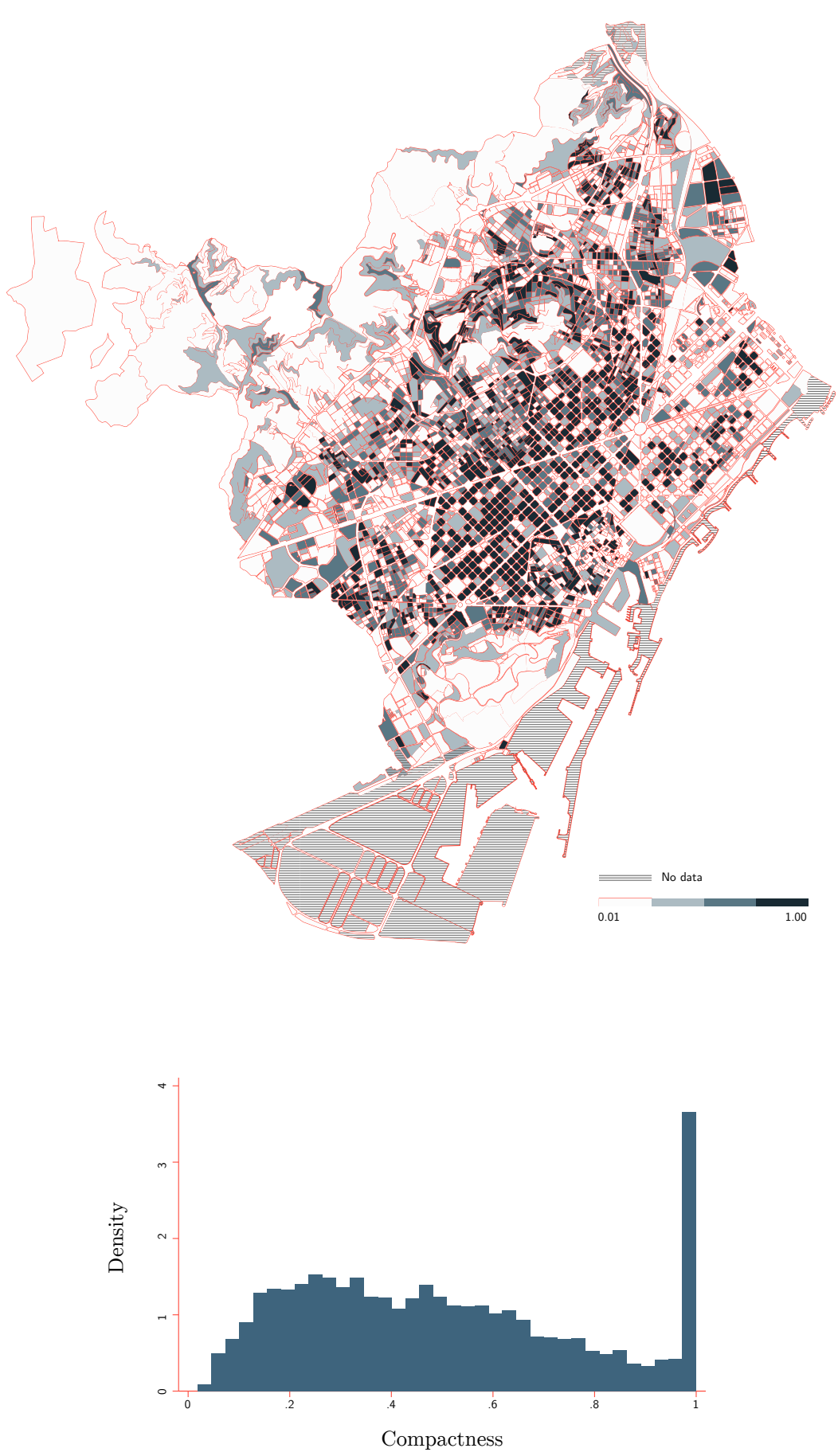

Figure 3-14: The Figure maps the spatial distribution of compactness for each block in the urban area. Highest levels of compactness are in the middle ring of development. The limited open spaces close to the historic center are reflected in the low levels of compactness in those areas. 
Shape metric | Coverage
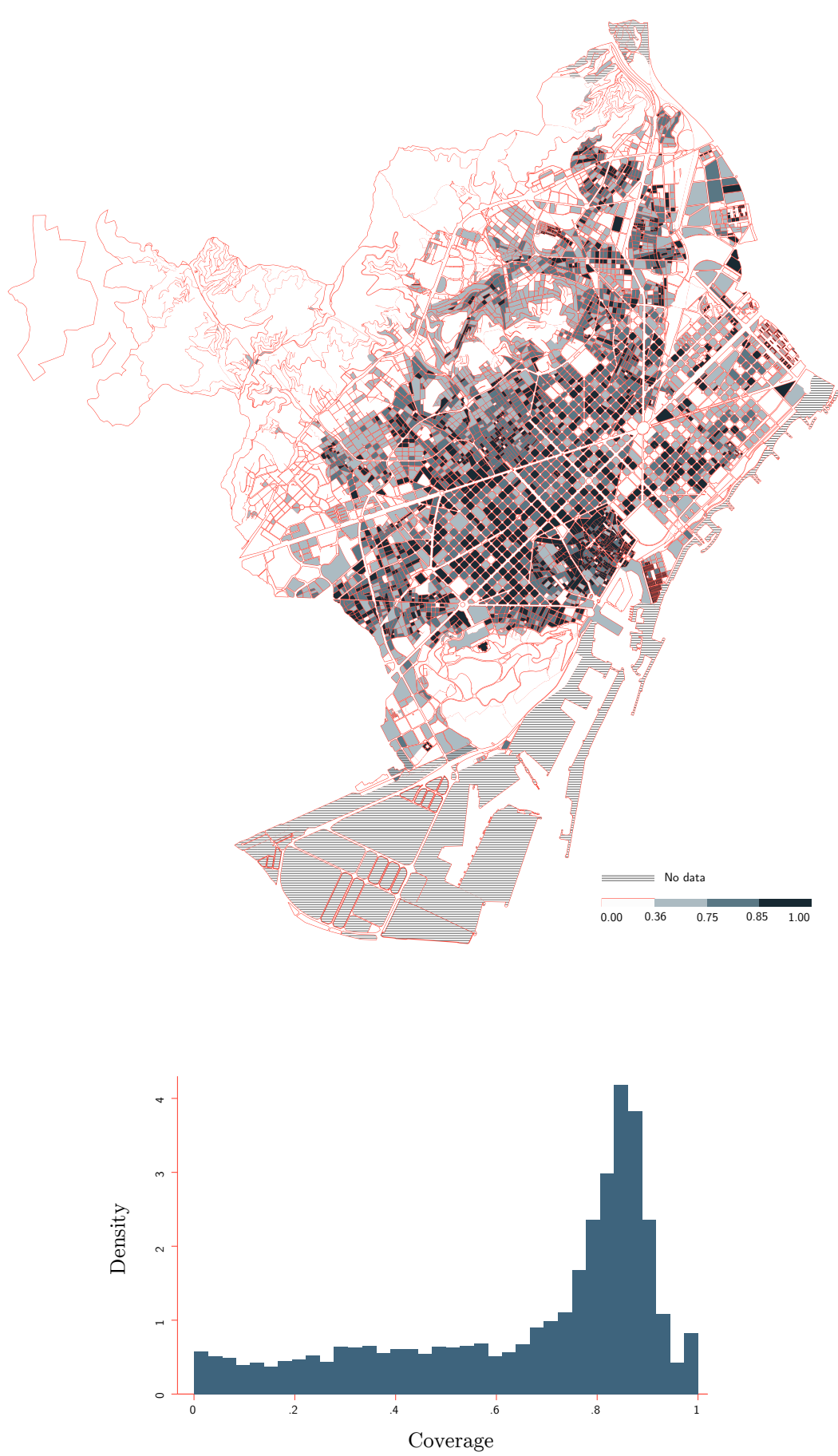

Figure 3-15: The Figure maps the spatial distribution of coverage for each block in the urban area. The highest coverage levels are located close to the historic center and its surrounding areas. The outer ring of development experiences the lowest coverage levels. 


\section{Chapter 4}

\section{Methodology}

\subsubsection{Building typologies}

Using the shape metrics described in Section 3.2, I construct eight building typologies or groupings that have similar spatial characteristics. To identify and classify the blocks, I use the K-means classification approach, which finds natural clusters in the data. The typological classification method consists of several steps. The method begins by identifying the cluster or seed variables that will be used to grow each group. For each cluster of blocks, a centroid is computed. Using the Euclidean distance, each block is assigned to the cluster with the closest centroid. The process of computing the centroid for each cluster and then reassigning blocks to the closest one continues until every cluster stabilizes. ${ }^{1}$

To group the data, the K-means method requires the number of clusters to be specified. I choose the number that maximizes the Calinski-Harabasz pseudo Fstatistic, which measures the extent of within-group similarity and between-group differences (see the details in the appendix). In addition, since the five shape metrics I propose have different variances (large variances tend to have a larger influence on the clusters than variables with small variances), I standardize them by subtracting the mean value and then dividing them by their standard deviation.

Although my methodology selects an optimal number of clusters, one might be concerned that this grouping is either too general or too specific. A too rough

\footnotetext{
${ }^{1}$ Since the K-means algorithm is NP-hard, the algorithm will always converge to a local minimum but will not always find the global (most optimal) minimum. The most optimal refers to where the Sum of Square Errors is smallest compared to any other possible solution.
} 
resolution - i.e., a typology that relies on too few variables - reduces the capacity to differentiate between them. In contrast, a very detailed representation tends to be dependent on large numbers of variables that make the method too complex and limit the analyst's ability to distill generic conclusions. This is not a concern in my case because the typologies that I obtain are easily distinguishable and they roughly match the distinctive historical epochs that comprise Barcelona's landscape. Since I group the blocks on the basis of shape metrics rather than historical epochs, I can further distinguish developments from the same epoch.

Table 4.1: Summary statistics for the resulting 8 typologies: K-means

\begin{tabular}{|c|c|c|c|c|c|c|c|c|c|c|}
\hline \multirow[t]{3}{*}{ Variables: } & \multicolumn{2}{|c|}{ Variable-wise summary } & \multicolumn{8}{|c|}{ Group-wise summary } \\
\hline & \multirow[b]{2}{*}{$R$-squared } & \multirow[b]{2}{*}{ Overall } & \multicolumn{3}{|c|}{ Suburban } & \multicolumn{2}{|c|}{ Mid-rise } & \multicolumn{2}{|c|}{ Compact } & \multirow{2}{*}{$\begin{array}{c}\text { Mixed } \\
6\end{array}$} \\
\hline & & & 1 & 2 & 7 & 5 & 8 & 3 & 4 & \\
\hline Coverage & 0.79 & $\begin{array}{c}0.387 \\
(0.380)\end{array}$ & $\begin{array}{c}0.263 \\
(0.146)\end{array}$ & $\begin{array}{l}1.000 \\
(0.234)\end{array}$ & $\begin{array}{c}0.682 \\
(0.229)\end{array}$ & $\begin{array}{c}0.214 \\
(0.184)\end{array}$ & $\begin{array}{c}0.101 \\
(0.077)\end{array}$ & $\begin{array}{c}0.118 \\
(0.146)\end{array}$ & $\begin{array}{c}0.126 \\
(0.151)\end{array}$ & $\begin{array}{c}0.614 \\
(0.328)\end{array}$ \\
\hline Building density & 0.74 & $\begin{array}{c}0.268 \\
(0.293)\end{array}$ & $\begin{array}{c}0.186 \\
(0.113)\end{array}$ & $\begin{array}{c}0.077 \\
(0.079)\end{array}$ & $\begin{array}{c}0.227 \\
(0.176)\end{array}$ & $\begin{array}{c}0.936 \\
(0.261)\end{array}$ & $\begin{array}{c}0.193 \\
(0.087)\end{array}$ & $\begin{array}{c}1.000 \\
(0.318)\end{array}$ & $\begin{array}{c}0.215 \\
(0.120)\end{array}$ & $\begin{array}{c}0.341 \\
(0.310)\end{array}$ \\
\hline Compactness & 0.674 & $\begin{array}{c}0.521 \\
(0.284)\end{array}$ & $\begin{array}{c}0.354 \\
(0.128)\end{array}$ & $\begin{array}{c}0.749 \\
(0.180)\end{array}$ & $\begin{array}{c}0.725 \\
(0.167)\end{array}$ & $\begin{array}{c}0.372 \\
(0.172)\end{array}$ & $\begin{array}{c}0.281 \\
(0.133)\end{array}$ & $\begin{array}{c}1.000 \\
(0.178)\end{array}$ & $\begin{array}{c}0.844 \\
(0.222)\end{array}$ & $\begin{array}{c}0.586 \\
(0.212)\end{array}$ \\
\hline Height variance & 0.617 & $\begin{array}{c}0.416 \\
(0.183)\end{array}$ & $\begin{array}{c}0.348 \\
(0.113)\end{array}$ & $\begin{array}{c}0.191 \\
(0.083)\end{array}$ & $\begin{array}{c}0.466 \\
(0.110)\end{array}$ & $\begin{array}{c}0.487 \\
(0.116)\end{array}$ & $\begin{array}{c}0.502 \\
(0.096)\end{array}$ & $\begin{array}{c}0.453 \\
(0.115)\end{array}$ & $\begin{array}{c}0.414 \\
(0.131)\end{array}$ & $\begin{array}{c}1.000 \\
(0.288)\end{array}$ \\
\hline Centrality & 0.542 & $\begin{array}{c}0.811 \\
(0.213)\end{array}$ & $\begin{array}{c}0.920 \\
(0.119)\end{array}$ & $\begin{array}{c}1.000 \\
(0.164)\end{array}$ & $\begin{array}{c}0.925 \\
(0.129)\end{array}$ & $\begin{array}{c}0.796 \\
(0.184)\end{array}$ & $\begin{array}{c}0.667 \\
(0.109)\end{array}$ & $\begin{array}{c}0.602 \\
(0.238)\end{array}$ & $\begin{array}{c}0.512 \\
(0.154)\end{array}$ & $\begin{array}{c}0.896 \\
(0.159)\end{array}$ \\
\hline$N$ & & 4311 & 836 & 746 & 562 & 337 & 1216 & 154 & 354 & 106 \\
\hline
\end{tabular}

Table 4.1 shows the summary statistics for the five individual shape metrics and the resulting typologies that my methodology produced. Columns (1) and (2) report the $\mathrm{R}$-squared and the overall mean for building density, coverage, height variance, compactness and centrality. The $\mathrm{R}$-squared value reflects how much of the variation in the original blocks data was retained after the grouping process. The larger the $\mathrm{R}$-squared is for a particular metric, the better that metric is at partitioning the groups. Columns (3) to (10) report the summary statistics for the eight typologies. To ease comparison of the typologies, I normalize the shape metrics by dividing each value by its largest statistic. All index values range between 0 and 1. A higher index value represents a higher value of the shape metric in question. The coverage variable - which evaluates the share of open space - shows the highest 
discriminant power with an $\mathrm{R}$-squared of 0.79 , followed by building density, which shows an $\mathrm{R}$-squared of 0.74 . Of the five measurements, centrality shows the lowest $\mathrm{R}$-squared (0.54). Overall, all the metrics in the model have a relatively high discriminant capacity, which results in typologies that differ substantially one from another in their urban form.

Figures 4-1, 4-2, 4-3 and 4-4 provide a graphic comparison of the resulting typologies. For ease of interpretation, I describe each group of typologies in terms of their spatial similarities and their underlining attributes. Figures 4-10 to 4-13 map the spatial allocation of each typology.

\section{The suburban typologies}

\section{1: Hillside | 2: Garden suburb | 7: Garden apartments}

Spatial metrics for the suburban typologies
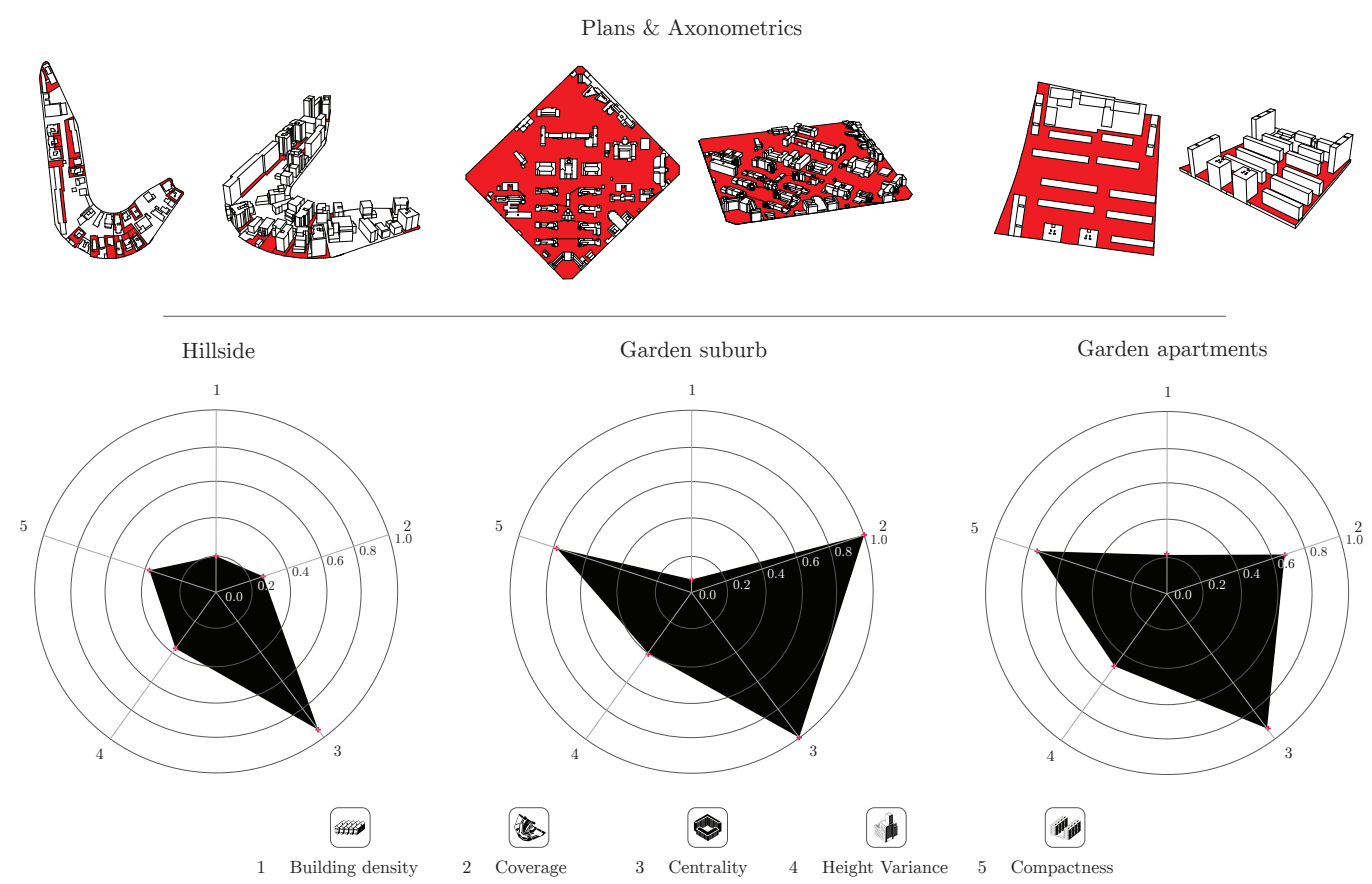

Figure 4-1: Shape metric values are plotted along each individual axis and are connected together to form a polygon. All axes are arranged radially and the distances between them are equal. The further away a value is from the center, the higher the shape metric value. The centrality index is the only shape metric that is interpreted inversely. The farther away a value is form the center the lower its level of centrality.

The suburban typologies (hillside, garden suburb and garden apartments) consistently exhibit the lowest building densities and the highest coverage levels compared to all other groups (see figure 4-1). These typologies are particularly common in 
suburban neighborhoods built during the 1900's. ${ }^{2}$ Their spatial layout is characterized by large plot subdivisions and privately-owned gardens, and they are mostly located at the periphery of the city, which is where the density of land occupation is the lowest. The hillside typology exhibits average levels of open space coverage that in a given block reach $20 \%$ of available land. Its share of open space is higher than in blocks located closer to the city center but it is lower than in garden suburb and garden apartment area blocks, which exhibit levels of coverage that range from $50 \%$ to around $70 \%$, respectively. Overall, the building density observed in the three typologies $(0.18,0.07$ and 0.22 for hillside, garden suburb and garden apartments, respectively) is well below the mean (0.39). The building height variance values of hillside and garden apartments resemble one another, ranging from 0.34 to 0.46 , respectively. In terms of height variance the hillside and garden apartments are more heterogeneous compared to garden suburbs, which report a value of 0.19 . The results suggest that in garden suburbs there is not a significant difference in building heights, and the result is a low-rise and relatively uniform environment.

Suburban typologies also are distinguished by their open space configurations. The three typologies exhibit the lowest levels of centrality (a centrality value of 1 implies a longer distance from the center and thus a less centrally located open space) relative to all other groups. The garden suburb types reach a centrality level of 1 , which is higher than the mean of 0.39. Indeed, it is the highest of all typologies (recall that these values are normalized by the largest value). Such a high level of centrality implies that most open spaces in these blocks are distributed adjacent to roads and are distant from the block center. In addition, the hillside's low compactness levels (0.35) relative to the mean (0.61) suggests a fragmented configuration of open spaces that can take the form of peripheral corridors or small scattered plazas rather than unique central spaces. Overall, garden apartments stand out as having the most balanced levels (close to average) for all the shape metrics. 
Spatial metrics for the mid-rise typologies

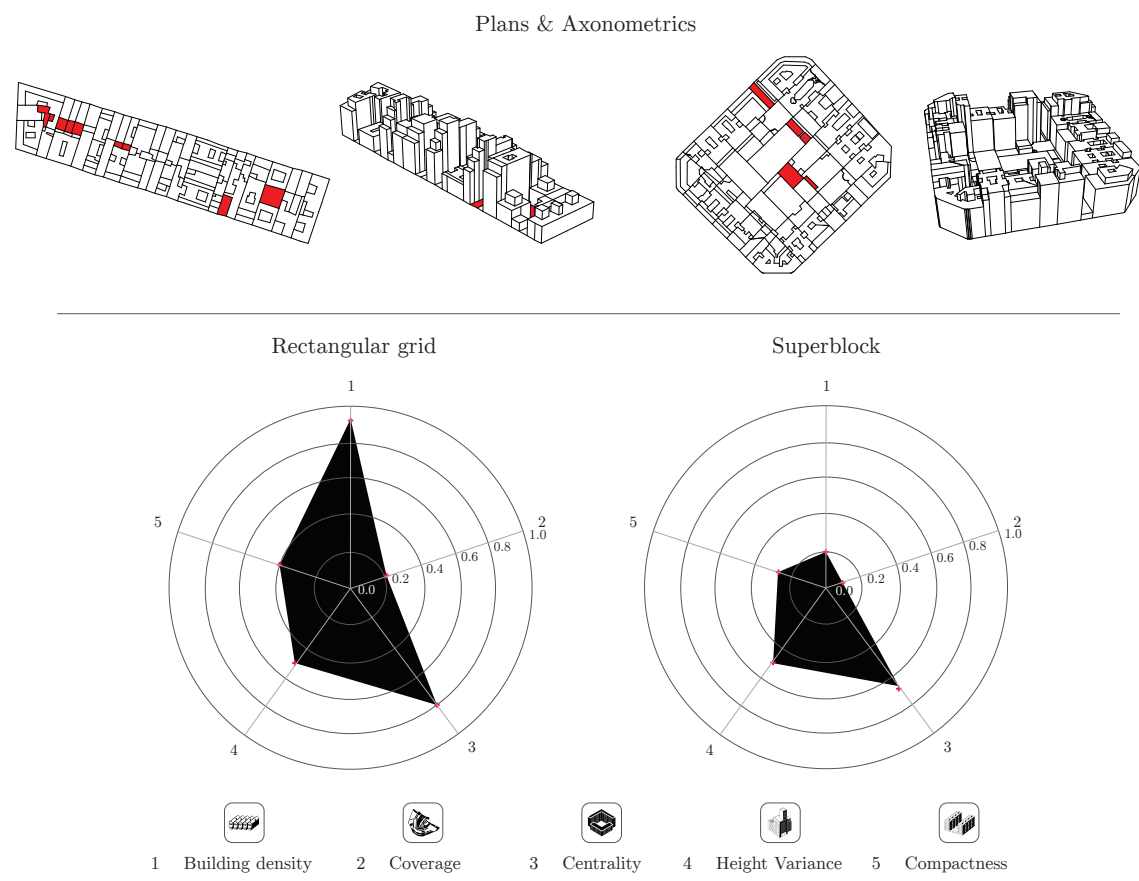

Figure 4-2: Shape metric values are plotted along each individual axis and are connected together to form a polygon. All axes are arranged radially and the distances between them are equal. The further away a value is from the center, the higher the shape metric value. The centrality index is the only shape metric that is interpreted inversely. The farther away a value is form the center the lower its level of centrality.

\section{The mid-rise typologies}

\section{5: rectangular grid | 8: superblock}

The rectangular grid and the superblock exhibit some of the lowest coverage and compactness levels of all the groups (see figure 4-2). In terms of layout they are characterized by scarce open spaces and dense developments, and they usually are located in neighborhoods that date to the 19th and early 20th centuries. Mostly formed by large regular road patterns and a rectangular grid, their spatial organization is fairly uniform. The rectangular grid type exhibits the second highest level of building density (0.93) and a relatively high level of building height variance (0.48).A high level of height variance suggests a very heterogeneous build-up, which may be explained by the intense process of redevelopment that has characterized these areas. The rectangular grid differs substantially from the superblock in terms of the availability of open space. The share of open space in the rectangular grid is 0.21 . In

\footnotetext{
${ }^{2}$ I define "suburban" and "urban" in terms of building density, regardless of their political boundaries.
} 
the superblock its share, 0.18 , is the lowest of all the groups. Despite their limited shares of open space, both typologies have average levels of centrality relative to the mean (0.79). Overall, the rectangular grid has the highest compactness level of all the groups (most of its open spaces are located adjacent to the street) while the superblock has the lowest level.

\section{The compact typologies}

\section{3: Historic core | 4: Urban grid}

Spatial metrics for the compact typologies

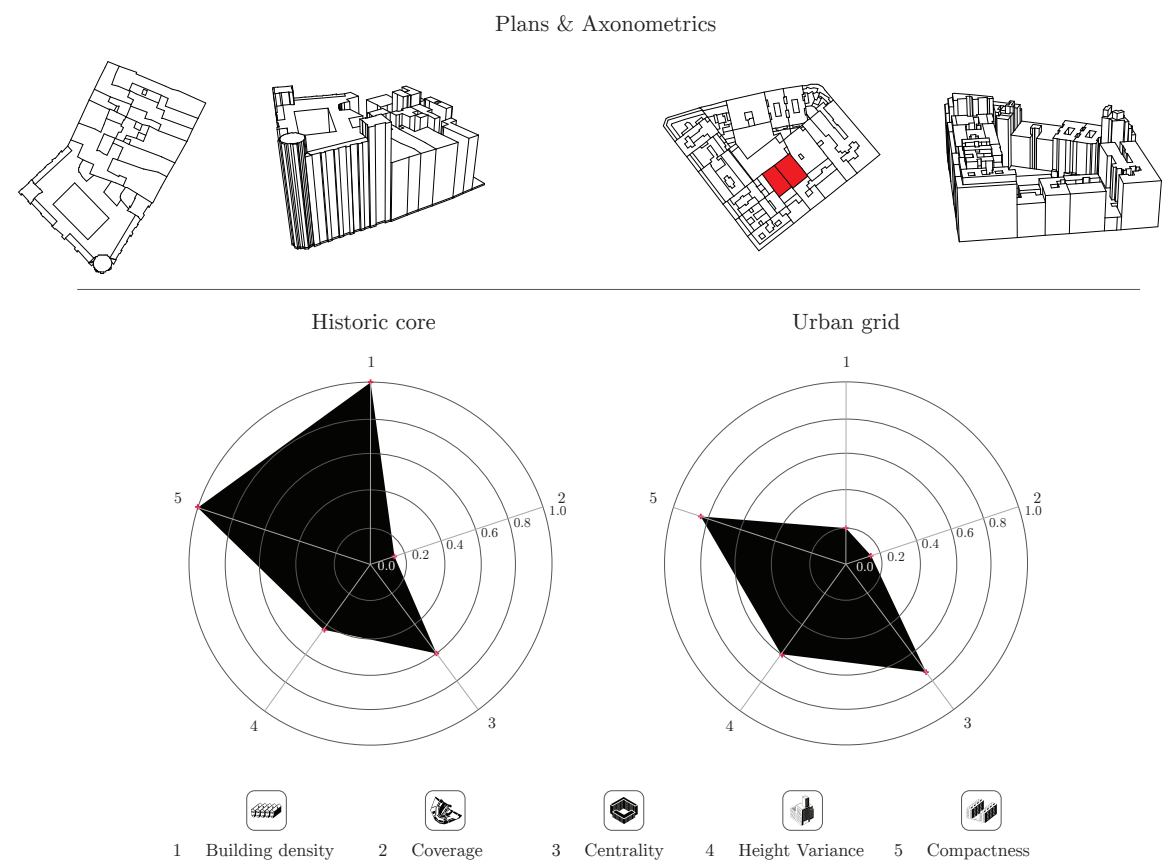

Figure 4-3: Shape metric values are plotted along each individual axis and are connected together to form a polygon. All axes are arranged radially and the distances between them are equal. The further away a value is from the center, the higher the shape metric value. The centrality index is the only shape metric that is interpreted inversely. The farther away a value is form the center the lower its level of centrality.

As is typical of areas located close to the city center, the historic core and urban grid exhibit high levels of compactness and density (see figure 4-3). The urban grid type consists of big blocks that have central open spaces, which in turn are bordered mostly by buildings that present continuous fronts. The historic core, which dates to the Gothic period, presents a continuous and highly dense urban environment that is characterized by very small plot sizes. Compared to a mean (0.61), the historic core and urban grid exhibit high levels of compactness - on the order of 1 and 0.84 , 
respectively. Although the two typologies resemble one another in terms of open space distribution, they differ substantially in terms of their built-up. Compared to building density in the historic core (level of 1 ), that of the urban grid (0.21) is quite low. This is not surprising given that most of the historic core is close to the city center, where open spaces are the most limited. These dense environments have relatively low building height variances. The historic core and urban grid have height variance levels of 0.45 and 0.41 , respectively, which resembles the levels of homogeneity in suburban types. Perhaps the uniformity of the build-up can be explained by the small size of the plots and the historic value of the buildings; during redevelopment these variables might prevent buildings from assuming greater heights.

\section{The civic-mixed typology}

\section{6: Civic-mixed}

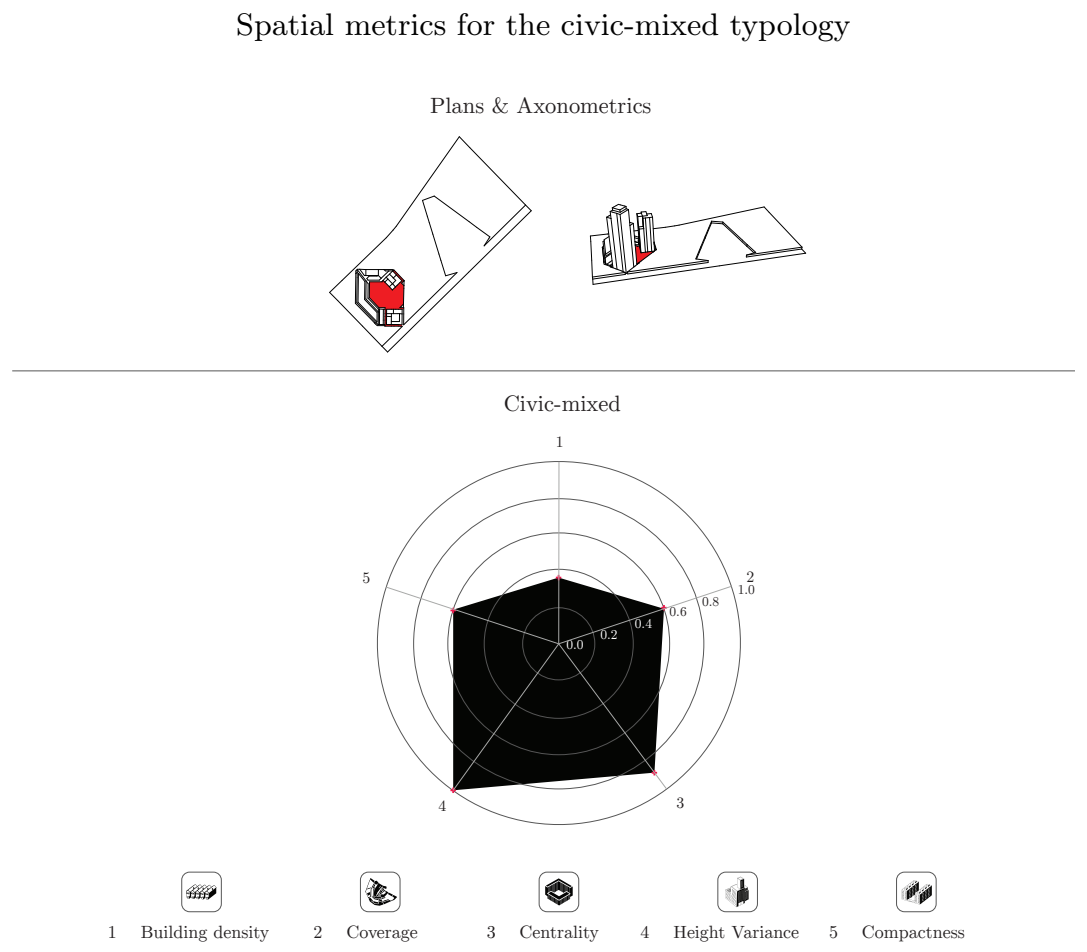

Figure 4-4: Shape metric values are plotted along each individual axis and are connected together to form a polygon. All axes are arranged radially and the distances between them are equal. The further away a value is from the center, the higher the shape metric value. The centrality index is the only shape metric that is interpreted inversely. The farther away a value is form the center the lower its level of centrality.

The civic-mixed typology describes neighborhoods that were newly redeveloped 
for major events, such as the Olympics in 1992 and the Forum de les Cultures in 2004 (see figure 4-4). These developments, which started in the mid-1980s, have continued to the present. This group, which has the widest variety of forms, includes industrial, commercial, and special buildings in the area. The urban landscape is dominated by large civic buildings, and these often have large footprints and a great range of uses. In new developments there is a significant increase in building height variance and building heights often reach maximum levels. The civic-mixed typology features a unique combination of medium density and a high availability of open space (0.61) that is greater than in all other typologies.

\section{Describing the immigrants demographic composition}

To describe the immigrant population that is settling in these typologies, I examine in a series of plots the share of population that consists of immigrants, the immigrant's levels of education, and the immigrant's age structure. Figure 4-5 plots the share of the immigrant and the native population in each typology from 1999 to 2008. The share of foreign-born residents, which has been steadily increasing, follows similar trends across all typologies. Starting in 1999 and continuing until 2008, the historic core received the highest share of immigrants. Across the ten year study period the hillside typology consistently shows the lowest share of immigrants.

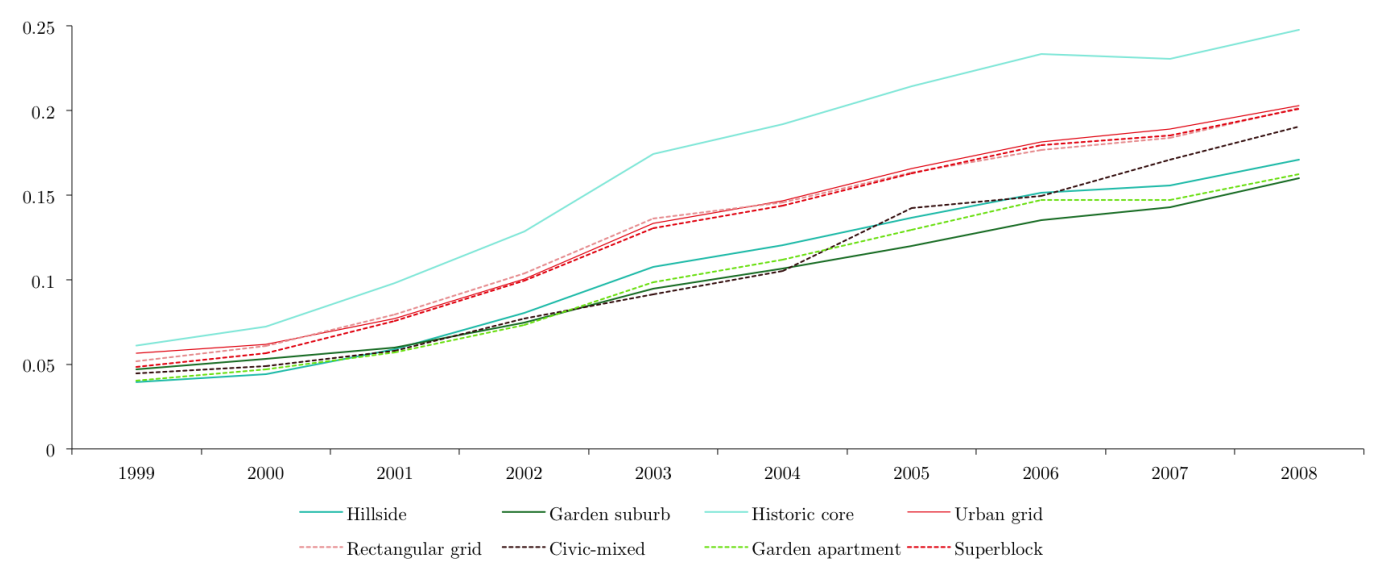

Figure 4-5: Share of immigrant population by typology, 1998-2008

Figures 4-6 and 4-7 show the education distribution of the immigrants who resided in each typology in 1999 and 2008. During both years demographic com- 
position, including primary education levels, are roughly the same across the eight typologies. The most variation in education is found in the hillside and the superblock typologies. For example, in 2008, the superblock typology had both the highest share of immigrants who had no high school education and the lowest share of immigrants who had no primary education. This trend is inverted in the hillside typology. In 2008 it had the lowest share of immigrant residents who had a high school education and the highest share of immigrants who had no primary education.

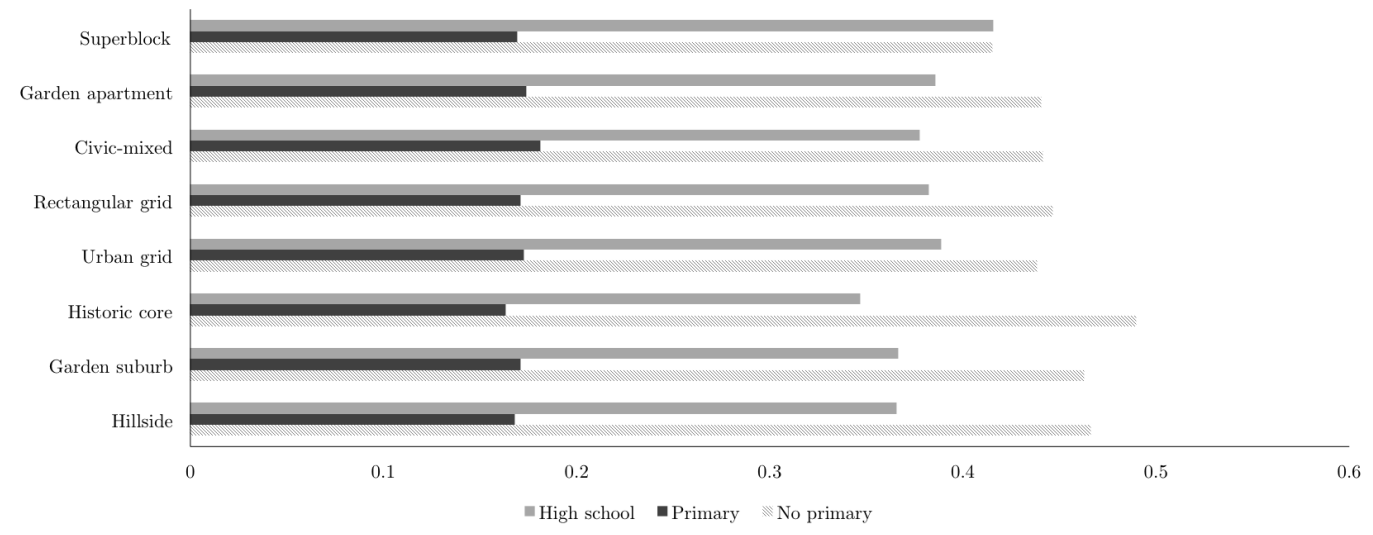

Figure 4-6: Education levels of immigrant populations in 1999

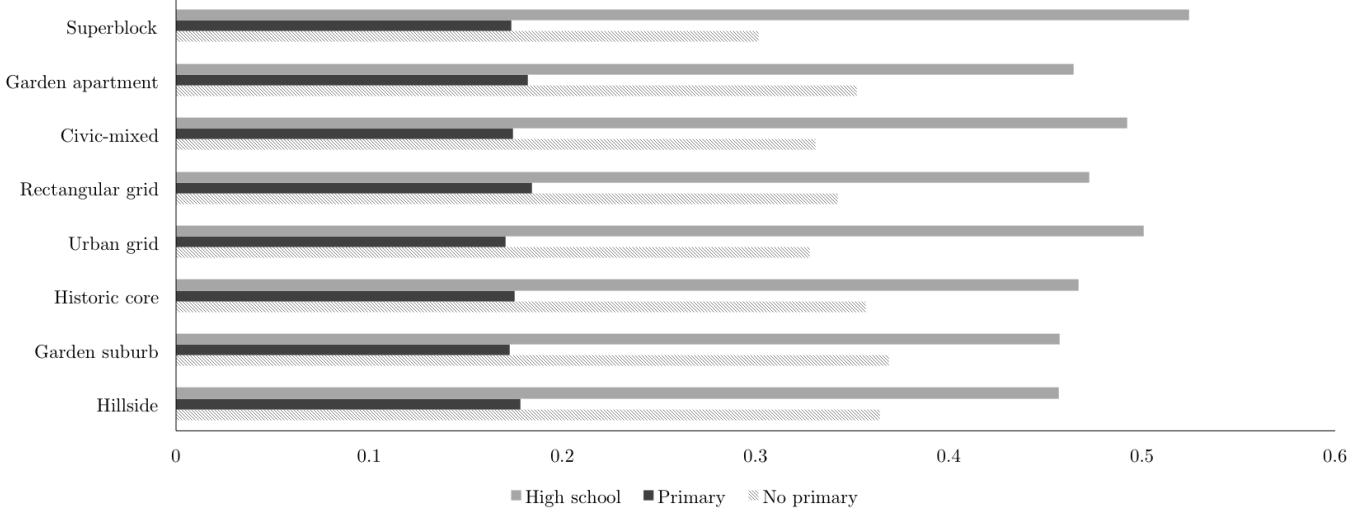

Figure 4-7: Education levels of the immigrant populations in 2008

Although education levels do not vary much across typologies, they did change substantially over time. From 1999 to 2008, the share of immigrants who had no primary education decreased while the share of immigrants who had a high school 
education increased. In the garden apartment typology, the share of immigrants who had a high school level education moved from 0.35 in 1998 to 0.45 in 2008 . The fact that this change occured accross all typologies suggests that two processes were at work: first, over time immigrants arrived with progessively more education; and, second, once in Barcelona immigrants opted for more years of education in the Spanish school system.

Figures 4-8 and 4-9 plot the age distribution of immigrants in 1999 and 2008, respectively. A 0.7 share of the total population of immigrants fell between 19 and 54 year of age; 0.20 were 50 years or older and 0.10 were younger than 18 years old. Overall, the age distribution is similar across all typologies and it changed little between 1999 and 2008.

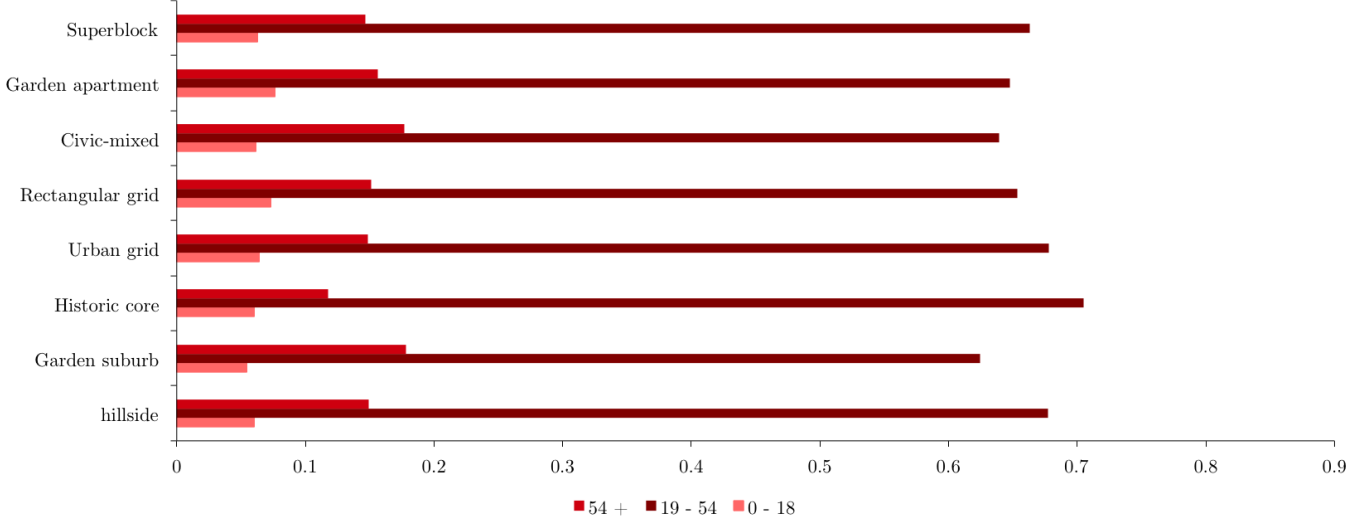

Figure 4-8: Age distribution of the immigrant population in 1999

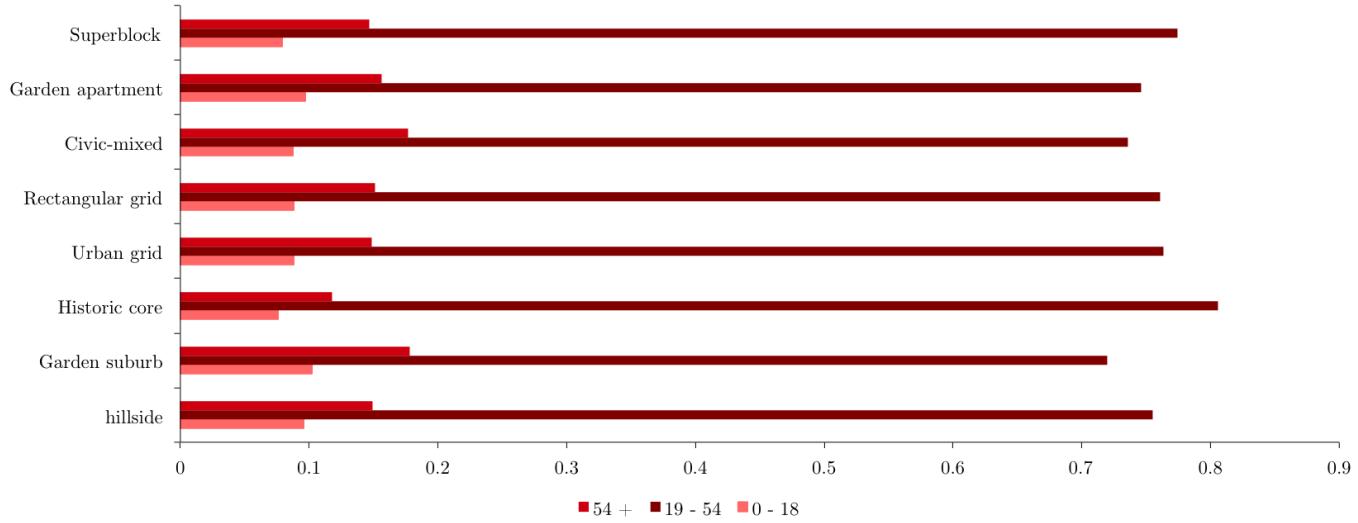

Figure 4-9: Age distribution of immigrant population in 2008 
Hillside and garden suburb typologies
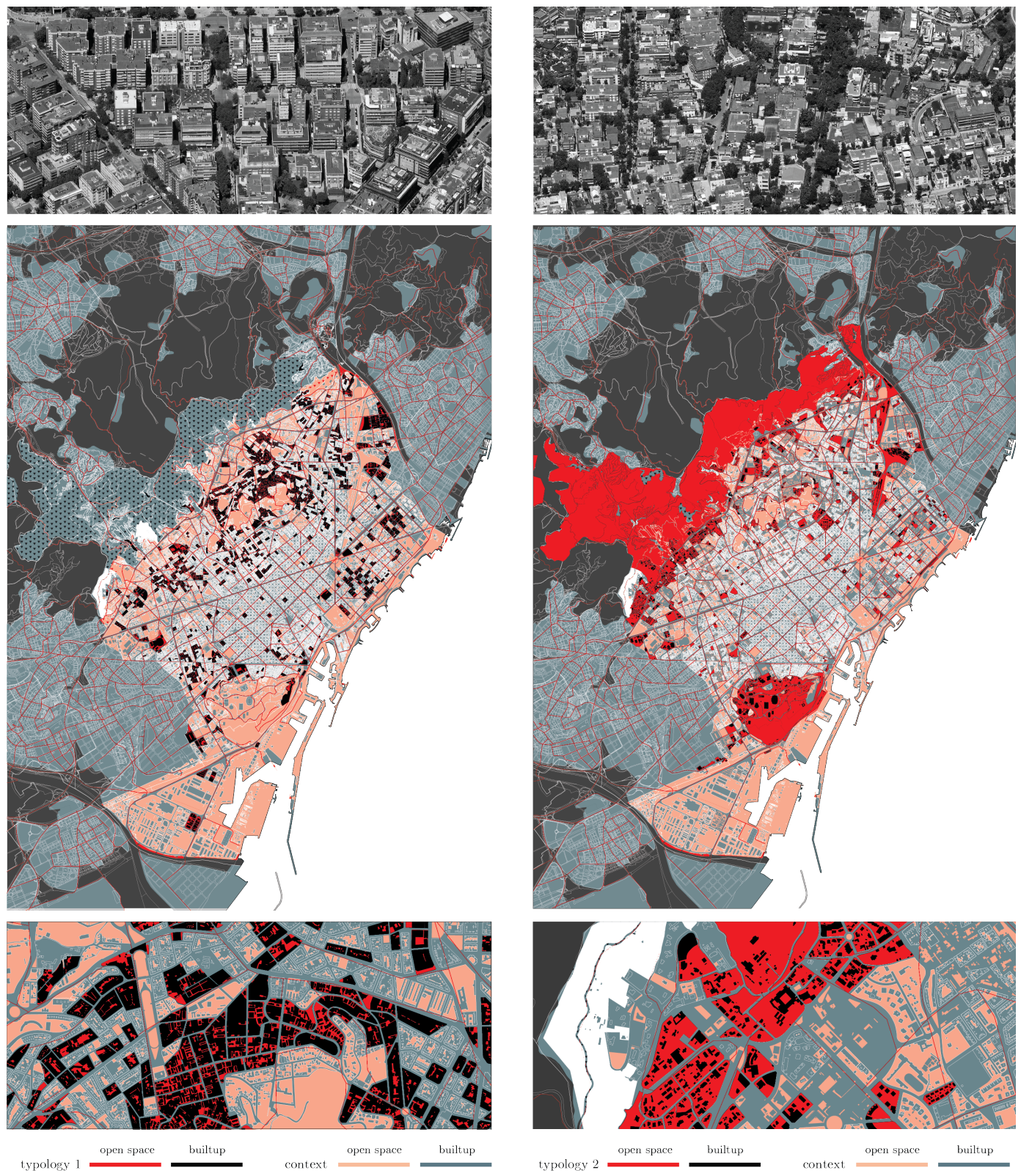

Figure 4-10: Typologies 1 (left) and 2 (right) Areas shown in black represent the build up belonging to the classified typology. Areas in red show the open areas located in those blocks. 
Historic core and urban grid typologies
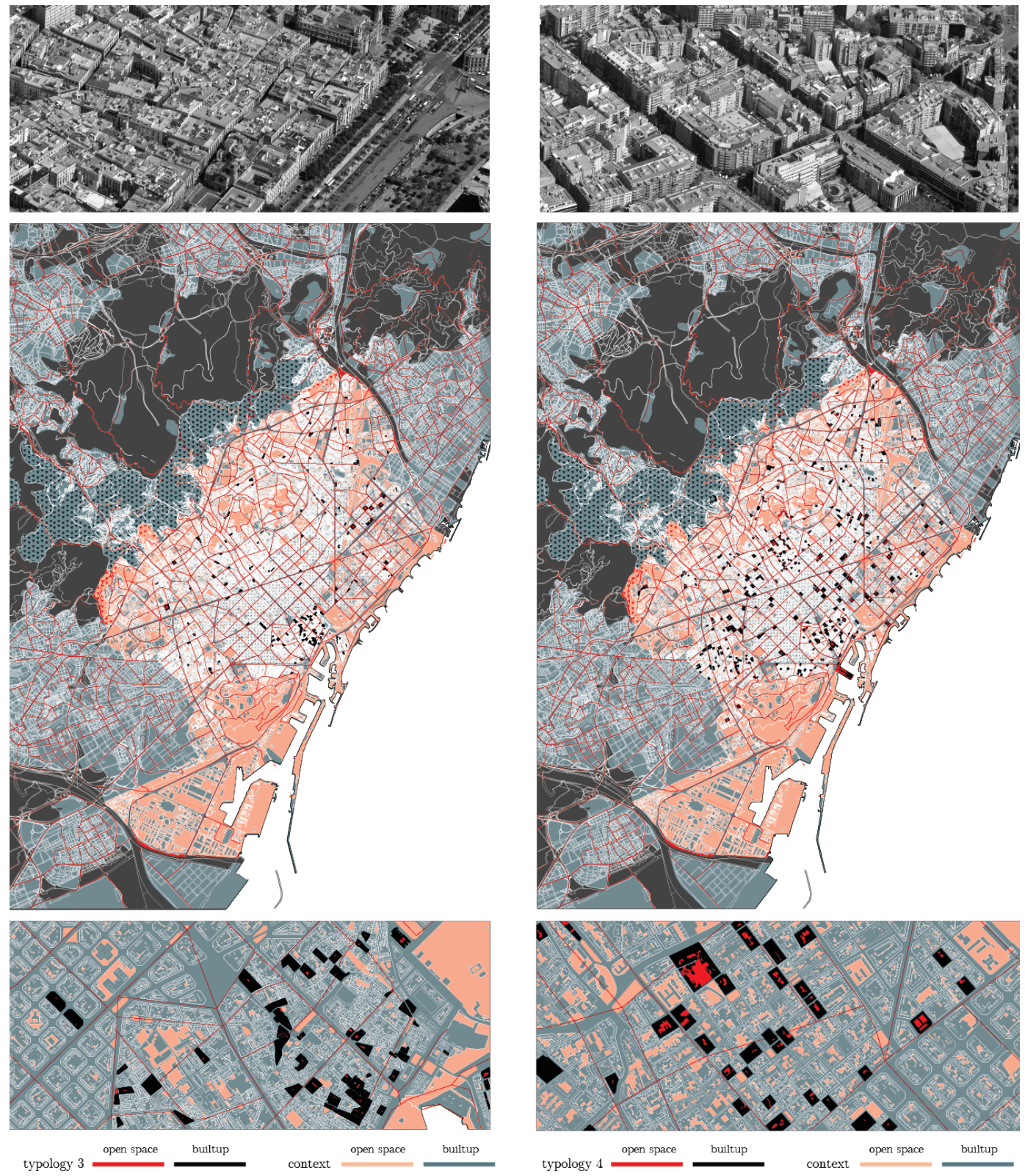

Figure 4-11: Typologies 3 (left) and 4 (right) Areas shown in black represent the build up belonging to the classified typology. Areas in red show the open areas located in those blocks. 
Rectangular grid and civic-mixed typologies
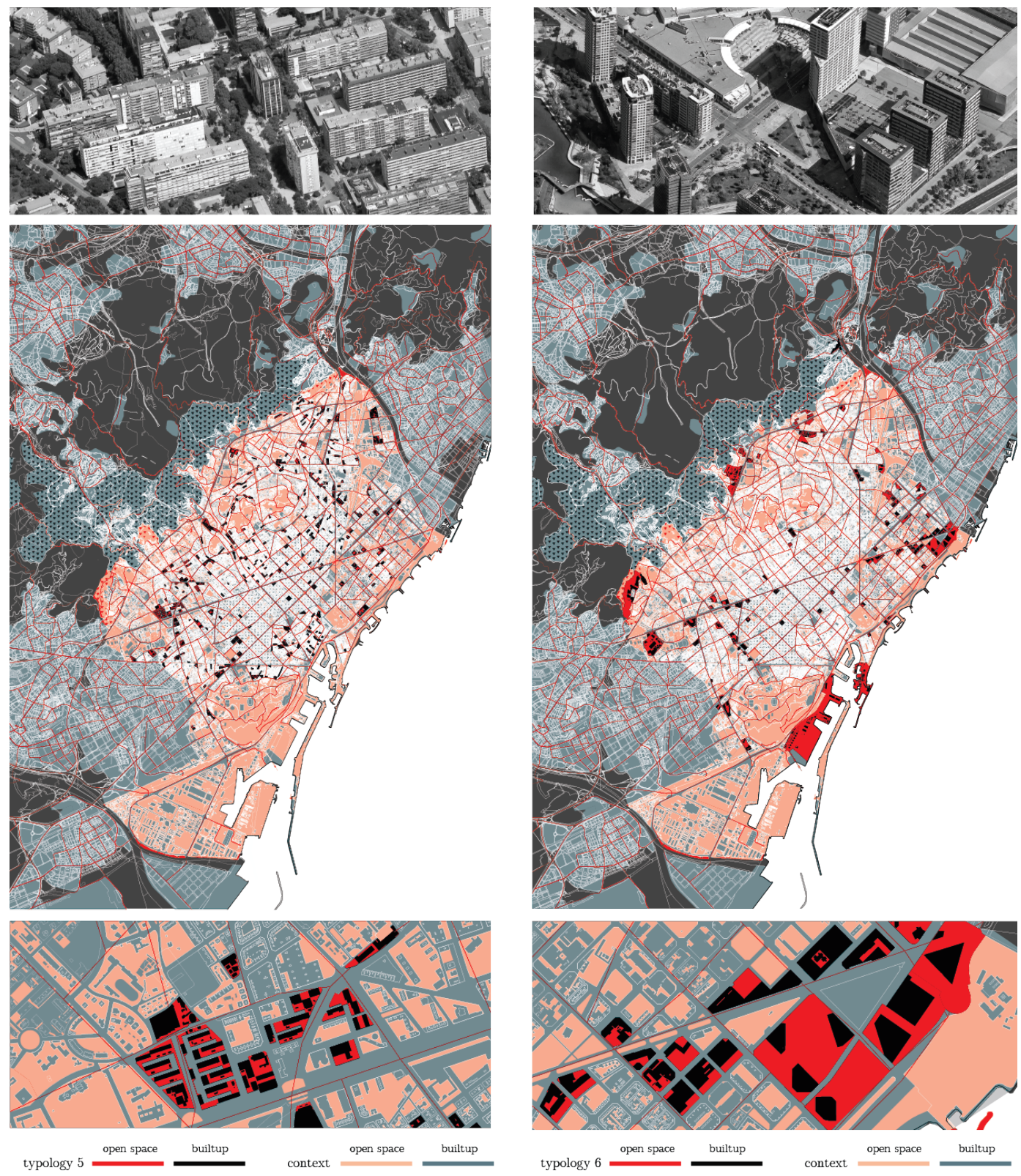

Figure 4-12: Typologies 5 (left) and 6 (right) Areas shown in black represent the build up belonging to the classified typology. Areas in red show the open areas located in those blocks. 
Garden apartments and superblock typologies
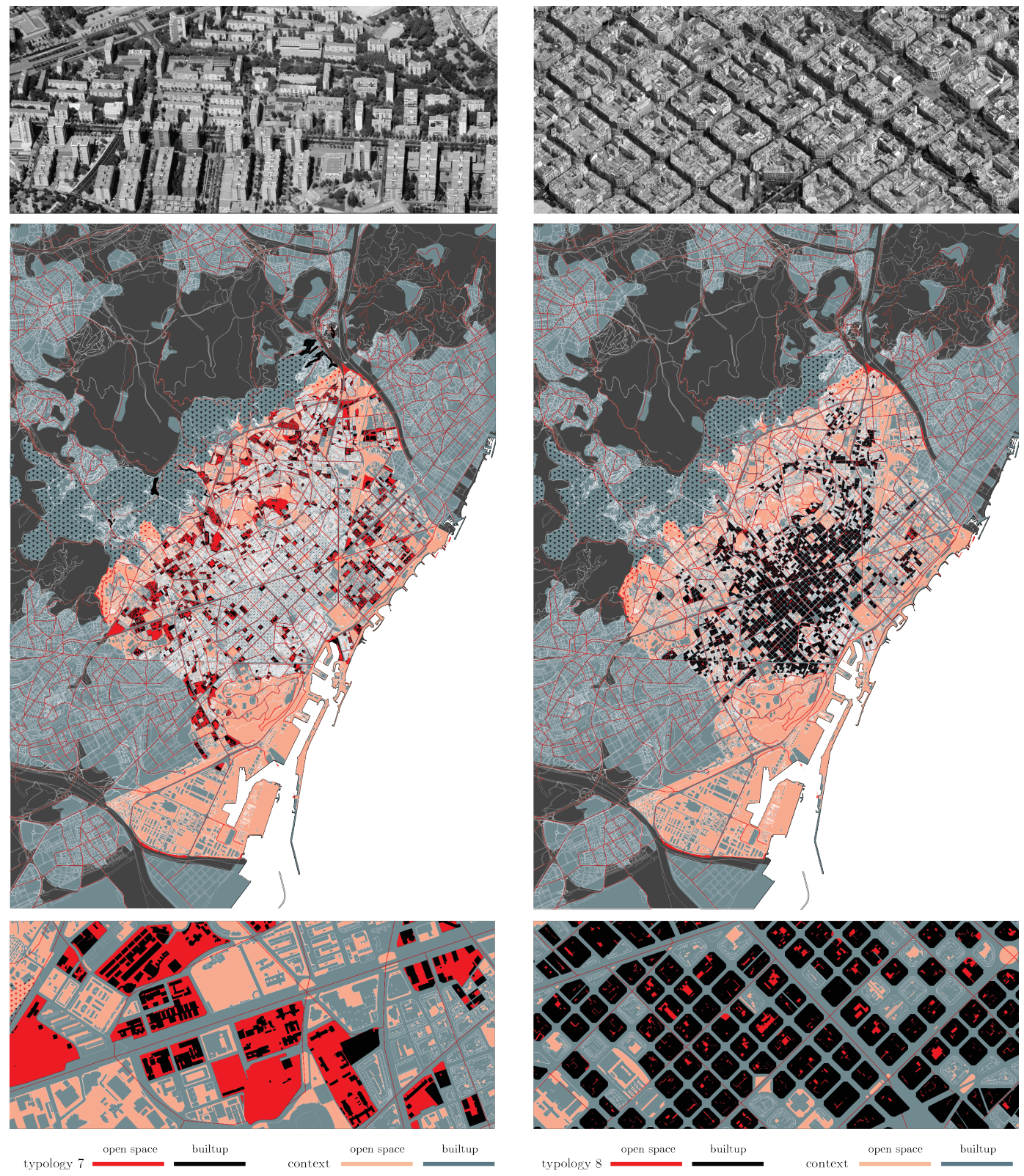

Figure 4-13: Typologies 7 (left) and 8 (right) Areas shown in black represent the build up belonging to the classified typology. Areas in red show the open areas located in those blocks. 


\section{Chapter 5}

\section{Empirical results}

\subsubsection{The impact of urban form on segregation}

The objective of my empirical analysis is to estimate the effect of built form on the segregation of immigrants at the building level. In particular, I explore whether there are certain typologies that are more conducive to the integration of natives and immigrants than others. Thus, the identification of the impact of urban form, relies on the comparison of segregation levels mediated through the change in the share of immigrants, for each typology, across ten years.

My first approach is to individually analyze the shape metrics that compose each of the typologies. ${ }^{1}$ I estimate the following regression:

$$
\Delta Y_{b}=\alpha \Delta I_{b}+\beta S M_{b}+\gamma \Delta I_{b} \times S M_{b}+\theta X_{b}+\varepsilon_{b}
$$

Here $\Delta Y_{b}$ is the change between 1999 and 2008 in the micro-dissimilarity and the micro-exposure indices, which are measured at the block level $b . \Delta I_{b}$ is the change between 1999 and 2008 in the share of immigrants who reside in block $b . S M_{b}$ corresponds to one of the shape metrics computed at the block level (building density, compactness, coverage, centrality and height variance). $X_{b}$ is a vector that contains additional neighborhood controls, which include socioeconomic characteristics and age of the building stock by decades. Finally, $\varepsilon_{b}$ is the error term of my regression model.

\footnotetext{
${ }^{1}$ Despite the measurements not being highly correlated with each other, I do not include them in the same specification in order to analyze their individual significance on segregation levels.
} 
Table 5.1 presents the OLS estimates of equation 5.1 using building density as the shape metric of interest. The first and second coefficients reported in each column are the main effects of the change in the immigrant share from 1999 to 2008 and building density, respectively. The third row presents the coefficient on the interaction of building density and the change in the share of immigrants. The interaction term identifies the role of building density in mediating how the additional arrival of immigrants affects segregation. Columns (1) and (2) use the micro-exposure index as the dependent variable with and without controls, respectively. Columns (3) and (4) present analogous models but focus on the micro-dissimilarity index in place of micro-exposure. I include the age of the building stock as part of my controls to deal with potential sources of bias. For example, one common concern is that segregation tends to be higher in older neighborhoods. Evidence showing similar estimates with and without controls, indicates that this selection bias could be a minor concern.

Table 5.1: Segregation levels and building density, 1999-2008: OLS estimates

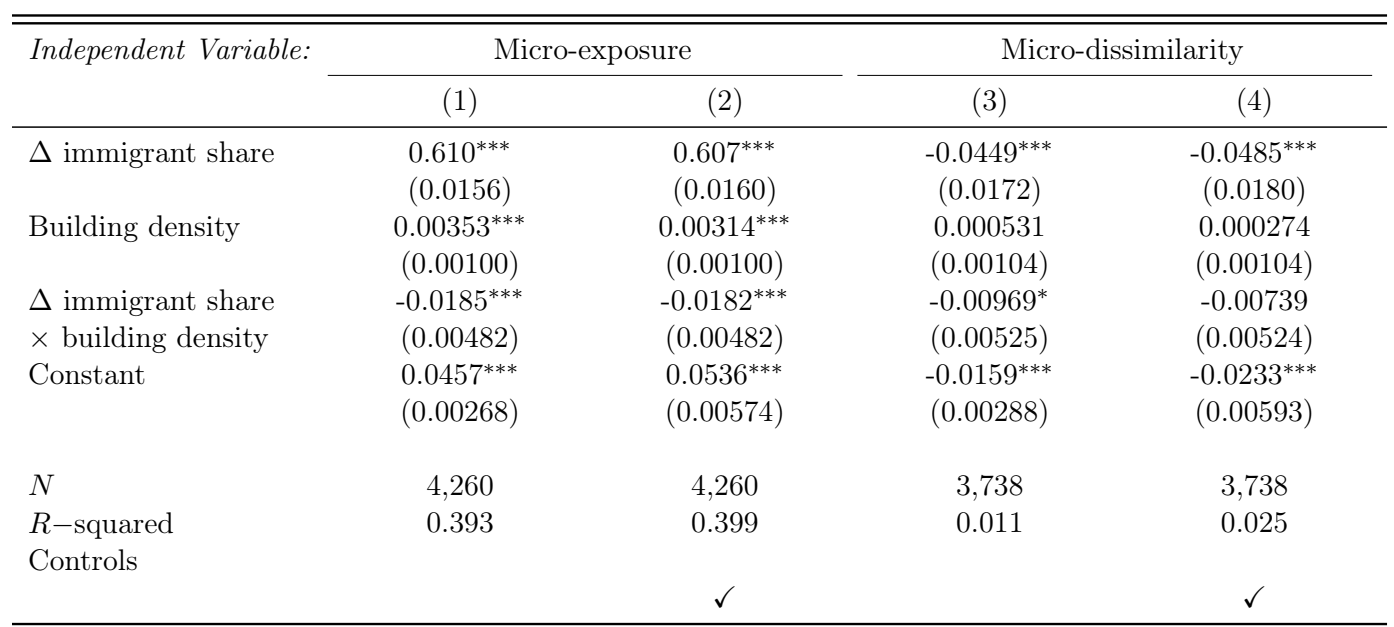

Notes: Standard deviation $=1.974$. The Table reports the regression coefficients of the immigrant share interacted with building density. Micro-dissimilarity results are shown in columns (1) and (2), and micro-exposure results appear in columns (3) and (4). Columns (2) and (4) include additional controls described in the main text. Robust standard errors in parentheses

*** denotes a coefficient significant at the $1 \%$ level, ${ }^{* *}$ at the $5 \%$ level, and $*$ at the $10 \%$ level.

Using the micro-exposure index as the dependent variable (Columns 1 and 2), the interaction coefficients in both specifications are consistently significant and associated with a negative impact of building density on segregation. The estimated coefficients imply that when an additional 10 percentage point of immigrants arrive, 
a one standard deviation in building density, decreases micro-exposure (increases segregation) by $0.003(0.018 \times 1.974 \times 0.10)$. Overall, segregation levels tend to be higher for immigrant groups residing in denser areas, though the relationship between the interaction term and micro-dissimilarity is not statistically significant after the inclusion of controls.

Table 5.2: Segregation levels and height variance, 1999-2008: OLS estimates

\begin{tabular}{lccccc}
\hline \hline \multirow{2}{*}{ Independent Variable: } & \multicolumn{2}{c}{ Micro-exposure } & & \multicolumn{2}{c}{ Micro-dissimilarity } \\
\cline { 2 - 3 } \cline { 5 - 5 } & $(1)$ & $(2)$ & & $(3)$ & $(4)$ \\
\hline$\Delta$ immigrant share & $0.573^{* * *}$ & $0.559^{* * *}$ & & $-0.156^{* * *}$ & $-0.156^{* * *}$ \\
& $(0.0195)$ & $(0.0200)$ & & $(0.0226)$ & -0.0232 \\
Height variance & $0.00302^{* * *}$ & $0.00256^{* * *}$ & & $-0.00107^{*}$ & $-0.00185^{* * *}$ \\
& $(0.000595)$ & $(0.000630)$ & & $(0.000645)$ & -0.000675 \\
$\Delta$ immigrant share & 0.000306 & 0.00222 & & $0.0167^{* * *}$ & $0.0176^{* * *}$ \\
$\times$ height variance & $(0.00339)$ & $(0.00346)$ & & $(0.00371)$ & -0.00377 \\
Constant & $0.0333^{* * *}$ & $0.0420^{* * *}$ & & $-0.0101^{* *}$ & $-0.0159^{* *}$ \\
& $(0.00387)$ & $(0.00631)$ & & $(0.00442)$ & -0.00669 \\
& & & & \\
$N$ & 4,240 & 4,240 & & 3,724 & 3,724 \\
$R$-squared & 0.398 & 0.402 & & 0.018 & 0.032 \\
Controls & & $\checkmark$ & & $\checkmark$ \\
& & & & \\
\hline
\end{tabular}

Notes: Standard deviation $=3.440$. The Table reports the regression coefficients of the immigrant share interacted with height variance. Micro-dissimilarity results are shown in columns (1) and (2), and micro-exposure results appear in columns (3) and (4). Columns (2) and (4) include additional controls described in the main text. Robust standard errors in parentheses

*** denotes a coefficient significant at the $1 \%$ level, ${ }^{* *}$ at the $5 \%$ level, and ${ }^{*}$ at the $10 \%$ level.

Table 5.2, 5.3, 5.4, and 5.5 report the results for the remaining shape metrics, which are constructed analogous to Table 5.1. A comparison between the coefficient magnitudes of the interaction terms suggests that the most salient spatial properties to mediate the effects of immigration on segregation are: open space compactness (Table 5.3) and coverage (Table 5.4), which capture, respectively, the degree to which the open spaces are spatially spread out in a given block, and the relation between the ground area and the open space. The estimated interaction effects for compactness and coverage show a positive and significant association with micro-exposure (Column 1). This suggests that immigrants arriving to typologies with higher levels of open space coverage and compactness segregate less than others. Column (2) shows a significant effect at the $1 \%$ level for the interaction terms of coverage and compactness that persist after controlling for socioeconomic and neighborhood differences. 
Table 5.3: Segregation levels and compactness, 1999-2008: OLS estimates

\begin{tabular}{lccccc}
\hline \hline \multirow{2}{*}{ Independent Variable: } & \multicolumn{2}{c}{ Micro-exposure } & & \multicolumn{2}{c}{ Micro-dissimilarity } \\
\cline { 2 - 3 } \cline { 5 - 5 } & $(1)$ & $(2)$ & & $(3)$ & $(4)$ \\
\hline$\Delta$ immigrant share & $0.493^{* * *}$ & $0.503^{* * *}$ & & $0.047^{*}$ & $0.054^{* *}$ \\
& $(0.026)$ & $(0.026)$ & & $(0.027)$ & $(0.028)$ \\
Compactness & $-0.032^{* * *}$ & $-0.026^{* * *}$ & & $0.016^{*}$ & $0.024^{* * *}$ \\
& $(0.008)$ & $(0.008)$ & & $(0.009)$ & $(0.009)$ \\
$\Delta$ immigrant share & $0.168^{* * *}$ & $0.154^{* * *}$ & & $-0.226^{* * *}$ & $-0.242^{* * *}$ \\
$\times$ compactness & $(0.043)$ & $(0.044)$ & & $(0.047)$ & $(0.047)$ \\
Constant & $0.068^{* * *}$ & $0.061^{* * *}$ & & $-0.023^{* * *}$ & $-0.035^{* * *}$ \\
& $(0.005)$ & $(0.007)$ & & $(0.005)$ & $(0.008)$ \\
$N$ & & & & 3,455 \\
$R$-squared & 3,949 & 3,949 & & 3,455 \\
Controls & 0.369 & 0.374 & & 0.017 & \\
& & $\checkmark$ & & $\checkmark$ \\
\end{tabular}

Notes: Standard deviation $=0.275$. The Table reports the regression coefficients of the immigrant share interacted with compactness. Micro-dissimilarity results are shown in columns (1) and (2), and micro-exposure results appear in columns (3) and (4). Columns (2) and (4) include additional controls described in the main text. Robust standard errors in parentheses

*** denotes a coefficient significant at the $1 \%$ level, ${ }^{* *}$ at the $5 \%$ level, and ${ }^{*}$ at the $10 \%$ level.

Table 5.4: Segregation levels and coverage, 1999-2008: OLS estimates

\begin{tabular}{lccccc}
\hline \hline \multirow{2}{*}{ Independent Variable: } & \multicolumn{2}{c}{ Micro-exposure } & & \multicolumn{2}{c}{ Micro-dissimilarity } \\
\cline { 2 - 3 } \cline { 5 - 5 } & $(1)$ & $(2)$ & & $(3)$ & $(4)$ \\
\hline$\Delta$ immigrant share & $0.517^{* * *}$ & $0.524^{* * *}$ & & -0.023 & -0.011 \\
& $(0.018)$ & $(0.019)$ & & $(0.018)$ & $(0.020)$ \\
Coverage & $-0.033^{* * *}$ & $-0.028^{* * *}$ & & 0.008 & $0.016^{* *}$ \\
& $(0.007)$ & $(0.007)$ & & $(0.008)$ & $(0.008)$ \\
$\Delta$ immigrant share & $0.171^{* * *}$ & $0.159^{* * *}$ & & $-0.160^{* * *}$ & $-0.189^{* * *}$ \\
$\times$ coverage & $(0.037)$ & $(0.037)$ & & $(0.044)$ & $(0.045)$ \\
Constant & $0.064^{* * *}$ & $0.060^{* * *}$ & & $-0.017^{* * *}$ & $-0.032^{* * *}$ \\
& $(0.003)$ & $(0.007)$ & & $(0.003)$ & $(0.007)$ \\
$N$ & & & & 3,455 \\
$R$-squared & 3,949 & 3,949 & & 3,455 & \\
Controls & 0.371 & 0.376 & & 0.012 & $\checkmark$ \\
& & & & \\
\hline
\end{tabular}

Notes: Standard deviation $=0.309$. The Table reports the regression coefficients of the immigrant share interacted with coverage. Micro-dissimilarity results are shown in columns (1) and (2), and micro-exposure results appear in columns (3) and (4). Columns (2) and (4) include additional controls described in the main text. Robust standard errors in parentheses

*** denotes a coefficient significant at the $1 \%$ level, ${ }^{* *}$ at the $5 \%$ level, and $*$ at the $10 \%$ level.

I find similar results when using the micro-dissimilarity as the dependent variable (Columns 3 and 4). The interaction coefficients, with the exception of height variance, consistently hold a negative association with segregation. Table 5.2 shows that blocks with more variation in building height are positively associated with segregation. When an additional 10 percentage points of immigrants arrive, a one standard 
deviation in height variance, increases micro-dissimilarity (increases segregation) by $0.006(0.017 \times 3.441 \times 0.10)$.

Table 5.5: Segregation levels and centrality, 1999-2008: OLS estimates

\begin{tabular}{lccccc}
\hline \hline \multirow{2}{*}{ Independent Variable: } & \multicolumn{2}{c}{ Micro-exposure } & & \multicolumn{2}{c}{ Micro-dissimilarity } \\
\cline { 2 - 3 } \cline { 5 - 5 } & $(1)$ & $(2)$ & & $(3)$ & $(4)$ \\
\hline$\Delta$ immigrant share & $0.472^{* * *}$ & $0.494^{* * *}$ & & -0.0667 & -0.0455 \\
& $(0.0461)$ & $(0.0478)$ & & $(0.0490)$ & $(0.0504)$ \\
Centrality & $-0.134^{* * *}$ & $-0.110^{* *}$ & & -0.0875 & -0.0621 \\
& $(0.0499)$ & $(0.0504)$ & & $(0.0541)$ & $(0.0543)$ \\
$\Delta$ immigrant share & $0.632^{* *}$ & $0.527^{*}$ & & -0.0064 & -0.130 \\
$\times$ centrality & $(0.265)$ & $(0.269)$ & & $(0.295)$ & $(0.297)$ \\
Constant & $0.0743^{* * *}$ & $0.0657^{* * *}$ & & 0.0005 & -0.0148 \\
& $(0.00876)$ & $(0.0105)$ & & -0.0092 & $(0.0108)$ \\
& & & & \\
$N$ & 3,946 & 3,946 & 3,453 & 3,453 \\
$R$-squared & 0.368 & 0.373 & 0.009 & 0.023 \\
Controls & & $\checkmark$ & & $\checkmark$ \\
& & & & \\
\hline
\end{tabular}

Notes: Standard deviation $=0.044$. The Table reports the regression coefficients of the immigrant share interacted with centrality. Micro-dissimilarity results are shown in columns (1) and (2), and micro-exposure results appear in columns (3) and (4). Columns (2) and (4) include additional controls described in the main text. Robust standard errors in parentheses

*** denotes a coefficient significant at the $1 \%$ level, ${ }^{* *}$ at the $5 \%$ level, and $*$ at the $10 \%$ level.

Overall, the results imply that certain spatial qualities are beneficial in mediating the effect of immigrants on segregation: coverage and compactness predict higher levels of micro-exposure and lower levels of micro-dissimilarity (reduces segregation). In contrast, results consistently show that following immigrant arrival, more heterogeneity in the built-up and overall denser environments are more conducive to high levels of segregation.

The results presented thus far suggest that following the arrival of immigrants, the configuration of the built environment has an affect on how the natives coexist with the immigrant populations within buildings. However, each shape metric alone is only able to convey information on a particular aspect of the built form. Although the individual shape metrics have a small impact on segregation, in the next part of the analysis I test if their joint effect is larger. To do so, instead of including each characteristic separately, I estimate a variant of equation 5.1 in which I take into account the role of the different typologies. 
My regression model takes the following form:

$$
\Delta Y_{b}=\sum_{i=1}^{8}\left(\alpha_{i} \text { Typology }_{i b}+\beta_{i} \Delta I_{b} \times \text { Typology }_{i b}\right)+\theta X_{b}+\varepsilon_{b}
$$

Here Typology $y_{i b}$ is a dummy variable that determines whether block $b$ belongs to the $i$-th typology. The coefficient $\alpha_{i}$ captures the main effect of the $i$-th typology. The coefficient $\beta_{i}$, which is my main object of interest, captures how well typology $i$ mediates the arrival of immigrants and its role in the assimilation between newcomers and native populations.

Table 5.6 and 5.7 present the OLS estimates of equation 5.2. In each table, the first eight coefficients reported in each column are the main effects of each typology. The subsequent rows present the coefficients on the interaction of each typology and the change in immigrant share from 1999 to 2008, which are the main objects of interest. Table 5.6 presents the interaction coefficients of the typologies and the immigrant share change. The interaction terms identifies the role of each typology in mediating the arrival of new immigrants and its effect on segregation, measured with the micro-exposure index. Likewise, Table 5.7 reports the interaction term using the micro-dissimilarity index in place for micro-exposure. For both tables, column (1) presents the regression estimates without controls. In column (2), I include controls for the share of buildings constructed by decade and the share of population with different levels of education. ${ }^{2}$ Column (3) shows the same specification as column (2) with additional controls for weighted distances (gravities) to points of interest - a measure of access to amenities/jobs in a given block-. In Columns (4) and (5), instead of controlling for the share of population with different education levels, I take a more demanding approach and include a full set of dummies for the deciles of these shares (a proxy for socio-economic status). Finally, column (5) includes additional controls for neighborhood fixed effects.

For completeness, Table 5.6 and 5.7 report the main effects of each typology. However, my focus will be on the interaction terms. There are several reasons for this. The first, is that if I only include an indicator for each typology, I might be

\footnotetext{
${ }^{2}$ The age of buildings includes twenty year periods starting in year 1900 and ending in year 2000 . The controls for education in levels correspond to four categories: illiterate, no primary education, primary education, and high school.
} 
capturing the locational preference of immigrants settling mostly in the suburban and city center areas. Thus, by including the interaction term I am able to observe the differential effect of each typology and compare neighborhood blocks where the same amount of immigrants arrive. Second, the main typology effects only capture how the built environment affects segregation in places that did not experience the arrival of immigrants. Instead, I would expect the built environment to mediate the arrival of immigrants and only have an effect in blocks that experienced a large inflow of immigrants.

Column (1) of table 5.6 reports the estimated interaction terms for all the typologies. The interaction coefficient for the garden apartments typology is 0.737 (standard error $=0.0394$ ), and for the garden suburb it is 0.613 (standard error $=0.0255$ ). These estimates imply that a 10 percentage points increase in immigration raises micro-exposure (reduces segregation) by 0.073 and 0.061 , after immigrants arrive to the garden apartments and garden suburb, respectively. This is in contrast to what happens in the rest of typologies, were a 10 percentage point increase in immigrant arrival has a smaller effect on micro-exposure (significant at the $1 \%$ level). Columns (2) to (5) show that coefficients remain of a similar size after the inclusion of different controls.

Likewise, column (1) of table 5.7, which uses the micro-dissimilarity index as the dependent variable, shows that the interaction coefficient for the garden apartments is -0.091 (standard error $=0.040$ ), and for the garden suburb it is -0.179 (standard error $=0.035$ ). These estimates imply that a 10 percentage points increase in immigration lowers micro-dissimilarity (reduces segregation) by 0.009 and 0.017 when immigrants settle in the garden apartments and garden suburbs, respectively. This is in contrast to what happens in the rest of typologies, were a 10 percentage point increase in immigrant arrival has a smaller effect on micro-dissimilarity, especially in the civic-mixed typology where the arrival of immigrants actually worsens segregation. Columns (2) to (5) show that the garden apartments and garden suburb typologies are robust to the inclusion of different controls. It is worth noting that the arrival of immigrants to a given block improves segregation indices mechanically, because the arrival of immigrants -as a minority group- theoretically creates more opportunities for interaction. However, the interesting result is that these opportu- 
nities only materialize when immigrants coexist with natives in certain typologies.

In both specifications (Table 5.6 and 5.7) the addition of five sets of controls, which improve the models' fit according to $\mathrm{R}$-squared measures, increases the effect of the interacted coefficients in most typologies. When comparing the interaction coefficients across tables for the garden apartments and the garden suburbs, they show to be consistent in both segregation measures and robust to the addition of new controls. In other words, typologies with lower segregation levels measured with the micro-dissimilarity index, also portray higher levels of micro-exposure.

The bottom row in Table 5.6 and 5.7 reports the F-statistic for a test of the null hypothesis that $\beta_{1}=\beta_{2} \ldots=\beta_{8}$. This test explores whether immigration has the same impact on segregation independent of the typology, or if instead there are differences across typologies. The reported $F$-statistics are all above critical values, which suggest that the null hypothesis can be comfortably rejected.

Figure 5-1 and 5-2 summarizes the findings by plotting in each panel the interaction coefficient estimates for each typology and for the different models (including various covariates). The results indicate that immigrant groups settling in the garden apartment and garden suburbs are consistently less segregated from the rest of the native population relative to other groups. In addition, the demographic composition of immigrants described in Section 4.0.1 is similar across all typologies, which suggests that the regression results are capturing the effect of typologies and not differences in the demographic composition of the population.

The differences between typologies can be further illustrated by a comparison between the suburban groups (Hillside, garden suburb, and garden apartments). Despite all three typologies have a similar building density, the hillside shows higher segregation levels relative to the rest. Why are segregation levels much higher at the hillside, relative to places like the garden suburb and the garden apartments? A plausible explanation is that the hillside not only provides less than half of the available open space, but also provides the most scattered and disconnected spaces compared to the garden suburb and the garden apartments. These results point towards lower segregation happening in typologies with low building densities, but only when combined with high levels of open space compactness and centrally configured open spaces. 
Differential effect of immigrant share change by typology (Micro-exposure index)

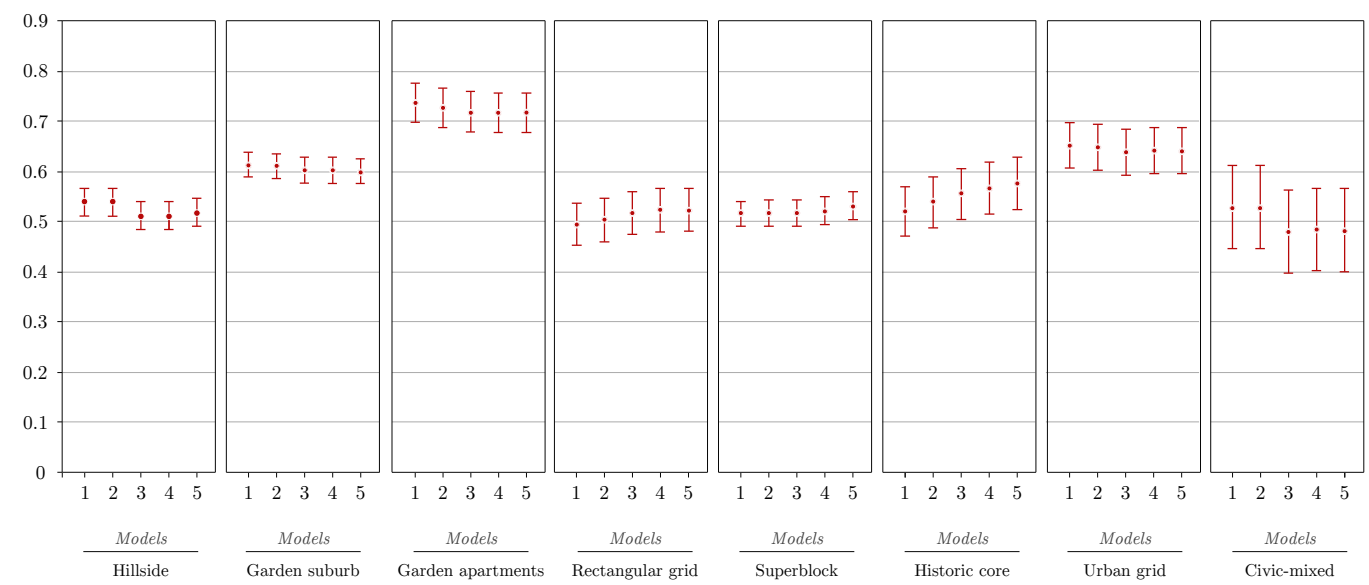

Figure 5-1: Each panel shows the interaction coefficient estimates for the typology and the different models (including various covariates)

Differential effect of immigrant share change by typology (Micro-dissimilarity index)

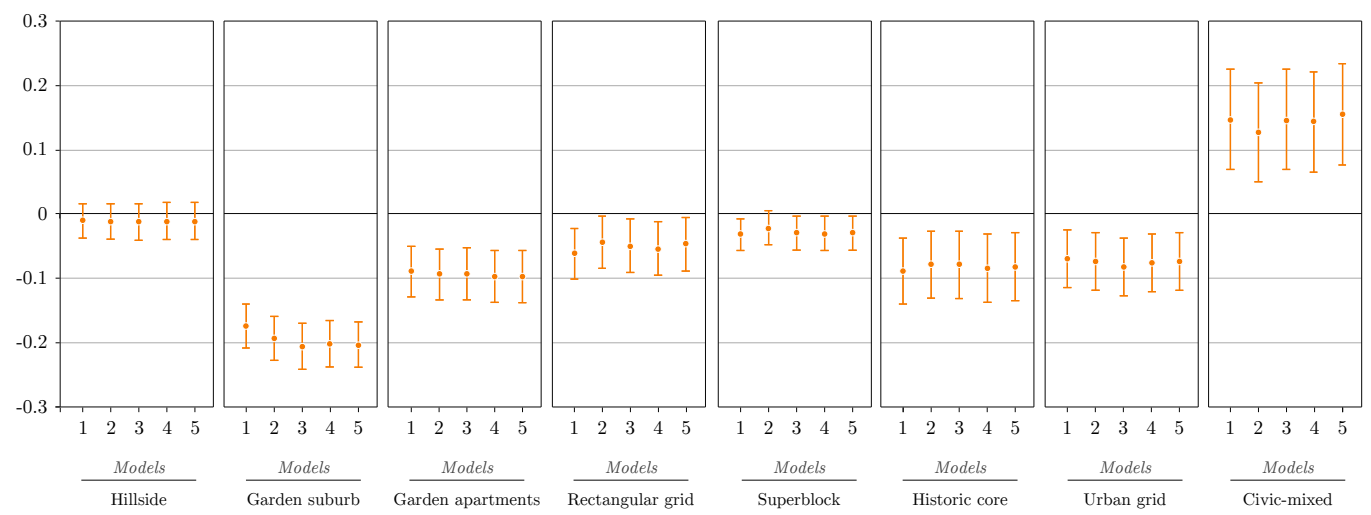

Figure 5-2: Each panel shows the interaction coefficient estimates for the typology and the different models (including various covariates)

According to my previous regressions, the hillside and the civic-mixed typologies are the least conducive to the assimilation of immigrants (highest micro-dissimilarity and lowest micro-exposure levels). In order to compare the effect of the typologies that are more conducive to the assimilation of immigrants, I group the hillside and the civic-mixed typologies and use them as the baseline (excluded category) in the following part of the analysis. The purpose of comparing the 'best' and 'worst' performing typologies is to understand the differential impacts of each group on the segregation of immigrants. In particular, it allows me to test explicitly if a set of typologies is more conducive than others in fostering assimilation between 
immigrants and natives.

In table 5.8 and 5.9, I introduce the groups into the standard regression specifications employed in equation 5.2, but leave the hillside and the civic-mixed types as the comparison group. Column (1) of Table 5.8 shows that the interaction coefficient for the garden apartments is 0.202 (standard error $=0.047$ ), and for the garden suburbs it is 0.078 (standard error $=0.036$ ). The magnitude of the estimated effect is interpreted as: a 10 percentage points increase in immigration raises micro-exposure (decreases segregation) by an additional 0.020 in the garden apartments and 0.007 in the garden suburbs, compared to the baseline (hillside and civic-mixed typologies). These effects are sizable, more so if we take into account that the standard deviation of the change in micro-exposure and micro-dissimilarity is 0.10 and 0.08 , respectively. Columns (2) to (5) show that the effects of the garden apartments and the garden suburbs, are robust to the inclusion of different controls.

The remaining regression results reported in Table 5.9 use the same specification as Table 5.8 but using the micro-dissimilarity index as the dependent variable. The results show a similar pattern as the segregation results measured with the microexposure index. Column (1) of Table 5.8 reports an interaction coefficient for the garden apartment type of -0.097 (standard error $=0.048$ ), and for the garden suburb of -0.186 (standard error $=0.043$ ). These estimates imply that a 10 percentage points increase in immigration lowers micro-dissimilarity (reduces segregation) by an additional 0.009 in the garden apartments and 0.018 in the garden suburbs, compared to the baseline.

In both Tables, columns (2) to (5) show that the garden suburb, the garden apartments and the urban grid typologies, continue to have a significant effect towards decreasing immigrant segregation even after controlling for socio-economic differences between groups, permanent differences in the characteristics of destination neighborhoods, and basic characteristics that vary across groups, neighborhoods, and time.

Since the most common development types are the rectangular grid and the superblock, in the following excercise I use them as the excluded category (in place of the hillside and civic-mixed typologies). Table 6.1 and 6.2 in the appendix show the results. In line with previous findings, the garden suburbs and garden apartments 
continue to have a significant effect towards decreasing segregation, particularly when measured with the micro-exposure index.

In my last empirical exercise, I consider the possibility that socio-economic and location characteristics may have a differential effect that depends on the built environment. For example, attitudes towards immigrants may differ depending on the socio-economic status of the host communities. I follow the same specification as Table 5.9 but include the interaction of my control variables with the typologies as regressors.

Table 5.10 and 5.11 show that additional inclusion of controls leads to some reduction in the estimated decrease in immigrant segregation. The reduction in significant positive effects for the garden apartment typology goes from 0.202 (Column 1) to 0.198 (Column 5) in the case of micro-exposure, and 0.097 (Column 1) to 0.093 (Column 5) for micro-dissimilarity. Similarly, the effects of micro-exposure in the garden suburbs attenuate with the inclusion of additional controls, but continue to persist for micro-dissimilarity.

In summary, the analysis shows that a decrease in immigrant segregation during the immigration boom may be to an extent attributed to spatial configuration differences. The results suggest that differences in the layout configuration of residence places might have an effect on how immigrants coexist with host communities. In particular, the effects are sizable in suburban typologies, which reinforces the idea that a process of suburbanization might have decreased segregation between immigrants and natives. A plausible explanation relates to native communities being less sensitive to co-existing with immigrant populations in less dense areas, where residence units tend to be larger, more spaced out and there ${ }^{3}$ is more available open spaces for potential co-presence to occur.

The fact that immigrants arriving to the garden suburbs and garden apartments experience lower segregation levels than the hillside and the civic-mixed typologies suggests that more open space and higher levels of open space compactness - key spatial features among most of the suburban layouts - are beneficial to mediate the levels of segregation between native and immigrant populations. In contrast, the civic-mixed typology — where most new developments and industrial activity takes

\footnotetext{
${ }^{3}$ The suburban types are mostly 3 -floor apartment units with very few single family housing.
} 
place - shows higher and significant segregation levels compared to all other groups. This could imply that urban form in these typologies gives weak support for a social use and potentially lacks the ability to foster patterns of co-presence between different ethnic groups. 
Table 5.6: Segregation levels by typology (1 to 8), 1999-2008: OLS estimates

\begin{tabular}{|c|c|c|c|c|c|}
\hline & \multicolumn{5}{|c|}{ Dependent variable: Micro-exposure } \\
\hline & $(1)$ & $(2)$ & $(3)$ & $(4)$ & $(5)$ \\
\hline \multirow[t]{2}{*}{ Hillside } & $0.127^{* * *}$ & $0.0358^{*}$ & 0.344 & 0.435 & -0.158 \\
\hline & $(0.00288)$ & $(0.0201)$ & $(0.445)$ & $(0.449)$ & $(0.615)$ \\
\hline \multirow[t]{2}{*}{ Garden suburb } & $0.119^{* * *}$ & 0.0271 & 0.341 & 0.434 & -0.161 \\
\hline & $(0.00375)$ & $(0.0202)$ & $(0.445)$ & $(0.450)$ & $(0.615)$ \\
\hline \multirow[t]{2}{*}{ Garden apartments } & $0.146^{* * *}$ & $0.0545^{* * *}$ & 0.362 & 0.453 & -0.142 \\
\hline & $(0.00371)$ & $(0.0201)$ & $(0.445)$ & $(0.449)$ & $(0.615)$ \\
\hline \multirow{2}{*}{ Rectangular grid } & $0.132^{* * *}$ & $0.0412^{* *}$ & 0.346 & 0.437 & -0.156 \\
\hline & $(0.00445)$ & $(0.0202)$ & $(0.445)$ & $(0.449)$ & $(0.615)$ \\
\hline \multirow[t]{2}{*}{ Superblock } & $0.145^{* * *}$ & $0.0547^{* * *}$ & 0.356 & 0.445 & -0.149 \\
\hline & $(0.00229)$ & $(0.0200)$ & $(0.445)$ & $(0.449)$ & $(0.615)$ \\
\hline \multirow[t]{2}{*}{ Historic core } & $0.137^{* * *}$ & $0.0473^{* *}$ & 0.352 & 0.444 & -0.148 \\
\hline & $(0.00703)$ & $(0.0207)$ & $(0.445)$ & $(0.450)$ & $(0.615)$ \\
\hline \multirow{2}{*}{ Urban grid } & $0.131^{* * *}$ & $0.0404^{* *}$ & 0.344 & 0.435 & -0.158 \\
\hline & $(0.00441)$ & $(0.0202)$ & $(0.445)$ & $(0.449)$ & $(0.615)$ \\
\hline \multirow[t]{2}{*}{ Civic-mixed } & $0.145^{* * *}$ & $0.0518^{* *}$ & 0.353 & 0.444 & -0.151 \\
\hline & $(0.00876)$ & $(0.0217)$ & $(0.445)$ & $(0.450)$ & $(0.615)$ \\
\hline$\Delta$ immigrant share & $0.538^{* * *}$ & $0.538^{* * *}$ & $0.511^{* * *}$ & $0.511^{* * *}$ & $0.517^{* * *}$ \\
\hline$\times$ hillside & $(0.0273)$ & $(0.0277)$ & $(0.0278)$ & $(0.0281)$ & $(0.0282)$ \\
\hline$\Delta$ immigrant share & $0.613^{* * *}$ & $0.610^{* * *}$ & $0.602^{* * *}$ & $0.601^{* * *}$ & $0.600^{* * *}$ \\
\hline$\times$ garden suburb & $(0.0255)$ & $(0.0257)$ & $(0.0257)$ & $(0.0258)$ & $(0.0258)$ \\
\hline$\Delta$ immigrant share & $0.737^{* * *}$ & $0.726^{* * *}$ & $0.718^{* * *}$ & $0.717^{* * *}$ & $0.716^{* * *}$ \\
\hline$\times$ garden apartments & $(0.0394)$ & $(0.0398)$ & $(0.0397)$ & $(0.0398)$ & $(0.0398)$ \\
\hline$\Delta$ immigrant share & $0.494^{* * *}$ & $0.502^{* * *}$ & $0.517^{* * *}$ & $0.522^{* * *}$ & $0.523^{* * *}$ \\
\hline$\times$ rectangular grid & $(0.0415)$ & $(0.0428)$ & $(0.0428)$ & $(0.0431)$ & $(0.0432)$ \\
\hline$\Delta$ immigrant share & $0.515^{* * *}$ & $0.517^{* * *}$ & $0.517^{* * *}$ & $0.521^{* * *}$ & $0.530^{* * *}$ \\
\hline$\times$ superblock & $(0.0257)$ & $(0.0271)$ & $(0.0274)$ & $(0.0276)$ & $(0.0276)$ \\
\hline$\Delta$ immigrant share & $0.520^{* * *}$ & $0.538^{* * *}$ & $0.555^{* * *}$ & $0.566^{* * *}$ & $0.575^{* * *}$ \\
\hline$\times$ Historic core & $(0.0506)$ & $(0.0514)$ & $(0.0512)$ & $(0.0514)$ & $(0.0515)$ \\
\hline$\Delta$ immigrant share & $0.652^{* * *}$ & $0.648^{* * *}$ & $0.637^{* * *}$ & $0.641^{* * *}$ & $0.641^{* * *}$ \\
\hline$\times$ Urban grid & $(0.0456)$ & $(0.0460)$ & $(0.0458)$ & $(0.0460)$ & $(0.0459)$ \\
\hline$\Delta$ immigrant share & $0.528^{* * *}$ & $0.528^{* * *}$ & $0.479^{* * *}$ & $0.484^{* * *}$ & $0.482^{* * *}$ \\
\hline$\times$ Civic-mixed & $(0.0821)$ & $(0.0822)$ & $(0.0821)$ & $(0.0824)$ & $(0.0824)$ \\
\hline$N$ & 3,793 & 3,793 & 3,793 & 3,793 & 3,793 \\
\hline$R$-squared & 0.387 & 0.393 & 0.409 & 0.413 & 0.417 \\
\hline$F$-test & 4.95 & 4.23 & 4.23 & 4.06 & 3.74 \\
\hline \multicolumn{6}{|l|}{ No constant } \\
\hline \multicolumn{6}{|l|}{ Controls: } \\
\hline Age of building stock & & $\checkmark$ & $\checkmark$ & $\checkmark$ & $\checkmark$ \\
\hline Education levels & & $\checkmark$ & $\checkmark$ & & \\
\hline Distance to POI & & & $\checkmark$ & $\checkmark$ & $\checkmark$ \\
\hline Education deciles & & & & $\checkmark$ & $\checkmark$ \\
\hline Neighborhood fixed effects & & & & & $\checkmark$ \\
\hline
\end{tabular}

Notes: The Table reports the regression coefficients of the immigrant share change (defined as the change from 1999 to 2008) interacted with the typologies. column (1) presents the regression estimates without controls. Column (2), includes controls for the share of buildings constructed by decade (1900-2000) and the share of population with different levels of education (illiterate, no primary education, primary education and high school). Column (3) includes additional controls for weighted distances to points of interest (POI). Columns (4) and (5), include controls for the education deciles and for neighborhood fixed effects. Robust standard errors in parentheses *** denotes a coefficient significant at the $1 \%$ level, ${ }^{* *}$ at the $5 \%$ level, and $*$ at the $10 \%$ level. 
Table 5.7: Segregation levels by typology (1 to 8), 1999-2008: OLS estimates

\begin{tabular}{|c|c|c|c|c|c|}
\hline & \multicolumn{5}{|c|}{ Dependent variable: Micro-dissimilarity } \\
\hline & $(1)$ & $(2)$ & $(3)$ & $(4)$ & $(5)$ \\
\hline \multirow[t]{2}{*}{ Hillside } & $-0.0226^{* * *}$ & 0.0116 & -0.682 & $-0.790^{*}$ & $-1.234^{*}$ \\
\hline & $(0.00281)$ & $(0.0232)$ & $(0.467)$ & $(0.473)$ & $(0.659)$ \\
\hline \multirow[t]{2}{*}{ Garden suburb } & $-0.0365^{* * *}$ & -0.00188 & -0.693 & $-0.802^{*}$ & $-1.247^{*}$ \\
\hline & $(0.00447)$ & $(0.0234)$ & $(0.468)$ & $(0.474)$ & $(0.659)$ \\
\hline \multirow[t]{2}{*}{ Garden apartments } & $-0.0322^{* * *}$ & 0.00156 & -0.693 & $-0.801^{*}$ & $-1.245^{*}$ \\
\hline & $(0.00363)$ & $(0.0233)$ & $(0.467)$ & $(0.473)$ & $(0.659)$ \\
\hline \multirow[t]{2}{*}{ Rectangular grid } & $-0.0279^{* * *}$ & 0.00548 & -0.689 & $-0.797^{*}$ & $-1.241^{*}$ \\
\hline & $(0.00422)$ & $(0.0234)$ & $(0.467)$ & $(0.473)$ & $(0.659)$ \\
\hline \multirow[t]{2}{*}{ Superblock } & $-0.0158^{* * *}$ & 0.0174 & -0.678 & $-0.785^{*}$ & $-1.230^{*}$ \\
\hline & $(0.00214)$ & $(0.0232)$ & $(0.467)$ & $(0.473)$ & $(0.659)$ \\
\hline \multirow[t]{2}{*}{ Historic core } & $-0.0350^{* * *}$ & 0.00111 & -0.694 & $-0.802^{*}$ & $-1.245^{*}$ \\
\hline & $(0.00710)$ & $(0.024)$ & $(0.468)$ & $(0.474)$ & $(0.659)$ \\
\hline \multirow[t]{2}{*}{ Urban grid } & $-0.0217^{* * *}$ & 0.0131 & -0.682 & $-0.789^{*}$ & $-1.233^{*}$ \\
\hline & $(0.00422)$ & $(0.0234)$ & $(0.467)$ & $(0.473)$ & $(0.659)$ \\
\hline \multirow{2}{*}{ Civic-mixed } & $-0.0158^{*}$ & 0.0178 & -0.679 & $-0.787^{*}$ & $-1.230^{*}$ \\
\hline & $(0.00847)$ & $(0.0246)$ & $(0.468)$ & $(0.474)$ & $(0.660)$ \\
\hline$\Delta$ immigrant share & -0.0111 & -0.0117 & -0.0130 & -0.0118 & -0.0123 \\
\hline$\times$ hillside & $(0.0280)$ & $(0.0286)$ & $(0.0291)$ & $(0.0293)$ & $(0.0295)$ \\
\hline$\Delta$ immigrant share & $-0.179^{* * *}$ & $-0.198^{* * *}$ & $-0.211^{* * *}$ & $-0.207^{* * *}$ & $-0.208^{* * *}$ \\
\hline$\times$ garden suburb & $(0.0350)$ & $(0.0357)$ & $(0.0363)$ & $(0.0365)$ & $(0.0365)$ \\
\hline$\Delta$ immigrant share & $-0.0914^{* *}$ & $-0.0962^{* *}$ & $-0.0952^{* *}$ & $-0.0990^{* *}$ & $-0.100^{* *}$ \\
\hline$\times$ garden apartments & $(0.0407)$ & $(0.0411)$ & $(0.0416)$ & $(0.0418)$ & $(0.0418)$ \\
\hline$\Delta$ immigrant share & -0.0633 & -0.0451 & -0.0514 & -0.0557 & -0.0484 \\
\hline$\times$ rectangular grid & $(0.0405)$ & $(0.0418)$ & $(0.0424)$ & $(0.0426)$ & $(0.0427)$ \\
\hline$\Delta$ immigrant share & -0.0331 & -0.0224 & -0.0304 & -0.0311 & -0.0303 \\
\hline$\times$ superblock & $(0.0252)$ & $(0.0267)$ & $(0.0273)$ & $(0.0275)$ & $(0.0276)$ \\
\hline$\Delta$ immigrant share & $-0.0916^{*}$ & -0.081 & -0.0812 & -0.0869 & -0.0840 \\
\hline$\times$ historic core & $(0.0524)$ & $(0.0531)$ & $(0.0536)$ & $(0.0538)$ & $(0.0541)$ \\
\hline$\Delta$ immigrant share & -0.0721 & -0.0755 & $-0.0852^{*}$ & $-0.0776^{*}$ & -0.0760 \\
\hline$\times$ urban grid & $(0.0456)$ & $(0.046)$ & $(0.0462)$ & $(0.0464)$ & $(0.0465)$ \\
\hline$\Delta$ immigrant share & $0.150^{*}$ & 0.13 & $0.150^{*}$ & $0.146^{*}$ & $0.158^{* *}$ \\
\hline$\times$ civic-mixed & $(0.0794)$ & $(0.0792)$ & $(0.0800)$ & $(0.0802)$ & $(0.0803)$ \\
\hline$N$ & 3354 & 3354 & 3354 & 3354 & 3354 \\
\hline$R$-squared & 0.020 & 0.034 & 0.042 & 0.051 & 0.056 \\
\hline$F$-test & 3.41 & 3.94 & 4.27 & 4.10 & 4.26 \\
\hline \multicolumn{6}{|l|}{ No constant } \\
\hline \multicolumn{6}{|l|}{ Controls: } \\
\hline Age of building stock & & $\checkmark$ & $\checkmark$ & $\checkmark$ & $\checkmark$ \\
\hline Education levels & & $\checkmark$ & $\checkmark$ & & \\
\hline Distance to POI & & & $\checkmark$ & $\checkmark$ & $\checkmark$ \\
\hline Education deciles & & & & $\checkmark$ & $\checkmark$ \\
\hline District fixed effects & & & & & $\checkmark$ \\
\hline
\end{tabular}

Notes: The Table reports the regression coefficients of the change in immigrant share (1999 to 2008) interacted with the typologies. column (1) presents the regression estimates without controls. Column (2), includes controls for the share of buildings constructed by decade (1900-2000) and the share of population with different levels of education (illiterate, no primary education, primary education and high school). Column (3) includes additional controls for weighted distances to points of interest (POI). Columns (4) and (5), include controls for the education deciles and for neighborhood fixed effects. Robust standard errors in parentheses *** denotes a coefficient significant at the $1 \%$ level, $* *$ at the $5 \%$ level, and $*$ at the $10 \%$ level. 
Table 5.8: Segregation levels by typology (groups), 1999-2008: OLS estimates

\begin{tabular}{|c|c|c|c|c|c|}
\hline & \multicolumn{5}{|c|}{ Dependent variable: Micro-exposure index } \\
\hline & (1) & $(2)$ & $(3)$ & (4) & $(5)$ \\
\hline \multirow[t]{2}{*}{ Garden suburb } & $-0.0105^{* *}$ & $-0.0103^{* *}$ & -0.00329 & -0.00193 & -0.00355 \\
\hline & $(0.00464)$ & $(0.00473)$ & $(0.00517)$ & $(0.00524)$ & $(0.00526)$ \\
\hline \multirow[t]{2}{*}{ Garden apartments } & $0.0168^{* * *}$ & $0.0171^{* * *}$ & $0.0169^{* * *}$ & $0.0165^{* * *}$ & $0.0151^{* * *}$ \\
\hline & $(0.00461)$ & $(0.00460)$ & $(0.00459)$ & $(0.00461)$ & $(0.00462)$ \\
\hline \multirow[t]{2}{*}{ Rectangular grid } & 0.00286 & 0.00379 & 0.00131 & 0.000964 & 0.000654 \\
\hline & $(0.00522)$ & $(0.00523)$ & $(0.00526)$ & $(0.00529)$ & $(0.00530)$ \\
\hline \multirow[t]{2}{*}{ Superblock } & $0.0158^{* * *}$ & $0.0174^{* * *}$ & $0.0111^{* * *}$ & $0.00931^{* *}$ & $0.00756^{*}$ \\
\hline & $(0.00356)$ & $(0.00368)$ & $(0.00385)$ & $(0.00389)$ & $(0.00393)$ \\
\hline \multirow[t]{2}{*}{ Historic core } & 0.00754 & 0.00987 & 0.00719 & 0.00810 & 0.00844 \\
\hline & $(0.00755)$ & $(0.00766)$ & $(0.00770)$ & $(0.00771)$ & $(0.00774)$ \\
\hline \multirow[t]{2}{*}{ Urban grid } & 0.00175 & 0.00305 & -0.000151 & -0.000843 & -0.00101 \\
\hline & $(0.00519)$ & $(0.00524)$ & $(0.00529)$ & $(0.00532)$ & $(0.00532)$ \\
\hline$\Delta$ immigrant share & $0.0784^{* *}$ & $0.0743^{* *}$ & $0.0951^{* * *}$ & $0.0932^{* *}$ & $0.0872^{* *}$ \\
\hline$\times$ garden suburb & $(0.0364)$ & $(0.0364)$ & $(0.0365)$ & $(0.0367)$ & $(0.0368)$ \\
\hline$\Delta$ immigrant share & $0.202^{* * *}$ & $0.191^{* * *}$ & $0.211^{* * *}$ & $0.210^{* * *}$ & $0.203^{* * *}$ \\
\hline$\times$ garden apartments & $(0.0472)$ & $(0.0472)$ & $(0.0469)$ & $(0.0470)$ & $(0.0470)$ \\
\hline$\Delta$ immigrant share & -0.0414 & -0.0330 & 0.0103 & 0.0147 & 0.0106 \\
\hline$\times$ rectangular grid & $(0.0490)$ & $(0.0493)$ & $(0.0493)$ & $(0.0496)$ & $(0.0497)$ \\
\hline$\Delta$ immigrant share & -0.0202 & -0.0184 & 0.0100 & 0.0140 & 0.0175 \\
\hline$\times$ superblock & $(0.0365)$ & $(0.0368)$ & $(0.0368)$ & $(0.0369)$ & $(0.0369)$ \\
\hline$\Delta$ immigrant share & -0.0149 & 0.00280 & 0.0494 & 0.0596 & 0.0634 \\
\hline$\times$ historic core & $(0.0569)$ & $(0.0571)$ & $(0.0570)$ & $(0.0571)$ & $(0.0572)$ \\
\hline$\Delta$ immigrant share & $0.117^{* *}$ & $0.113^{* *}$ & $0.130^{* *}$ & $0.133^{* *}$ & $0.128^{* *}$ \\
\hline$\times$ urban grid & $(0.0525)$ & $(0.0524)$ & $(0.0522)$ & $(0.0524)$ & $(0.0523)$ \\
\hline \multirow[t]{2}{*}{$\Delta$ immigrant share } & $0.535^{* * *}$ & $0.536^{* * *}$ & $0.507^{* * *}$ & $0.507^{* * *}$ & $0.513^{* * *}$ \\
\hline & $(0.0259)$ & $(0.0263)$ & $(0.0265)$ & $(0.0268)$ & $(0.0269)$ \\
\hline$N$ & 3,793 & 3,793 & 3,793 & 3,793 & 3,793 \\
\hline$R$-squared & 0.387 & 0.393 & 0.409 & 0.413 & 0.418 \\
\hline \multicolumn{6}{|l|}{ Controls: } \\
\hline Age of building stock & & $\checkmark$ & $\checkmark$ & $\checkmark$ & $\checkmark$ \\
\hline Education levels & & $\checkmark$ & $\checkmark$ & & \\
\hline Distance to POI & & & $\checkmark$ & $\checkmark$ & $\checkmark$ \\
\hline Education deciles & & & & $\checkmark$ & $\checkmark$ \\
\hline District fixed effects & & & & & $\checkmark$ \\
\hline
\end{tabular}

Notes: The Table reports the regression coefficients of the change in immigrant share (1999 to 2008) interacted with the typologies. The hillside and civic-mixed types are the excluded category. column (1) presents the regression estimates without controls. Column (2), includes controls for the share of buildings constructed by decade (1900-2000) and the share of population with different levels of education (illiterate, no primary education, primary education and high school). Column (3) includes additional controls for weighted distances to points of interest (POI). Columns (4) and (5), include controls for the education deciles and for neighborhood fixed effects. Robust standard errors in parentheses

*** denotes a coefficient significant at the $1 \%$ level, ** at the $5 \%$ level, and $*$ at the $10 \%$ level. 
Table 5.9: Segregation levels by typologies (groups), 1999-2008: OLS estimates

\begin{tabular}{|c|c|c|c|c|c|}
\hline & \multicolumn{5}{|c|}{ Dependent variable: Micro-dissimilarity index } \\
\hline & $(1)$ & $(2)$ & (3) & (4) & $(5)$ \\
\hline Garden suburb & $\begin{array}{c}-0.0144^{* * *} \\
(0.00520)\end{array}$ & $\begin{array}{l}-0.0138^{* * *} \\
(0.00524)\end{array}$ & $\begin{array}{l}-0.0113^{* *} \\
(0.00563)\end{array}$ & $\begin{array}{l}-0.0124^{* *} \\
(0.00569)\end{array}$ & $\begin{array}{l}-0.0131^{* *} \\
(0.00571)\end{array}$ \\
\hline Garden apartments & $\begin{array}{l}-0.0100^{* *} \\
(0.00450)\end{array}$ & $\begin{array}{l}-0.0104^{* *} \\
(0.00449)\end{array}$ & $\begin{array}{l}-0.0110^{* *} \\
(0.00452)\end{array}$ & $\begin{array}{l}-0.0109^{* *} \\
(0.00454)\end{array}$ & $\begin{array}{l}-0.0112^{* *} \\
(0.00456)\end{array}$ \\
\hline Rectangular grid & $\begin{array}{l}-0.00582 \\
(0.00499)\end{array}$ & $\begin{array}{l}-0.00653 \\
(0.00498)\end{array}$ & $\begin{array}{l}-0.00674 \\
(0.00507)\end{array}$ & $\begin{array}{l}-0.00673 \\
(0.00509)\end{array}$ & $\begin{array}{l}-0.00733 \\
(0.00512)\end{array}$ \\
\hline Superblock & $\begin{array}{l}0.00628^{*} \\
(0.00342)\end{array}$ & $\begin{array}{c}0.00540 \\
(0.00353)\end{array}$ & $\begin{array}{c}0.00396 \\
(0.00372)\end{array}$ & $\begin{array}{c}0.00511 \\
(0.00376)\end{array}$ & $\begin{array}{c}0.00412 \\
(0.00380)\end{array}$ \\
\hline Historic core & $\begin{array}{l}-0.0129^{*} \\
(0.00758)\end{array}$ & $\begin{array}{c}-0.0109 \\
(0.00766)\end{array}$ & $\begin{array}{l}-0.0120 \\
(0.00777)\end{array}$ & $\begin{array}{c}-0.0117 \\
(0.00778)\end{array}$ & $\begin{array}{c}-0.0111 \\
(0.00782)\end{array}$ \\
\hline Urban grid & $\begin{array}{l}0.000388 \\
(0.00499)\end{array}$ & $\begin{array}{c}0.00116 \\
(0.00503)\end{array}$ & $\begin{array}{l}0.000276 \\
(0.00513)\end{array}$ & $\begin{array}{c}0.00126 \\
(0.00516)\end{array}$ & $\begin{array}{c}0.00129 \\
(0.00517)\end{array}$ \\
\hline $\begin{array}{l}\Delta \text { immigrant share } \\
\times \text { garden suburb }\end{array}$ & $\begin{array}{c}-0.186^{* * *} \\
(0.0439)\end{array}$ & $\begin{array}{c}-0.202^{* * *} \\
(0.0439)\end{array}$ & $\begin{array}{c}-0.217^{* * *} \\
(0.0447)\end{array}$ & $\begin{array}{c}-0.213^{* * *} \\
(0.0448)\end{array}$ & $\begin{array}{c}-0.215^{* * *} \\
(0.0449)\end{array}$ \\
\hline $\begin{array}{l}\Delta \text { immigrant share } \\
\times \text { garden apartments }\end{array}$ & $\begin{array}{c}-0.0978^{* *} \\
(0.0485)\end{array}$ & $\begin{array}{l}-0.100^{* *} \\
(0.0484)\end{array}$ & $\begin{array}{l}-0.101^{* *} \\
(0.0486)\end{array}$ & $\begin{array}{l}-0.106^{* *} \\
(0.0489)\end{array}$ & $\begin{array}{l}-0.108^{* *} \\
(0.0489)\end{array}$ \\
\hline $\begin{array}{l}\Delta \text { immigrant share } \\
\times \text { rectangular grid }\end{array}$ & $\begin{array}{l}-0.0697 \\
(0.0484)\end{array}$ & $\begin{array}{l}-0.0483 \\
(0.0486)\end{array}$ & $\begin{array}{l}-0.0561 \\
(0.0491)\end{array}$ & $\begin{array}{l}-0.0608 \\
(0.0494)\end{array}$ & $\begin{array}{l}-0.0544 \\
(0.0496)\end{array}$ \\
\hline $\begin{array}{l}\Delta \text { immigrant share } \\
\times \text { superblock }\end{array}$ & $\begin{array}{l}-0.0395 \\
(0.0365)\end{array}$ & $\begin{array}{l}-0.0257 \\
(0.0366)\end{array}$ & $\begin{array}{l}-0.0353 \\
(0.0370)\end{array}$ & $\begin{array}{l}-0.0364 \\
(0.0371)\end{array}$ & $\begin{array}{l}-0.0365 \\
(0.0372)\end{array}$ \\
\hline $\begin{array}{l}\Delta \text { immigrant share } \\
\times \text { historic core }\end{array}$ & $\begin{array}{l}-0.0980^{*} \\
(0.0587)\end{array}$ & $\begin{array}{l}-0.0844 \\
(0.0587)\end{array}$ & $\begin{array}{l}-0.0862 \\
(0.0594)\end{array}$ & $\begin{array}{l}-0.0923 \\
(0.0595)\end{array}$ & $\begin{array}{l}-0.0903 \\
(0.0597)\end{array}$ \\
\hline $\begin{array}{l}\Delta \text { immigrant share } \\
\times \text { urban grid }\end{array}$ & $\begin{array}{l}-0.0785 \\
(0.0527)\end{array}$ & $\begin{array}{l}-0.0793 \\
(0.0526)\end{array}$ & $\begin{array}{l}-0.0905^{*} \\
(0.0528)\end{array}$ & $\begin{array}{l}-0.0833 \\
(0.0530)\end{array}$ & $\begin{array}{l}-0.0827 \\
(0.0531)\end{array}$ \\
\hline$\Delta$ immigrant share & $\begin{array}{l}0.00639 \\
(0.0264)\end{array}$ & $\begin{array}{l}0.00402 \\
(0.0270)\end{array}$ & $\begin{array}{l}0.00556 \\
(0.0275)\end{array}$ & $\begin{array}{l}0.00608 \\
(0.0277)\end{array}$ & $\begin{array}{c}0.00705 \\
(0.0278)\end{array}$ \\
\hline$N$ & 3,354 & 3,354 & 3,354 & 3,354 & 3,354 \\
\hline $\begin{array}{l}R \text {-squared } \\
\text { Controls: }\end{array}$ & 0.019 & 0.034 & 0.041 & 0.051 & 0.055 \\
\hline Age of building stock & & $\checkmark$ & $\checkmark$ & $\checkmark$ & $\checkmark$ \\
\hline Education levels & & $\checkmark$ & $\checkmark$ & & \\
\hline Distance to POI & & & $\checkmark$ & $\checkmark$ & $\checkmark$ \\
\hline Education deciles & & & & $\checkmark$ & $\checkmark$ \\
\hline District fixed effects & & & & & $\checkmark$ \\
\hline
\end{tabular}

Notes: The Table reports the regression coefficients of the change in immigrant share (1999 to 2008) interacted with the typologies. The hillside and civic-mixed types are the excluded category. column (1) presents the regression estimates without controls. Column (2), includes controls for the share of buildings constructed by decade (1900-2000) and the share of population with different levels of education (illiterate, no primary education, primary education and high school). Column (3) includes additional controls for weighted distances to points of interest (POI). Columns (4) and (5), include controls for the education deciles and for neighborhood fixed effects. Robust standard errors in parentheses

*** denotes a coefficient significant at the $1 \%$ level, ${ }^{* *}$ at the $5 \%$ level, and $*$ at the $10 \%$ level. 
Table 5.10: Segregation levels by typology controlling for interaction effects, 1999-2008: OLS estimates

\begin{tabular}{lccccc}
\hline \hline & \multicolumn{5}{c}{ Dependent variable: Micro-exposure index } \\
\cline { 2 - 6 } & $(1)$ & $(2)$ & $(3)$ & $(4)$ & $(5)$ \\
\hline$\Delta$ immigrant share & $0.0784^{* *}$ & 0.0443 & 0.0415 & 0.0400 & 0.0284 \\
$\times$ garden suburb & $(0.0364)$ & $(0.0373)$ & $(0.0428)$ & $(0.0423)$ & $(0.0429)$ \\
$\Delta$ immigrant share & $0.202^{* * *}$ & $0.189^{* * *}$ & $0.179^{* * *}$ & $0.206^{* * *}$ & $0.198^{* * *}$ \\
$\times$ garden apartments & $(0.0472)$ & $(0.0471)$ & $(0.0479)$ & $(0.0479)$ & $(0.0487)$ \\
$\Delta$ immigrant share & -0.0414 & -0.00959 & 0.0278 & 0.0589 & 0.0510 \\
$\times$ rectangular grid & $(0.0490)$ & $(0.0500)$ & $(0.0508)$ & $(0.0511)$ & $(0.0517)$ \\
$\Delta$ immigrant share & -0.0202 & 0.0121 & 0.0481 & 0.0493 & 0.0405 \\
$\times$ superblock & $(0.0365)$ & $(0.0382)$ & $(0.0401)$ & $(0.0402)$ & $(0.0407)$ \\
$\Delta$ immigrant share & -0.0149 & 0.0710 & $0.130^{* *}$ & $0.147^{* *}$ & $0.156^{* *}$ \\
$\times$ historic core & $(0.0569)$ & $(0.0593)$ & $(0.0610)$ & $(0.0609)$ & $(0.0615)$ \\
$\Delta$ immigrant share & $0.117^{* *}$ & $0.113^{* *}$ & $0.125^{* *}$ & $0.137^{* *}$ & $0.131^{* *}$ \\
$\times$ urban grid & $(0.0525)$ & $(0.0526)$ & $(0.0532)$ & $(0.0533)$ & $(0.0536)$ \\
$\Delta$ immigrant share & $0.535^{* * *}$ & $0.247^{*}$ & $7.559^{* *}$ & $8.938^{* * *}$ & $10.95^{* * *}$ \\
& $(0.0259)$ & $(0.146)$ & $(3.301)$ & $(3.301)$ & $(4.185)$ \\
& & & & & \\
$N$ & 3,793 & 3,793 & 3,793 & 3,793 & 3,793 \\
$R$-squared & 0.387 & 0.402 & 0.427 & 0.433 & 0.438 \\
Controls \& interactions: & & & & & \\
Typology main effects & $\checkmark$ & $\checkmark$ & $\checkmark$ & $\checkmark$ & $\checkmark$ \\
Age of building stock & & $\checkmark$ & $\checkmark$ & $\checkmark$ & $\checkmark$ \\
Education levels & & $\checkmark$ & $\checkmark$ & & $\checkmark$ \\
Distance to POI & & & $\checkmark$ & $\checkmark$ & $\checkmark$ \\
Education deciles & & & & $\checkmark$ & $\checkmark$ \\
District fixed effects & & & & \\
\hline
\end{tabular}

Notes: The Table reports the regression coefficients of the change in immigrant share (1999 to 2008) interacted with the typologies. The control variables are interacted with the typologies as regressors. The hillside and civic-mixed types are the excluded category. column (1) presents the regression estimates without controls. Column (2), includes controls for the share of buildings constructed by decade (1900-2000) and the share of population with different levels of education (illiterate, no primary education, primary education and high school). Column (3) includes additional controls for weighted distances to points of interest (POI). Columns (4) and (5), include controls for the education deciles and for neighborhood fixed effects. Robust standard errors in parentheses *** denotes a coefficient significant at the $1 \%$ level, ${ }^{* *}$ at the $5 \%$ level, and $*$ at the $10 \%$ level. 
Table 5.11: Segregation levels by typology controlling for interaction effects, 1999-2008: OLS estimates

\begin{tabular}{|c|c|c|c|c|c|}
\hline & \multicolumn{5}{|c|}{ Dependent variable: Micro-dissimilarity index } \\
\hline & (1) & $(2)$ & (3) & (4) & (5) \\
\hline$\Delta$ immigrant share & $-0.186^{* * *}$ & $-0.195^{* * *}$ & $-0.172^{* * *}$ & $-0.181^{* * *}$ & $-0.175^{* * *}$ \\
\hline$\times$ garden suburb & $(0.0439)$ & $(0.0450)$ & $(0.0505)$ & $(0.0506)$ & $(0.0512)$ \\
\hline$\Delta$ immigrant share & $-0.0978^{* *}$ & $-0.106^{* *}$ & -0.0680 & $-0.0844^{*}$ & $-0.0934^{*}$ \\
\hline$\times$ garden apartments & $(0.0485)$ & $(0.0486)$ & $(0.0502)$ & $(0.0504)$ & $(0.0511)$ \\
\hline$\Delta$ immigrant share & -0.0697 & -0.0419 & -0.0362 & -0.0522 & -0.0476 \\
\hline$\times$ rectangular grid & $(0.0484)$ & $(0.0496)$ & $(0.0513)$ & $(0.0517)$ & $(0.0527)$ \\
\hline$\Delta$ immigrant share & -0.0395 & -0.0191 & -0.00840 & -0.0184 & -0.0184 \\
\hline$\times$ superblock & $(0.0365)$ & $(0.0386)$ & $(0.0409)$ & $(0.0412)$ & $(0.0419)$ \\
\hline$\Delta$ immigrant share & $-0.0980^{*}$ & -0.0946 & -0.0611 & -0.0648 & -0.0813 \\
\hline$\times$ historic core & $(0.0587)$ & $(0.0613)$ & $(0.0644)$ & $(0.0645)$ & $(0.0654)$ \\
\hline$\Delta$ immigrant share & -0.0785 & -0.0733 & -0.0776 & -0.0627 & -0.0556 \\
\hline$\times$ urban grid & $(0.0527)$ & $(0.0532)$ & $(0.0546)$ & $(0.0550)$ & $(0.0553)$ \\
\hline \multirow[t]{2}{*}{$\Delta$ immigrant share } & 0.00639 & -0.00491 & 5.721 & 6.828 & 9.751 \\
\hline & $(0.0264)$ & $(0.190)$ & $(4.226)$ & $(4.267)$ & $(5.969)$ \\
\hline$N$ & 3,354 & 3,354 & 3,354 & 3,354 & 3,354 \\
\hline$R$-squared & 0.019 & 0.041 & 0.059 & 0.064 & 0.071 \\
\hline \multicolumn{6}{|l|}{ Controls \& interactions: } \\
\hline Typology main effects & $\checkmark$ & $\checkmark$ & $\checkmark$ & $\checkmark$ & $\checkmark$ \\
\hline Age of building stock & & $\checkmark$ & $\checkmark$ & $\checkmark$ & $\checkmark$ \\
\hline Education levels & & $\checkmark$ & $\checkmark$ & & \\
\hline Distance to POI & & & $\checkmark$ & $\checkmark$ & $\checkmark$ \\
\hline Education deciles & & & & $\checkmark$ & $\checkmark$ \\
\hline District fixed effects & & & & & $\checkmark$ \\
\hline
\end{tabular}

Notes: The Table reports the regression coefficients of the change in immigrant share (1999 to 2008) interacted with the typologies. The control variables are interacted with the typologies as regressors. The hillside and civic-mixed types are the excluded category. column (1) presents the regression estimates without controls. Column (2), includes controls for the share of buildings constructed by decade (1900-2000) and the share of population with different levels of education (illiterate, no primary education, primary education and high school). Column (3) includes additional controls for weighted distances to points of interest (POI). Columns (4) and (5), include controls for the education deciles and for neighborhood fixed effects. Robust standard errors in parentheses *** denotes a coefficient significant at the $1 \%$ level, $* *$ at the $5 \%$ level, and $*$ at the $10 \%$ level. 


\section{Chapter 6}

\section{Conclusions}

Segregation can prevent individuals from accessing social, cultural and economic opportunities, impede relations between groups, and exacerbate social exclusion. By focusing on the city of Barcelona during the 1999-2008 boom period, this thesis explores how urban form mediates the segregation of immigrants. My empirical analysis combines several geometric indicators for urban shape with measures of segregation constructed at the building level. To my knowledge, this is the first study to examine segregation and urban form at such a granular scale of analysis.

The results imply that certain spatial qualities affect the degree to which immigrants become segregated: open space centrality, coverage and, compactness predict higher levels of micro-exposure and lower levels of micro-dissimilarity, reducing immigrant segregation. Thus, suburban typologies, which are distinguished by high levels of open space compactness, are less likely than urban typologies to promote immigrant segregation. Although the documented relationships between urban form and segregation are robust to controlling for a variety of socieconomic differences, more evidence is needed to understand the extent to which urban form can foster integration processes.

My findings are potentially relevant to the fields of urban design and planning. If urban form mediates how native populations coexist with immigrants, then urban design can be used as a tool to address segregation. My research sheds light on spatial qualities that appear to reduce segregation, and it provides guidelines that planners and urban designers can employ to enhance current design practices. 
My results point to a paradox: urban planning practitioners typically promote urbanity, but suburban typologies, not urban ones, appear to reduce segregation. If suburban layouts promote the assimilation of peoples of different ethnicities, then how can we as planners accommodate or shape these dynamics? The problem is complex both in terms of its character and solution. Dense urban settlements provide many benefits, but integration does not seem to be one of them. Indeed, the evidence suggests that ethnic diversity is more likely to be achieved under conditions of dispersed development. When it comes to livability and sustainability the two built landscape types-the urban and the suburban - provide different advantages and disadvantages. As my research suggests, where the goal is integration, a compromise must be made between urban and suburban development types. Urbanity may not always provide the best context in which to achieve ethnic diversity.

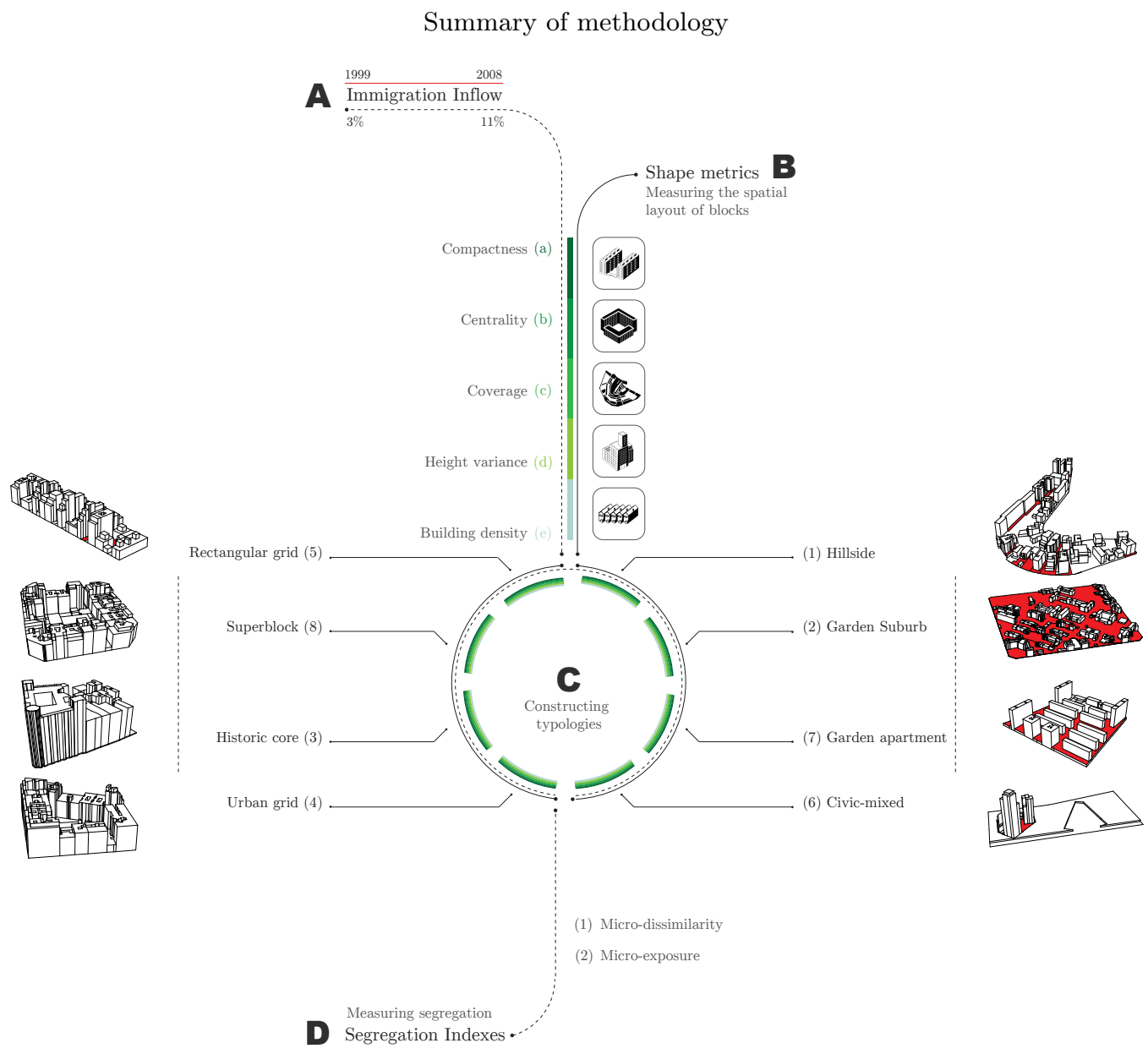

Figure 6-1 
In this thesis I propose a methodology (see Figure 6-1) that defines in new terms typologies that summarize the distinctive spatial characteristics of urban form. My methodology could be adapted to examine how the built environment affects a variety of social phenomena in other cities. For example, the typologies defined in this study could serve as a baseline measure of urban layout in cities other than Barcelona, and as such it could provide researchers with a consistent set of urban form measurements. Moreover, this methodology could be expanded to include additional typologies appropriate for other contexts.

My study, in other words, reveals several directions for future methodological improvements. First, analyzing the co-presence in public space of different social groups would allow us to determine whether (as my study suggests) shared spaces facilitate interaction between immigrants and natives. Second, the shape measures themselves could be improved. My shape metrics measure the configuration of each urban block, and, thus, they focus solely on each block's internal layout. To better approximate the true interaction possibilities between peoples of different ethnic groups, future research could incorporate shape metric calculations that account for street connectivity and distances to adjacent blocks. Finally, it would be worthwhile to more fully examine the channels through which urban form affects segregation. 


\section{References}

Anderson, S. (1993). Savannah and the Issue of Precedent: City Plan as Resource. Settlements in the Americas: cross-cultural perspectives. R. Bennett. Newark.

Banerjee, T., \& Verma, N. (2005). Sprawl and Segregation. Desegregating the city: Ghettos, enclaves, and inequality, 200.

Bell, B., and S. Machin (2013): "Immigrant Enclaves And Crime," Journal of Regional Science, 53(1), 118-141.

Berghauser-Pont, M. Y., \& Haupt, P. (2010). Spacematrix: Space, density and urban form. Rotterdam: NAi Publishers.

Bertaud, A., \& Malpezzi, S. (2003). The spatial distribution of population in 48 world cities: Implications for economies in transition. World Bank Report.

Bolt, G., \& Van Kempen, R. (2010). Ethnic segregation and residential mobility: relocations of minority ethnic groups in the Netherlands. Journal of Ethnic and Migration Studies, 36(2), 333-354.

Borjas, G. J. (2009). The analytics of the wage effect of immigration (No. w14796). National Bureau of Economic Research.

Bosch, M., Carnero, M., \& Farre, L. (2011). Rental housing discrimination and the persistence of ethnic enclaves.

Burchfield, M., Overman, H. G., Puga, D., \& Turner, M. A. (2006). Causes of sprawl: A portrait from space. The Quarterly Journal of Economics, 587-633.

Charalambous, N. Understanding segregation: the relationship between urban form and social exclusion.

Churchman, A. (1999). Disentangling the concept of density. Journal of Planning Literature, 13(4), 389-411. 
Conzen, M. R. G., \& Conzen, M. P. (2004). Thinking about urban form: papers on urban morphology, 1932-1998. Peter Lang.

INE (2005): Censo de Poblacion y Viviendas. Volumen IV. Indicadores inframunicipales. Secciones censales y unidades poblacionales CD Rom. Madrid.

Microdatos del Padron Municipal de Habitantes. (2009). Madrid.

Charles, C. Z. (2003). The dynamics of racial residential segregation. Annual review of sociology, 167-207.

Cutler, D. M., E. L. Glaeser, and J. L. Vigdor (2008): "Is the Melting Pot Still Hot? Explaining the Resurgence of Immigrant Segregation," The Review of Economics and Statistics, 90(3), 478-497.

Crowder, K., Pais, J., \& South, S. J. (2012). Neighborhood diversity, metropolitan constraints, and household migration. American Sociological Review, $77(3), 325-353$.

Galster, G., Hanson, R., Ratcliffe, M. R., Wolman, H., Coleman, S., \& Freihage, J. (2001). Wrestling sprawl to the ground: defining and measuring an elusive concept. Housing policy debate, 12(4), 681-717.

Galster, G. (2008). Quantifying the effect of neighbourhood on individuals: challenges, alternative approaches, and promising directions. Schmollers jahrbuch, 128(1), 7-48.

Glaeser, E., \& Vigdor, J. (2012). The end of the segregated century: Racial separation in America's neighborhoods, 1890-2010. New York, NY: Manhattan Institute for Policy Research.

Hanson, J. (2000). Urban transformations: a history of design ideas. Urban design international, 5(2), 97-122.

Hillier, B., Hanson, J., \& Graham, H. (1987). Ideas are in things: an application of the space syntax method to discovering house genotypes. Environment and Planning B: Planning and Design, 14(4), 363-385.

Hillier, B. (2007). Space is the machine: a configurational theory of architecture.

Hyde, T., Busquets, J., \& Rowe, P. (2008). Barcelona: The Urban Evolution of a Compact City.

Hoehner, C. M., Ramirez, L. K. B., Elliott, M. B., Handy, S. L., \& 
Brownson, R. C. (2005). Perceived and objective environmental measures and physical activity among urban adults. American journal of preventive medicine, 28(2), 105-116.

Jacobs, J. (1961). The life and death of great American cities.

Jacobs, A. (1993). Great Streets Cambridge.

Kansky, K. J. (1963). Structure of transportation networks: relationships between network geometry and regional characteristics.

Kunstler, J. H. (1994). Geography Of Nowhere: The Rise And Declineof America'S Man-Made Landscape. Simon and Schuster.

ESRI (2009): StreetMap Premium Europe NAVTEQ 2009 Release 2.

Legeby, A. (2010). Urban segregation and urban form: From residential segregation to segregation in public space.

Li, W. (1998). Anatomy of a new ethnic settlement: The Chinese ethnoburb in Los Angeles. Urban studies, 35(3), 479-501.

Mangin, D., \& Panerai, P. (1999). Projet urbain. Parenth $\tilde{A}^{*}$ ses.

Marshall, S. (2004). Streets and patterns. Routledge.

Massey, D. S., and N. A. Denton (1988): "The Dimensions of Residential Segregation," Social Forces, 67(2), 281-315.

Massey, D. S., \& Denton, N. A. (1993). American apartheid: Segregation and the making of the underclass. Harvard University Press.

Mesev, T. V., Longley, P. A., Batty, M., \& Xie, Y. (1995). Morphology from imagery: detecting and measuring the density of urban land use. Environment and Planning A, 27(5), 759-780.

Moudon, A. V. (1986). Built for change: neighborhood architecture in San Francisco. Mit Press.

Munnell, A. H., Tootell, G. M., Browne, L. E., \& McEneaney, J. (1996). Mortgage lending in Boston: Interpreting HMDA data. The American Economic Review, 25-53.

Newman, P., \& Kenworthy, J. (1999). Sustainability and cities: overcoming automobile dependence. Island Press.

Organisation for Economic Co-operation and Development. (2005). OECD factbook: economic, environmental and social statistics. OECD. 
Pendola, R., \& Gen, S. (2008). Does"Main Street" promote sense of community? A comparison of San Francisco neighborhoods. Environment and behavior, 40(4), 545-574.

Portnov, B. A., \& Erell, E. (2001). Urban clustering: the benefits and drawbacks of location. Ashgate Pub Ltd.

Rundle, A., \& Roux, A. V. D. The Urban Built Environment and Obecity in New York City. American Journal of Health Promotion.

Sabatini, F. (2006). The social spatial segregation in the cities of Latin America. Inter-American Development Bank.

Saiz, A., and S. Wachter (2011):"Immigration and the Neighborhood," American Economic Journal: Economic Policy, 3(2), 169-88.

Song, Y., \& Knaap, G. J. (2004). Measuring urban form: Is Portland winning the war on sprawl?. Journal of the American Planning Association, 70(2), 210-225.

Song, Y., \& Knaap, G. J. (2003). New urbanism and housing values: a disaggregate assessment. Journal of Urban Economics, 54(2), 218-238.

Talen, E. (2012). Design for diversity. Routledge.

Torrens, P. M., \& Alberti, M. (2000). Measuring sprawl.

Urhahn, G., \& Bobic, M. (1994). A Pattern Image: A typological tool for quality in urban planning. Thoth.

Vaughan, L., Clark, D. L. C., Sahbaz, O., \& Haklay, M. M. (2005). Space and exclusion: does urban morphology play a part in social deprivation?. Area, 37(4), 402-412.

Wilson, A. G. (2000). Complex spatial systems: the modelling foundations of urban and regional analysis. Pearson Education. 


\section{Appendix A}

\section{Calinski-Harabasz pseudo F-statistic}

Grouping effectiveness is measured using the Calinski-Harabasz pseudo F-statistic, which is a ratio reflecting within-group similarity and between-group difference

$$
\begin{gathered}
\left(\frac{R^{2}}{n_{c}-1}\right)\left(\frac{1-R^{2}}{n-n c}\right) \\
R^{2}=\frac{S S T-S S E}{S S T} \\
S S T=\sum_{i=1}^{n_{c}} \sum_{j=1}^{n_{i}} \sum_{k=1}^{n_{v}}\left(V_{i j}^{k}-\overline{V^{k}}\right)^{2} \\
S S E=\sum_{i=1}^{n_{c}} \sum_{j=1}^{n_{i}} \sum_{k=1}^{n_{v}}\left(V_{i j}^{k}-\overline{V_{t}^{k}}\right)^{2}
\end{gathered}
$$

$S S T$ is a reflection of between-group differences and $S S E$ reflects within-group similarity. Here $n$ is the number of blocks. $n_{i}$ and $n_{c}$ corresponds to the number of blocks in group $i$ and total number of groups, respectively. $n_{v}$ indicates the number

of shape metrics used to group the blocks. $V_{i j}^{k}$ is the value of the $k$-th shape metric of the $j$-th block in the $i$-th group. $\overline{V^{k}}$ is the mean value of the $k$-th shape metric and $\overline{V_{t}^{k}}$ is the mean value of the $k$-th shape metric in group $i$.

\section{Gravities}

I include two measures of distance to amenities: (1) distance to the closest feature and (2) a gravity measure that provides the sum of every amenity weighted by the inverse of the distance between the amenity and the address. 
Following (Moraga \& Ferrer-Carbonell, 2015) I estimate the impedance function with the following equation:

$$
\operatorname{gravity}_{i}^{p, \alpha}=\sum_{n_{p}=1}^{N_{p}} d_{i, n p}^{-\alpha}
$$

Here $i$ is an address, $p$ is a POI (point of interest), $N_{p}$ is the number of points of interest $p$ located in the block where $i$ is located. $\alpha$ is a coefficient that takes the value of 2 , and $d_{i, n p}$ is the distance between address $i$ and one particular point of interest $n_{p}$.

\section{Tables}


Table 6.1: Segregation levels by typology (groups), 1999-2008: OLS estimates

\begin{tabular}{|c|c|c|c|c|c|}
\hline & \multicolumn{5}{|c|}{ Dependent variable: Micro-exposure index } \\
\hline & (1) & $(2)$ & $(3)$ & $(4)$ & $(5)$ \\
\hline \multirow[t]{2}{*}{ Hillside } & $-0.0148^{* * *}$ & $-0.0158^{* * *}$ & $-0.00961^{* *}$ & $-0.00808^{* *}$ & $-0.00654^{*}$ \\
\hline & $(0.00352)$ & $(0.00360)$ & $(0.00375)$ & $(0.00378)$ & $(0.00381)$ \\
\hline \multirow[t]{2}{*}{ Garden suburb } & $-0.0236^{* * *}$ & $-0.0245^{* * *}$ & $-0.0116^{* *}$ & -0.00886 & $-0.00917^{*}$ \\
\hline & $(0.00427)$ & $(0.00451)$ & $(0.00542)$ & $(0.00550)$ & $(0.00549)$ \\
\hline \multirow[t]{2}{*}{ Garden apartments } & 0.00368 & 0.00285 & $0.00842^{*}$ & $0.00950^{* *}$ & $0.00946^{* *}$ \\
\hline & $(0.00423)$ & $(0.00430)$ & $(0.00441)$ & $(0.00444)$ & $(0.00444)$ \\
\hline \multirow{2}{*}{ Historic core } & -0.00560 & -0.00448 & -0.00156 & 0.000863 & 0.00270 \\
\hline & $(0.00732)$ & $(0.00740)$ & $(0.00738)$ & $(0.00741)$ & $(0.00744)$ \\
\hline \multirow[t]{2}{*}{ Urban grid } & $-0.0114^{* *}$ & $-0.0115^{* *}$ & $-0.00916^{*}$ & $-0.00836^{*}$ & -0.00705 \\
\hline & $(0.00486)$ & $(0.00486)$ & $(0.00484)$ & $(0.00486)$ & $(0.00487)$ \\
\hline \multirow[t]{2}{*}{ Civic-mixed } & 0.00223 & 0.000279 & -0.000468 & 0.000578 & 0.000564 \\
\hline & $(0.00900)$ & $(0.00909)$ & $(0.00925)$ & $(0.00928)$ & $(0.00928)$ \\
\hline$\Delta$ immigrant share & 0.0274 & 0.0249 & -0.00615 & -0.0110 & -0.0118 \\
\hline$\times$ hillside & $(0.0350)$ & $(0.0353)$ & $(0.0353)$ & $(0.0355)$ & $(0.0355)$ \\
\hline$\Delta$ immigrant share & $0.103^{* * *}$ & $0.0974^{* * *}$ & $0.0853^{* *}$ & $0.0790^{* *}$ & $0.0715^{* *}$ \\
\hline$\times$ garden suburb & $(0.0336)$ & $(0.0344)$ & $(0.0347)$ & $(0.0349)$ & $(0.0349)$ \\
\hline$\Delta$ immigrant share & $0.227^{* * *}$ & $0.213^{* * *}$ & $0.200^{* * *}$ & $0.195^{* * *}$ & $0.187^{* * *}$ \\
\hline$\times$ garden apartments & $(0.0451)$ & $(0.0453)$ & $(0.0450)$ & $(0.0451)$ & $(0.0452)$ \\
\hline$\Delta$ immigrant share & 0.0100 & 0.0242 & 0.0382 & 0.0443 & 0.0471 \\
\hline$\times$ historic core & $(0.0552)$ & $(0.0552)$ & $(0.0548)$ & $(0.0550)$ & $(0.0550)$ \\
\hline$\Delta$ immigrant share & $0.141^{* * *}$ & $0.135^{* * *}$ & $0.120^{* *}$ & $0.119^{* *}$ & $0.112^{* *}$ \\
\hline$\times$ urban grid & $(0.0506)$ & $(0.0506)$ & $(0.0503)$ & $(0.0505)$ & $(0.0504)$ \\
\hline$\Delta$ immigrant share & 0.0179 & 0.0148 & -0.0388 & -0.0378 & -0.0466 \\
\hline$\times$ civic-mixed & $(0.0851)$ & $(0.0853)$ & $(0.0853)$ & $(0.0855)$ & $(0.0855)$ \\
\hline \multirow[t]{2}{*}{$\Delta$ immigrant share } & $0.510^{* * *}$ & $0.513^{* * *}$ & $0.517^{* * *}$ & $0.522^{* * *}$ & $0.529^{* * *}$ \\
\hline & $(0.0219)$ & $(0.0236)$ & $(0.0240)$ & $(0.0242)$ & $(0.0243)$ \\
\hline$N$ & 3,793 & 3,793 & 3,793 & 3,793 & 3,793 \\
\hline$R$-squared & 0.386 & 0.392 & 0.408 & 0.413 & 0.417 \\
\hline \multicolumn{6}{|l|}{ Controls: } \\
\hline Age of building stock & & $\checkmark$ & $\checkmark$ & $\checkmark$ & $\checkmark$ \\
\hline Education levels & & $\checkmark$ & $\checkmark$ & & \\
\hline Distance to POI & & & $\checkmark$ & $\checkmark$ & $\checkmark$ \\
\hline Education deciles & & & & $\checkmark$ & $\checkmark$ \\
\hline District fixed effects & & & & & $\checkmark$ \\
\hline
\end{tabular}

Notes: The Table reports the regression coefficients of the change in immigrant share (1999 to 2008) interacted with the typologies. The rectangular grid and superblock types are the excluded category. column (1) presents the regression estimates without controls. Column (2), includes controls for the share of buildings constructed by decade (1900-2000) and the share of population with different levels of education (illiterate, no primary education, primary education and high school). Column (3) includes additional controls for weighted distances to points of interest (POI). Columns (4) and (5), include controls for the education deciles and for neighborhood fixed effects. Robust standard errors in parentheses

*** denotes a coefficient significant at the $1 \%$ level, $* *$ at the $5 \%$ level, and $*$ at the $10 \%$ level. 
Table 6.2: Segregation levels by typology (groups), 1999-2008: OLS estimates

\begin{tabular}{|c|c|c|c|c|c|}
\hline & \multicolumn{5}{|c|}{ Dependent variable: Micro-dissimilarity index } \\
\hline & (1) & (2) & (3) & (4) & (5) \\
\hline Hillside & $\begin{array}{l}-0.00428 \\
(0.00340)\end{array}$ & $\begin{array}{l}-0.00318 \\
(0.00347)\end{array}$ & $\begin{array}{l}-0.00143 \\
(0.00364)\end{array}$ & $\begin{array}{l}-0.00231 \\
(0.00367)\end{array}$ & $\begin{array}{l}-0.00139 \\
(0.00372)\end{array}$ \\
\hline Garden suburb & $\begin{array}{l}-0.0182^{* * *} \\
(0.00486)\end{array}$ & $\begin{array}{c}-0.0165^{* * *} \\
(0.00503)\end{array}$ & $\begin{array}{l}-0.0123^{* *} \\
(0.00583)\end{array}$ & $\begin{array}{l}-0.0142^{* *} \\
(0.00588)\end{array}$ & $\begin{array}{l}-0.0140^{* *} \\
(0.00588)\end{array}$ \\
\hline Garden apartments & $\begin{array}{l}-0.0139^{* * *} \\
(0.00411)\end{array}$ & $\begin{array}{c}-0.0132^{* * *} \\
(0.00416)\end{array}$ & $\begin{array}{c}-0.0123^{* * *} \\
(0.00430)\end{array}$ & $\begin{array}{c}-0.0130^{* * *} \\
(0.00433)\end{array}$ & $\begin{array}{c}-0.0124^{* * *} \\
(0.00434)\end{array}$ \\
\hline Historic core & $\begin{array}{l}-0.0167^{* *} \\
(0.00735)\end{array}$ & $\begin{array}{l}-0.0137^{*} \\
(0.00739)\end{array}$ & $\begin{array}{l}-0.0137^{*} \\
(0.00744)\end{array}$ & $\begin{array}{l}-0.0142^{*} \\
(0.00747)\end{array}$ & $\begin{array}{l}-0.0126^{*} \\
(0.00751)\end{array}$ \\
\hline Urban grid & $\begin{array}{l}-0.00345 \\
(0.00463)\end{array}$ & $\begin{array}{l}-0.00181 \\
(0.00463)\end{array}$ & $\begin{array}{l}-0.00148 \\
(0.00466)\end{array}$ & $\begin{array}{l}-0.00139 \\
(0.00467)\end{array}$ & $\begin{array}{l}-0.000406 \\
(0.00469)\end{array}$ \\
\hline Civic-mixed & $\begin{array}{c}0.00245 \\
(0.00869)\end{array}$ & $\begin{array}{c}0.00323 \\
(0.00877)\end{array}$ & $\begin{array}{c}0.00121 \\
(0.00902)\end{array}$ & $\begin{array}{l}0.000695 \\
(0.00905)\end{array}$ & $\begin{array}{c}0.00213 \\
(0.00906)\end{array}$ \\
\hline $\begin{array}{l}\Delta \text { immigrant share } \\
\times \text { hillside }\end{array}$ & $\begin{array}{c}0.0298 \\
(0.0353)\end{array}$ & $\begin{array}{c}0.0173 \\
(0.0354)\end{array}$ & $\begin{array}{c}0.0232 \\
(0.0359)\end{array}$ & $\begin{array}{c}0.0258 \\
(0.0360)\end{array}$ & $\begin{array}{c}0.0226 \\
(0.0361)\end{array}$ \\
\hline $\begin{array}{l}\Delta \text { immigrant share } \\
\times \text { garden suburb }\end{array}$ & $\begin{array}{c}-0.139^{* * *} \\
(0.0411)\end{array}$ & $\begin{array}{c}-0.169^{* * *} \\
(0.0417)\end{array}$ & $\begin{array}{c}-0.175^{* * *} \\
(0.0427)\end{array}$ & $\begin{array}{c}-0.170^{* * *} \\
(0.0430)\end{array}$ & $\begin{array}{c}-0.173^{* * *} \\
(0.0431)\end{array}$ \\
\hline $\begin{array}{l}\Delta \text { immigrant share } \\
\times \text { garden apartments }\end{array}$ & $\begin{array}{l}-0.0505 \\
(0.0460)\end{array}$ & $\begin{array}{l}-0.0675 \\
(0.0462)\end{array}$ & $\begin{array}{l}-0.0595 \\
(0.0465)\end{array}$ & $\begin{array}{l}-0.0619 \\
(0.0466)\end{array}$ & $\begin{array}{l}-0.0660 \\
(0.0468)\end{array}$ \\
\hline $\begin{array}{l}\Delta \text { immigrant share } \\
\times \text { historic core }\end{array}$ & $\begin{array}{l}-0.0507 \\
(0.0566)\end{array}$ & $\begin{array}{l}-0.0525 \\
(0.0565)\end{array}$ & $\begin{array}{l}-0.0449 \\
(0.0567)\end{array}$ & $\begin{array}{l}-0.0490 \\
(0.0569)\end{array}$ & $\begin{array}{l}-0.0481 \\
(0.0570)\end{array}$ \\
\hline $\begin{array}{l}\Delta \text { immigrant share } \\
\times \text { urban grid }\end{array}$ & $\begin{array}{l}-0.0312 \\
(0.0504)\end{array}$ & $\begin{array}{l}-0.0474 \\
(0.0503)\end{array}$ & $\begin{array}{l}-0.0494 \\
(0.0505)\end{array}$ & $\begin{array}{l}-0.0405 \\
(0.0507)\end{array}$ & $\begin{array}{l}-0.0420 \\
(0.0507)\end{array}$ \\
\hline $\begin{array}{l}\Delta \text { immigrant share } \\
\times \text { civic-mixed }\end{array}$ & $\begin{array}{l}0.191^{* *} \\
(0.0822)\end{array}$ & $\begin{array}{c}0.158^{*} \\
(0.0823)\end{array}$ & $\begin{array}{l}0.185^{* *} \\
(0.0832)\end{array}$ & $\begin{array}{l}0.182^{* *} \\
(0.0834)\end{array}$ & $\begin{array}{l}0.193^{* *} \\
(0.0835)\end{array}$ \\
\hline$\Delta$ immigrant share & $\begin{array}{l}-0.0409^{*} \\
(0.0214)\end{array}$ & $\begin{array}{l}-0.0286 \\
(0.0234)\end{array}$ & $\begin{array}{l}-0.0359 \\
(0.0241)\end{array}$ & $\begin{array}{l}-0.0373 \\
(0.0242)\end{array}$ & $\begin{array}{l}-0.0345 \\
(0.0243)\end{array}$ \\
\hline$N$ & 3,354 & 3,354 & 3,354 & 3,354 & 3,354 \\
\hline $\begin{array}{l}R \text {-squared } \\
\text { Controls: }\end{array}$ & 0.018 & 0.033 & 0.041 & 0.050 & 0.054 \\
\hline Age of building stock & & $\checkmark$ & $\checkmark$ & $\checkmark$ & $\checkmark$ \\
\hline Education levels & & $\checkmark$ & $\checkmark$ & & \\
\hline Distance to POI & & & $\checkmark$ & $\checkmark$ & $\checkmark$ \\
\hline Education deciles & & & & $\checkmark$ & $\checkmark$ \\
\hline District fixed effects & & & & & $\checkmark$ \\
\hline
\end{tabular}

Notes: The Table reports the regression coefficients of the change in immigrant share (1999 to 2008) interacted with the typologies. The rectangular grid and superblock types are the excluded category. column (1) presents the regression estimates without controls. Column (2), includes controls for the share of buildings constructed by decade (1900-2000) and the share of population with different levels of education (illiterate, no primary education, primary education and high school). Column (3) includes additional controls for weighted distances to points of interest (POI). Columns (4) and (5), include controls for the education deciles and for neighborhood fixed effects. Robust standard errors in parentheses

*** denotes a coefficient significant at the $1 \%$ level, ${ }^{* *}$ at the $5 \%$ level, and $*$ at the $10 \%$ level. 
Appendix B

Figures 
Spatial variation captured by shape metrics

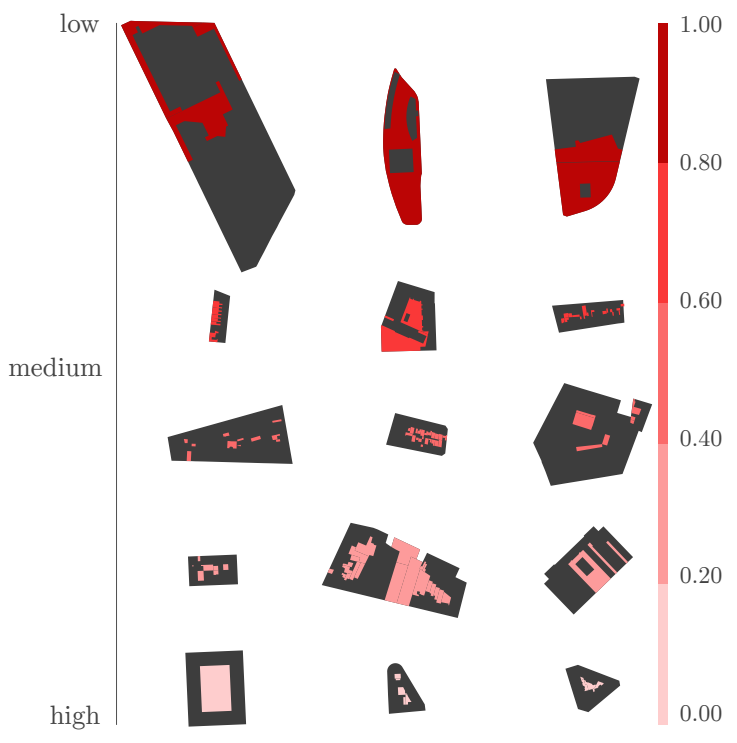

open space centrality

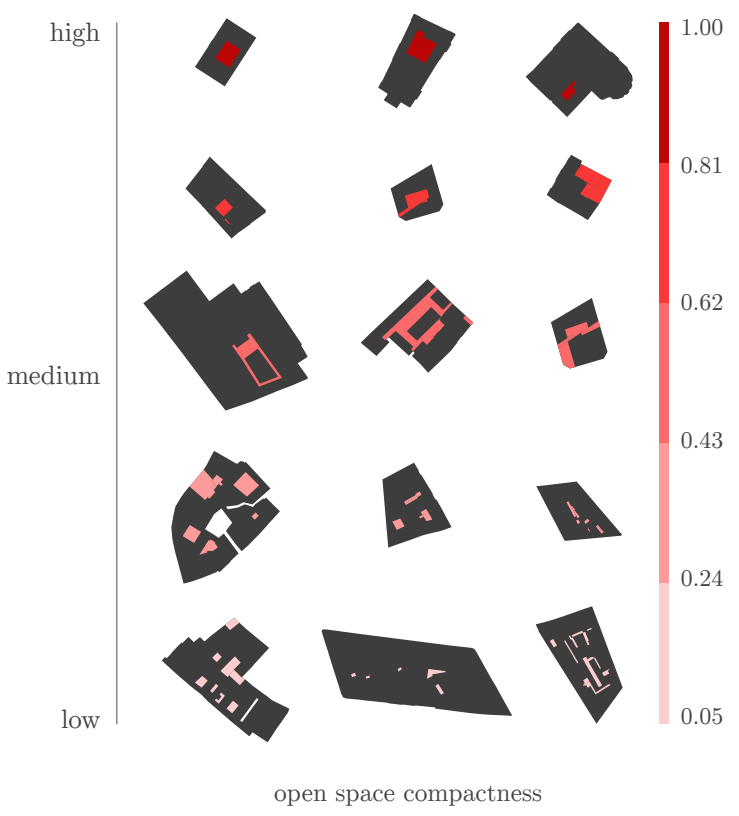

Figure 6-2: Sample of blocks showing highest and lowest values 
Spatial variation captured by shape metrics

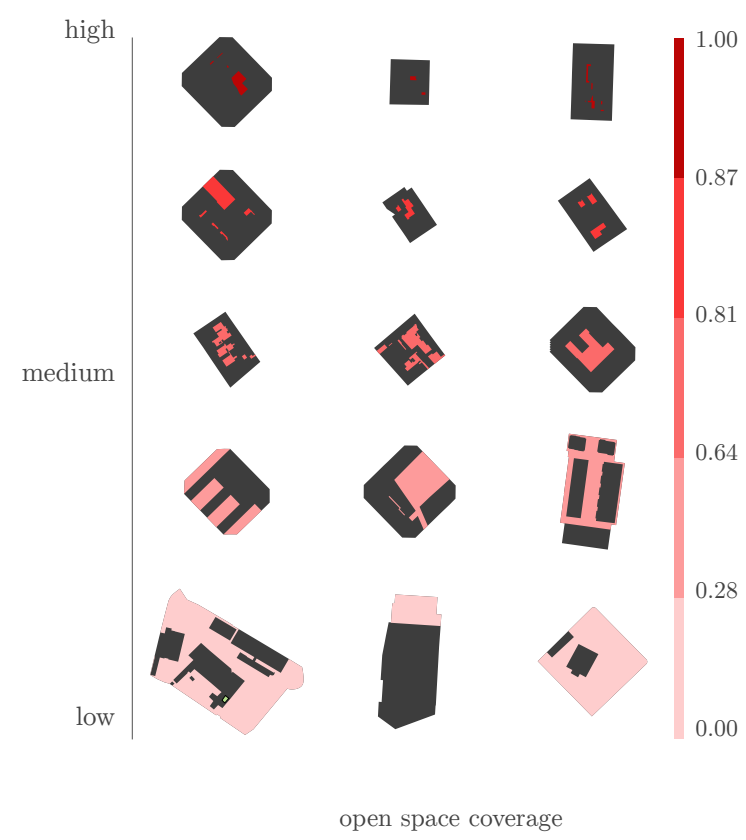

Figure 6-3: Sample of blocks showing highest and lowest values 
Aerial images of typologies
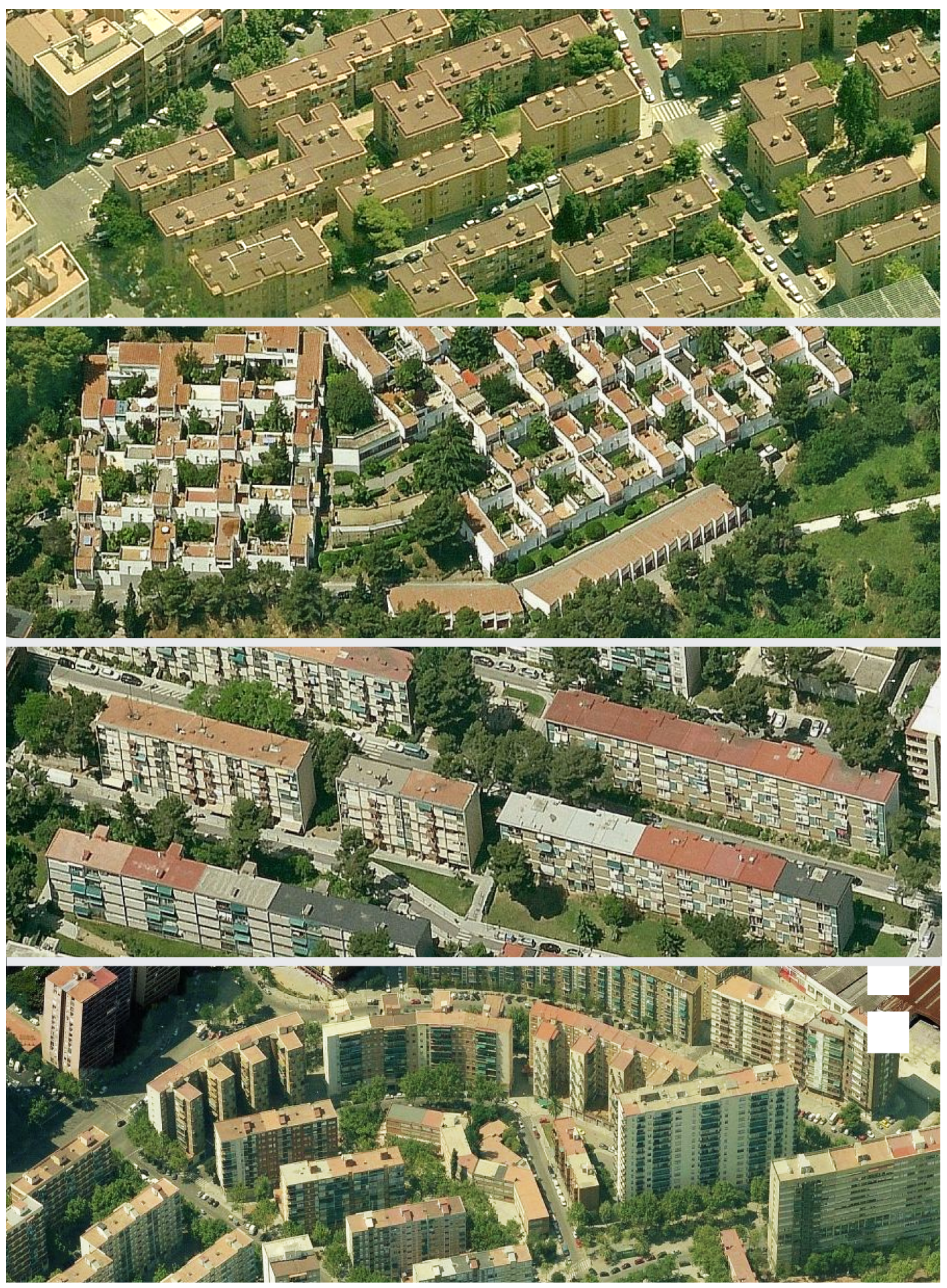

Figure 6-4: 1: Hillside | 2: Garden suburb |7: Garden apartments | 5: Rectagular grid 
Aerial images of typologies
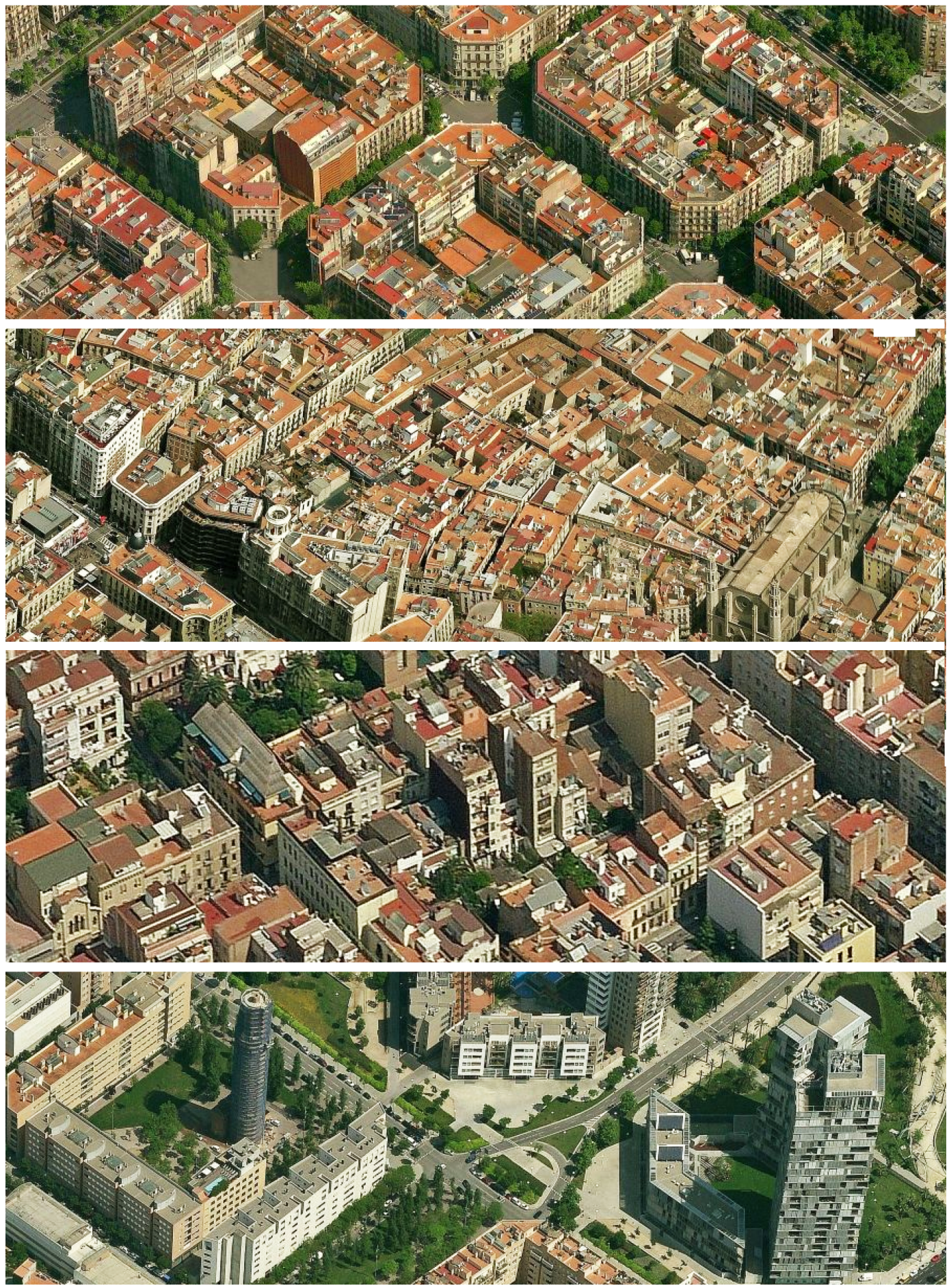

Figure 6-5: 8: Superblock | 3: Historic core | 4: Urban grid | 6: Mixed-civic 